\title{
Outages of Electric Power Supply Resulting from Cable Failures Boston Edison Company System
}

July 1980

Prepared for:

U.S. Department of Energy

Economic Regulatory Administration

Division of Power Supply and Reliability

Under Contract No. AC01-78RG06674 


\section{DISCLAIMER}

This report was prepared as an account of work sponsored by an agency of the United States Government. Neither the United States Government nor any agency Thereof, nor any of their employees, makes any warranty, express or implied, or assumes any legal liability or responsibility for the accuracy, completeness, or usefulness of any information, apparatus, product, or process disclosed, or represents that its use would not infringe privately owned rights. Reference herein to any specific commercial product, process, or service by trade name, trademark, manufacturer, or otherwise does not necessarily constitute or imply its endorsement, recommendation, or favoring by the United States Government or any agency thereof. The views and opinions of authors expressed herein do not necessarily state or reflect those of the United States Government or any agency thereof. 


\section{DISCLAIMER}

Portions of this document may be illegible in electronic image products. Images are produced from the best available original document. 


\section{NOTICE}

This report was prepared as an account of work sponsored by the United States Government. Neither the United States nor the United States Department of Energy, nor any of their employees, makes any warranty, express or implied, or assumes any legal liability or responsibility for the accuracy, completeness, or usefulness of any information, apparatus, product, or process disclosed, or represents that its use would not infringe privately owned rights. Reference herein to any specific commercial product, process, or service by trade name, mark, manufacturer, or otherwise, does not necessarily constitute or imply its endorsement, recommendation, or favoring by the United States Government or any agency thereof. The views and opinions of authors expressed herein do not necessarily state or reflect those of the United States Government or any agency thereof.

National Technical Inforwation Service (Krrs)

U.S. Department of Commerce

5285 Port Royal Road

Springfield, Virginia 22161

Price:

Printed Copy:

Printed Copy: $\quad \$ 13.00$
Microfiche:

Avaflable from:

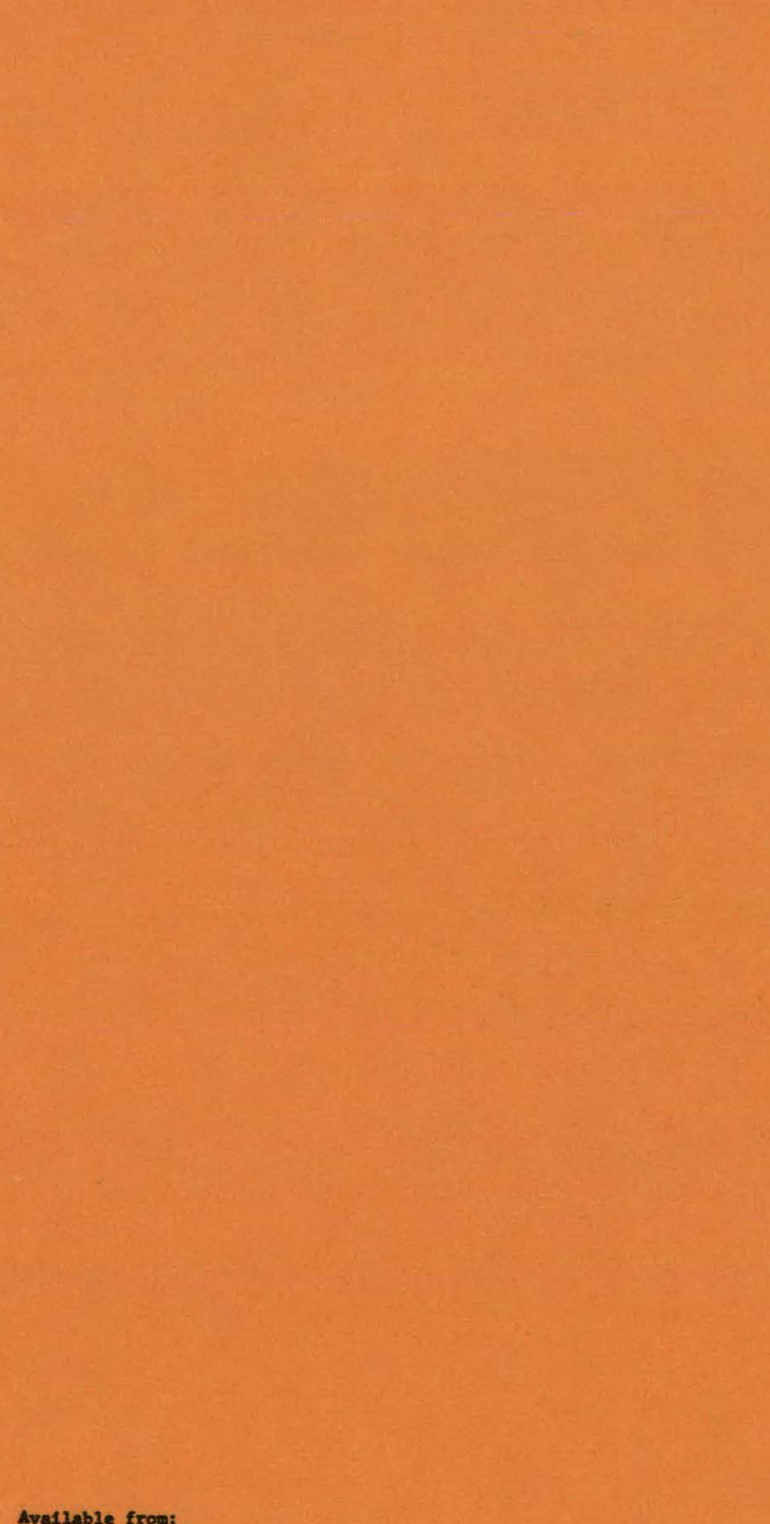




\section{Outages of Electric Power Supply Resulting from Cable Failures Boston Edison Company System}

July 1980

\section{Prepared for:}

U.S. Department of Energy

Economic Regulatory Administration

Division of Power Supply and Reliability

Washington, D.C. 20461

Prepared by:

Commonwealth Associates Inc. Jackson, Michigan 49201 Under Contract No. AC01-78RG06674

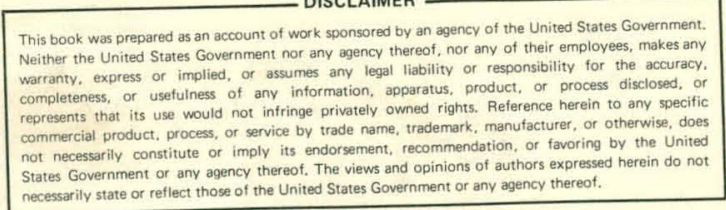

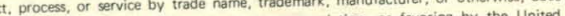

tates Government or any agency thereot. The views and onment or any agency thereo 
TABLE OF CONTENTS (Cont'd)

\section{LIST OF EXHIBITS}

Follows Page:

Exhibit 1 - Boston Edison Company Service Territory . . . . . . . . . . 14

Exhibit 2 - General Location of Outages . . . . . . . . . . • . 15

Exhibit 3 - Back Bay Area ". . ... . . . . 16

Exhibit 4 - Station 492 - Scotia Street, Connection Diagram. . . . . . . . 16

Exhibit 5 - Back Bay Network Underground System, Manholes and $14 \mathrm{kV}$ Cables on Boyiston Street . . . . . 20

Exhibit 6 - Duct Face, Manhole 1456 Boylston and Dartmouth Streets . . . 21

Exhibit 7 - Chronology, Back Bay Area Interruption, April 1-4, 1979. . . . 23

Exhibit 8 - Typical Electrical Connection, $250 \mathrm{~kW}$ Power Rectifier ... . . . . . 27

Exhibit 9 - Sequence of $14 \mathrm{kV}$ Circuit Breaker Operations, Brighton Substation . . . . . . . 40

Exhibit 10 - Simplified Diagram, Chelsea/East Boston Incident . . . 46

Exhibit 11 - Wellesley $14 \mathrm{kV}$ Distribution Supply system .. . . . . . . . 51

Exhibit 12 - Sequence of Events on Wellesley Supply Lines, June 18-22, 1979 . . . . . . . 52

Exhibit 13 - Estimated Loads, Wellesley Supply Cables . . . . . . . . . 53

Exhibit 14 - Roslindale Area, $14 \mathrm{kV}$ Distribution System . . . . . . 58 
TABLE OF CONTENTS

Page

FOREWORD . . . . . . . . . . . . . . . . . 1

EXECUTIVE SUMMARY AND RECOMMENDATIONS . . . . . . 7

ANALYSIS OF ELECTRIC SUPPLY OUTAGES . . . . . . . . 13

BACK-BAY AREA INTERRUPTION . . . . . . . . . . 16

BRIGHTON AREA INTERRUPTION . . . . . . . . . 38

CHELSEA/EAST BOSTON AREA INTERRUPTION . . . . . . 46

TOWN OF WELLESLEY ABINUKMAL SYSTEM CONNTTIONS . . . . bU

ROSLINDALE AREA INTFRRUPTION . . . . . . . . . . . 58

MITIGATIVE MEASURES ............... 65

RESTORATION MEASURES . . . . . . . . . . . . 71

\section{APPENDICES}

A. FOUR UTILITIES EXPERIENCE WITH METROPOLITAN

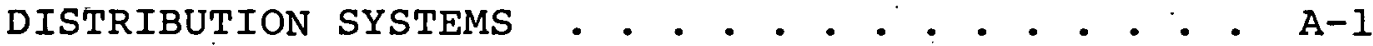

B: BOSTON EDISON'S TROUBLE INFORMATION MANAGEMENT SYSTEM . • • . . . . . . . . . . . . . B-1

C. OPERATING AND MAINTFNANANCE EXPENSES . . . . . . . . C-1

D. CABLE OPERATION ${ }^{\circ}$. . . . . . . . . . . . . D-1

E. COST OF INTERRUPTIONS . . . . . . . . . . . . E-1

F. DISTRIBUTION SYSTEMS . . . . . . . . . . . . . . F-1

G. GLOSSARY • . . . . . . . . . . . . . . . G-1

H. BOSTON EDISON COMPANY COMMENTS . . . . . . . . . . . H-l 
TABLE OF CONTENTS (Cont'd)

Follows Page:

Exhibit 15 - Major Secondary Network Disturbance Plan of Restoration . . . . . . . . . 72

Exhibit 16 - Major Emergency Plan of Operation . . . . . . . . . 72

Exhibit 17 - Major System Outage, Plan of Restoration . . . . . . . . . 72

Exhibit 18 - Steam Deficiency - Steam Emergency, Plan of Operation . . . 72

Exhibit C-1 - Annual Operating and Maintenance Expenses, Underground Distribution System ............. . . C-6

Exhibit C-2 - Distribution Operating and Maintenance Expenses, Percent of Underground Distribution Investment ... . . . . . . . . C-6

Exhibit C-3 - Accumulated Operating and Maintenance Expenses, Underground Distribution Systems $: . . \cdot . \cdot . \cdot . \cdot . \cdot . \quad \mathrm{C}-6$

Exhibit D-1 - Boston Edison Company, Cable System Failure Rates, $6.9 \mathrm{kV}$ and Above . . . . . . . . . . . D-4

Exhibit F-I - Radial Distribution System . . . . F-6

Exhibit F-2 - Radial System - Multiple Supply: . . F-6

Exhibit F-3 - Primary Network . . . . . . . F-6

Exhibit F-4 - Secondary Network Distribution. System . . . . . . . . . . F-6

Exhibit F-5 - Spot Network . . . . . . . . . F-6 
FOREWORD

This report reflects work done primarily by Commonwealth Associates Inc. under U.S. Department of Energy (DOE) contract EB-78-C-01-6664. Under this technical support service contract, Commonwealth is to provide technical power system engineering and operations expertise to the Economic Regulatory Administration's Division of Power Supply and Reliability.

During April and May of 1979, Lhere wcre two separate major outages involving the underground facilities of the Boston Edison Company. These outages were reported to the Department of Energy as required. Prior to these service interruptions, Boston Edison had experienced similar outages in October 197.7 and February 1978 .

Public media reports indicated that these outages had caused a significant amount of public inconvenience. The frequency of their occurrence and the public inconvenience was of concern from an electric power supply and reliability viewpoint. On this basis, the Division of Power Supply and Reliability contacted the Massachusetts Department of Public Utilities (DPU) to determine their concerns about these outages. As a result of this communication, it was decided that a joint investigation.would be initiated to independently ascertain the base causes of these outages and to determine if there were lessons to be learned from these incidents that may have broad applicability. A meeting of the 
Department of Energy staff, the Massachusetts Department of Public Utilities staff and the Boston Edison Company to discuss this investigation was held...on June 26, 1979; in Boston, Mässachusetts. A Federal Register announcement of this investigation was issued on August $2,1979$.

During June, 1979, the Boston Edison Company experienced three outages which were primarily the result of underground cable failures. Based on these more recent incidents, it was derided by the DOE and the Massachusetts DPI that the investigation should include the three June, 1979, incidents and tho 1977 and 1978 uutages were eliminated from the investigation. In addition to determining the causes of the outages, it was decided to have the consultant do an in-depth review of the restoration procedures and processes employed by the Boston Edison Company.

The report is the result of the contractor's efforts. The DOE staff reviewed a draft of the report and several ilianges were made. On receipt of the contractor's final document, it was forwarded to the Boston Edison Company for review. The utility replied by letter dated April 9, 1980, and expressed sharp concern regarding the contractor's introduction and summary to the report. (This letter is printed as Appendix $\mathrm{H}$ to the report.) . All factual errors listed in the Boston Edison letter have been corrected. The contractor's introduction and summary sections have been replaced by this foreword. The conclusions and a recommendations section were prepared by the staff of the Division of Power 
Supply and Reliability from the contractor's work and other knowledge of electric power supply systems. Thus, some of the Boston Edison comments do not apply to the report as printed.

The five separate incidents investigated by the contractor are identified by the following subtitles:

- Back Bay Area Interruption $(14 \mathrm{kV}$ and $208 \cdot \mathrm{V}$ cable failures, Apr11:1-4, 1979)

- Brighton Area Interruption (14 kV cable failure and subsequent substation damage, May 21-22, 1979)

- Chelsea/East Boston Area Interruption $(25 \mathrm{kV}$ cable failure, June 2, 1979)

- Town of Wellesley Partial Interruption (14 kV cable failures, June 18-23, 1979)

- Roslindale Area Interruption (14 kV cable failures, June 23-26, 1979)

The Boston Edison Company operates 7,416 miles of distribution system conductor, contained in 1,119 miles of conduit bank. Oil-impregnated paper insulated, lead sheathed cable is used almost exclusively. For many years this type cable has been the most reliable obtainable. However, it is absolutely dependent on the integrity of the lead sheath, and any crack or wear area that admits moisture results in certain failure. 
In some areas, such as the Back Bay area of downtown Boston, a secondary network system is employed, whereby multiple primary circuits (14 kV) supply a large number of transformers which in turn supply a network of secondary conductors $(208 / 120 \mathrm{~V})$. Customer connections are made directly to the secondary network. This type of system is designed to have the highest attainable continuity of service to the customer. However, a companion feature of this system is that a disturbance that is large pnough to ciuse an interruption aduses all of the customers on the network to he isolated from electric service. Boston Edisun operates five separate secondary network systems: in downtown Boston.

In other areas a multiple-radial. system is used, whereby several primary circuits $(14$ or $25 \mathrm{kV}$ ) receive power from a substation with each supplying customer load through many transformers and independent secondary systems. The total capacity is greater. than the total peak load, so that service may be quickly restored to all cilstomers by appropriate manual or automatic switching in case one or more of the primary circuits is removed from service for any reason.

The objective of this report is to investigate the causes of the five outages listed above and to determine measures that will prevent or make less probable future occurrences of similar outages. A part of this determination is a synopsis of four other major metropolitan electric utilities' experiences in operating underground systems. The utilities surveyed were: 
- Commonwealth Edison Company, Chicago

- Consolidated Edison Company, New York

- The Detroit Edison Company, Detroit

- Philadelphia Electric Company, Philadelphia

All of these companies operate major urban underground distribution systems. All have secondary networks and multiple-feeder network systems similar in many ways to those of Boston Edison. There are differences in some aspects of design, equipment, maintenance and testing. among all the companies. Evaluation of these different practices as applied to the Boston: Edison situation is an objective of this report.

This report is divided into five major sections and seven appendices. Section $I$ is the Foreword, and Section II is an Executive Summary which contains certain DOE staff recommenda-. tions. Section III, Analysis of Electric Supply Outages, is a detailed evaluation of each of the five incidents. Included in each discussion are background information, description of the incident, causes and contributing factors, restoration measures; and mitigative measures. Sections IV and V summarize Mitigative and Restoration Measures, respectively.

These sections have been included to summarize and to serve as quick reference to the mitigative and restoration measures discussed in the body and appendices of this report.

Appendix $A$ is a synopsis of the experiences of the four other utilities interviewed. Appendix B summarizes Boston 
Edison's Trouble Information Management System. Appendix C contains Operations and Maintenance expense data drawn from public information reported on FPC Form 1 and compiled in "Statistics of Privately-Owned Utilities in the Inited states" by FPC and later by DOE/EIA.

Appendix D contains data regarding undergjround oable opcration, with failures classified by cause. Boston Edison experience is also oompared lu national averages. The ooot of service restoration and an estimate of the impact of lost revenue is conlained in Appendix E.

Several types of distribution systems are described in broad terms in Appendix F. The systems included are radial, radial-multiple supply, primary network, secondary network, and spot network.

A glossary, containing some of the technical terms used In this report, is included as Appendix G.

Appendix $\mathrm{H}$ constitutes the comments of Boston Edison on the contractor's report. 


\section{EXECUTIVE SUMMARY AND RECOMMENDATIONS}

This Power System Interruption Investigative Report provides factual data regarding five electric power supply interruptions that occurred in the Boston Metropolitan area during the April to June, 1979 period. These outages resulted in over 566,000 customer outage hours. The U. S. Department of Energy (DOE) and the Massachusetts Department of Public Utilities (MDPU) jointly initiated this investigation in June of 1979. Commonwealth Associates Inc. of Jackson, Michigan was retained by the DOE to do the primary investigative work.

Common to all of these outages was the failure of an underground cable as the initiating event, followed by multiple equipment fallures. There was significant variation in the voltage ratings and types of cables which failed. The investigation was unable to delineate a single specific Boston Edison design or operating practice that could be cited as the cause of the outages. Detailed attention was given to the maintenance programs of the Boston Edison Company and comparisons were made with other utilities operating large underground electric power network distribution systems. It was evident that the expenditure of funds for maintenance by the Boston Edison Company were slightly less than the apparent average. However, it must be recognized that the actual maintenance crews have difficulty in uniformly classifying which part of their work is maintenance and which part is capital improvements. The differences were mot enough to support a conclusion of inadequate maintenance. 
Underground electric power network distribution systems primarily exist in high population density urban areas. They are usually old, having been first installed in the 1930's and 1940's. These systems were usually expanded as the downtown areas developed until the late 1950's and early 1960's when many downtown areas were initiating urban renewal programs. When this. occurred, the new electrical loads were often too large for the existing networks and special service feeders or spot networks cuuld be developed more economically than expanding the main network. Thus, there has been only minimal load qrowth on the main networks and only minimal capital improvement investments were made. The Boston Edison. system is typical in this regard.

While reviewing the consultant's input, it becomes very evident that the design and operation of an underground network is controlled by many factors other than good ulility engineering practices. There is a significant amount of congestion in the area below the streets. Electric power facilities must compete with water lines, sewer facilities, subway lines, and telephone cables for the limited space available under the streets. Boston Edison's Back Bay network is divided into a. north and south section by the Massachusetts Turnpike which is a depressed, almost tunnel-like road through the downtown area. This factor has made it almost impossible for Boston Edison to have an adequate number of links between these two network sections. The lack of these ties was a significant factor in the extent of the Back Bay outage. 
Due to the limited space available, the Boston Edison Company has placed ten or more circuits in some manholes and duct banks. This factor was extremely significant in the extent of the outages.

The Back Bay outage was initiated by the failure of a direct current circuit. This direct current system supplies slightly over 1650 customers and yet it requires 210 miles of underground cable. Boston Edison has not offered direct current service to new customers for many years, however, a major effort and sizeable expenditures are required to eliminate this type of service. It is evident that the customers currently receiving this direct current service are not paying its total costs, especially if outage costs are considered.

Operation of an electric utility distribution system involves the proper functioning of many equipment items as well as many humans performing their tasks correctly. The Brighton outage was the result of an incorrect relay setting - a human error. Roslindale's outages were caused by equipment failures. The Chelsea/East Boston interruption occurred on. Saturday when a failure occurred while other maintenance work was in progress. This is a combination human error/equipment failure:

The management of the Boston Edison Company cooperated fully in our investigative efforts and had made their own investigation prior to the start of the government work. It was evident 
from our investigation that Boston Edison had properly analyzed each situation and had initiated many actions to prevent reoccurrence and/or to mitigate any public health and safety concern or other public discomfort. It was noted that the utility has an olyuling positive relationship with the local government, fire and police organizations. The Fire Department recognized the manhole fires as elprtrioul in nature and used appropriate extinguishing means. The police role is extremely important duxing a llldor power outage. Nol vily do they have their normal public health and salety roles, they must handlc significant traffic congestion witliut automatic signals and. work areas for utility forces must be cleared. Boston Edison's prior planning coordination with these city agencies was impressive. The utility did not have a restoration plan for a major network outage when these incidents occurred. Despite this deficiency, it mobilized its work forces and the service restorations were handled expeditiously. Warm food was dclivered to diews at their work locations, thereby expediting the repair:

RECOMIENDA'IIONS

After reviewing the contractor's investigative report, we believe the Boston Edison Company' should consider the following actions:

- Develop and implement, in coordination with the Massachusetts Department of Public Utilities, a plan to eliminate the direct current cable network. 
Consider providing this service on a customerby-customer basis where required by means of rectifier on the customer's premise.

- Complete its restoration plan for major network outages. Ensure that plans are maintained on a current basis.

- Regroup primary feeder cables wherever possible to minimize the number of circuits in manloles, and to separate feeders to high load density areas.

- Develop a program to detect incipient cable faults.

- Evaluate the separation of the north and south sections of Back Bay network into separate networks; as a minimum, install the necessary facilities to make it possible to re-energize one section without interfering with the other.

- In Roslindale, re-evaluate the cathodic protection scheme.

These recommendations are primarily directed to the Boston Edison Company; however, other electric utilities, especially those with major underground networks, should review them for applicability to their systems. The presence of a 
recommendation is not intended to imply that Boston Edison has not taken positive corrective action since the subject interruptions occurred. In fact, the DOE staff is aware of many actions taken by Boston Edison to hopefully prevent a re-occurrence, to mitigate the societal impacts of a future uutage, and to expedite the restoration. 


\section{ANALYSIS OF ELECTRIC SUPPLY OUTAGES}

The Boston Edison Company supplies electricity at retail to an area of approximately 590 square miles within 30 miles of Boston, encompassing the City of Boston and 39 surrounding cities and towns. The population of this territory is approximately 1,600,000. Boston Edison also supplies electricity to other utilities and municipal electric departments for resale. About 80 percent of the company's revenues are derived from retail electric sales, 12 percent from wholesale electric sales, and 8 percent from other sources. The area served by Boston Edison is shown by Exhibit 1 .

The Boston Edison system peak load was 2,031 MW which occurred on August 17, 1978. The annual load factor was 57.7 percent. The growth in sales over the past 6 years has averaged about 3 percent per year with total energy sales reaching 11,627,000 MWH in.1978. The percent sales by customer class were:

$$
\begin{aligned}
& 48 \% \text { - Commercial } \\
& 27 \% \text { - Residential } \\
& 19 \% \text { - Industrial } \\
& \text { 6\% - Other } \\
& 100 \% \text { - Total }
\end{aligned}
$$

The Boston Edison underground transmission and distribution supply system contains about 7,500 miles of cable, classified as follows: 


$$
\begin{aligned}
& 87 \text { miles - transmission (115-345 kV) } \\
& 2,138 \text { miles - distribution primary }(6.9-25 \mathrm{kV}) \\
& 4,981 \text { miles - ac distribution secondary }(120-480 \mathrm{~V}) \\
& \frac{210}{7,410} \text { miles - dc distribution secondary }(250 \mathrm{~V}) \\
&
\end{aligned}
$$

A two-square mile area in downtown Boston is served by five $208 \mathrm{Y} / 120 \mathrm{~V}$ ac secondary networks, a single $240 / 120 \mathrm{~V}$ dc network, and a number of $480 \mathrm{Y} / 277 \mathrm{~V}$ spot networks. The 1978 peak load on the networks was approximately 360 MW, including less than 3 MW of dc load.

In a three-month span in early 1979, the Boston Edison Company experienced five separate incidents that resulted in service interruptions to a total of approximately 80,000 customers. All five incidents, characterized by multiple equipment and/or cable failures that eventually resulted in the service interruptions, were initiated by underground rable faults. A description of, each incident, causes and contributing factors, restoration measures, and mitigative measures are presented in the following sections. A list of the five incidents is provided below, and the approximate geographical location of each is shown on Exhibit 2. The dates listed indicate the approxi-. mate period of abnormal system operation and should not be interpreted as the duration of the outage. 


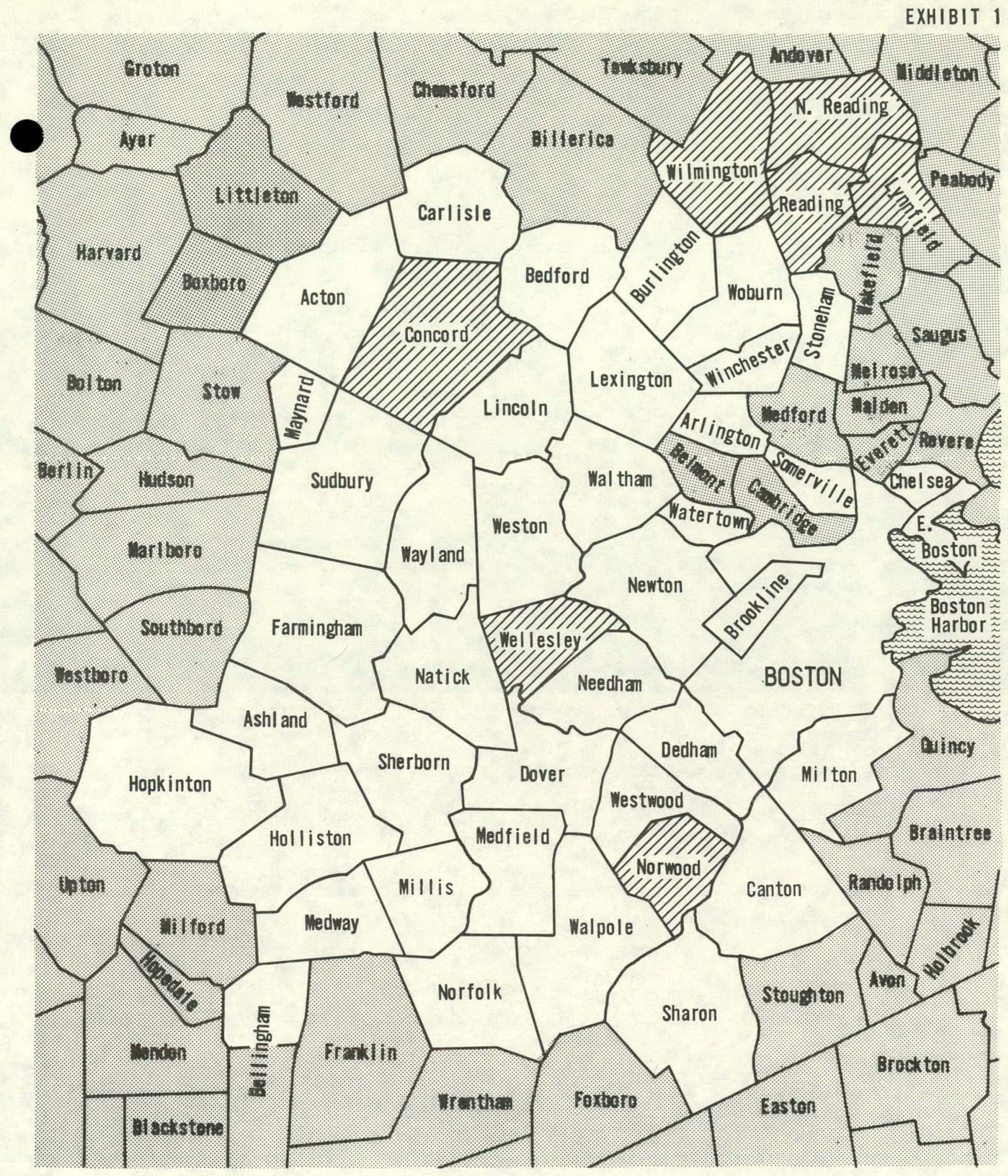

$\square$ TOWN SERVEd At RETAIL

TOWN SERVED BY OTHERS

UA TOWN SERVED IN BULK 
- Back Bay Area Interruption, April 1-4

- Brighton Area Interruption, May 21-22

- Chelsea/East Boston Area Interruption, June 2

- Town of Wellesley Abnormal System Conditions, June $18-23$

- Roslindale Area Interruption, June 23-26.

The outage duration and number of customers involved can be combined to derive a reasonably accurate estimate of the outage magnitude in terms of domestic customer-hours. The following table shows the derivation:

$$
\begin{array}{ccc}
\begin{array}{c}
\text { Outage Duration } \\
\text { Hr-Min. }
\end{array} & \begin{array}{c}
\text { Customers } \\
\text { Out }
\end{array} \text { Cust.-Hrs. } \\
\hline
\end{array}
$$

Back Bay Network:

Beacon St. Sta.

South Grid

North Grid

Total, Back Bay

Brighton

Chelsea/East Boston

Wellesley

Roslindale

Total, All Incidents

$$
0-35
$$

$4-42$

$38-10$

1,500

5,000

6,000

$\underline{229,000}$

253,400

$4-22$ (avg)

$1-22$ (avg)

$32-12$

3-48 (avg)

1,000

6,200

50,600

220,600

25,000

36,200

32,200

23,600

566,000 


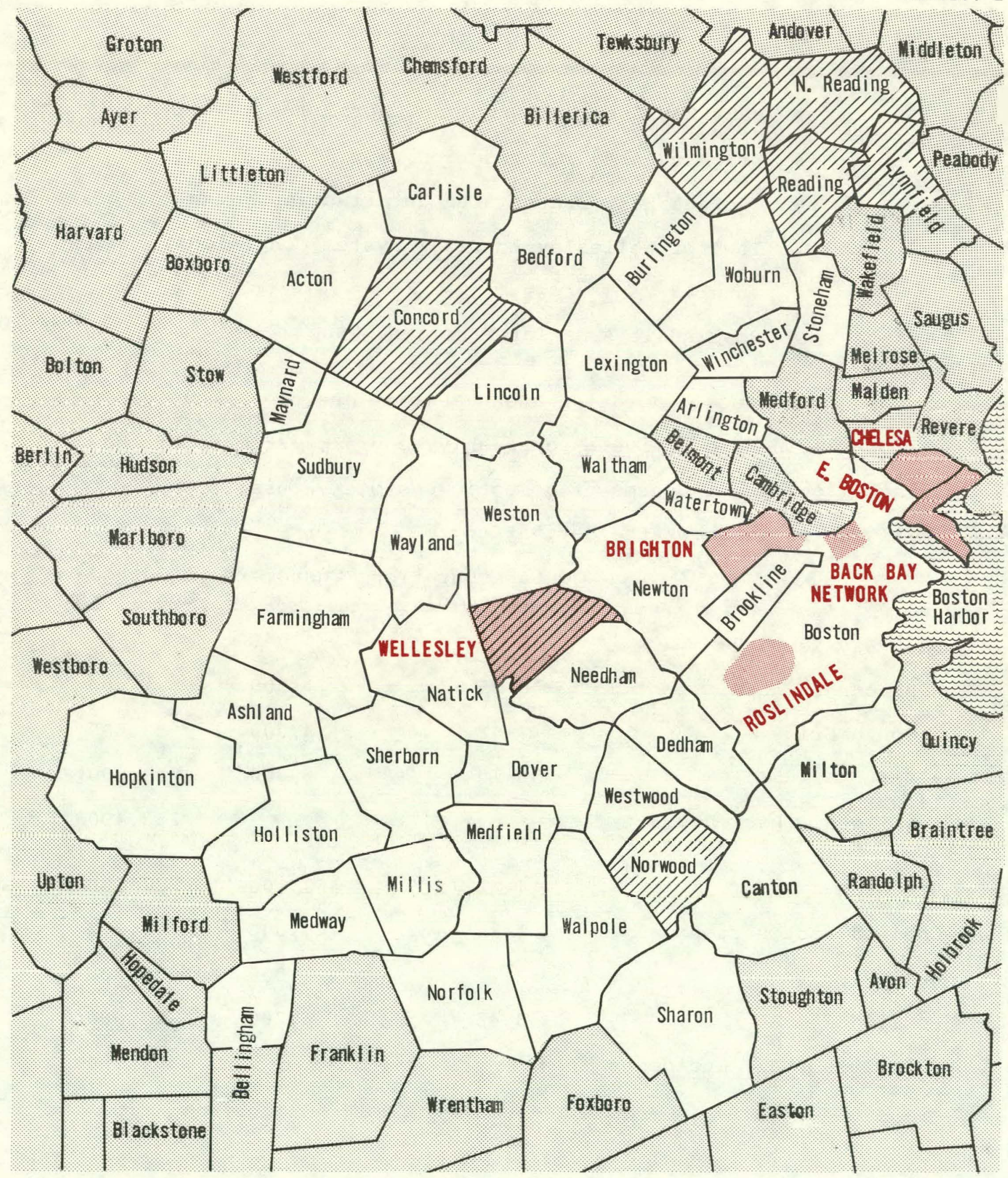

$\square$ TOWN SERVED AT RETAIL

EA TOWN SERVED IN BULK

TOWN SERVED BY OTHERS

SCALE IN MILES 
BACK BAY AREA INTERRUPTION, APRIL 1-4, 1979

The Back Bay Network is one of five ac secondary networks in the two-square mile area of downtown Boston. This network is roughly bounded by Storrow Drive on the north, Clarendon Street on the east, the New Haven Railroad on the south, and the Fenway on the west. The Massachusetts Turnpike splits this network into two lightly interconnected north and south secondary grids. The Prudential Complex is located near the center of the network and is supplied by several spot networks. The John Hancock Tower and several hotels are also supplied by spot networks. See Exhibit 3 for geographic locations.

Scotia Street Station 492 , a $115-14 \mathrm{kV}$ bulk power station built in 1973, is the source for the Back Bay Network and Beacon Street Station 49. Station 492 includes two 115-14-14 kV, 75/100/125 MVA transformers supplying four metal-clad $14 \mathrm{kV}$ bus sections. (See Exhibit 4.) Each bus section consists of one bus tie breaker, one transformer secondary breaker, one metering and control cubicle, and six line feeder positions. The present arrangement consists of sixteen $14 \mathrm{kV}$ feeders supplying the Back Bay Network and three $14 \mathrm{kV}$ feeders (distribution supply lines) supplying Beacon Street Station 49. This station supplies twelve $4 \mathrm{kV}$ radial distribution circuits serving 1,500 customers with a recorded 1978 peak load of $20,100 \mathrm{kVA}$. 


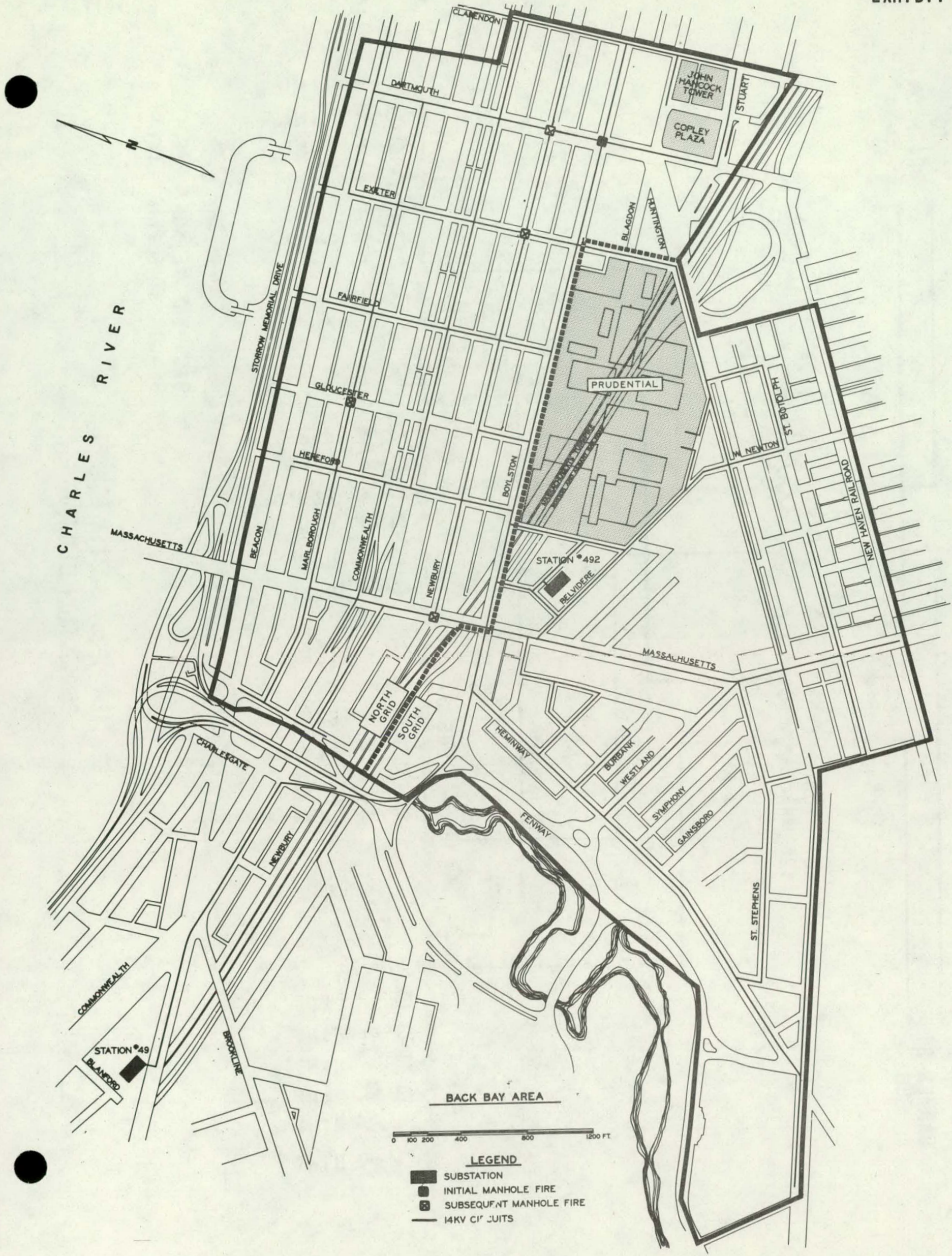




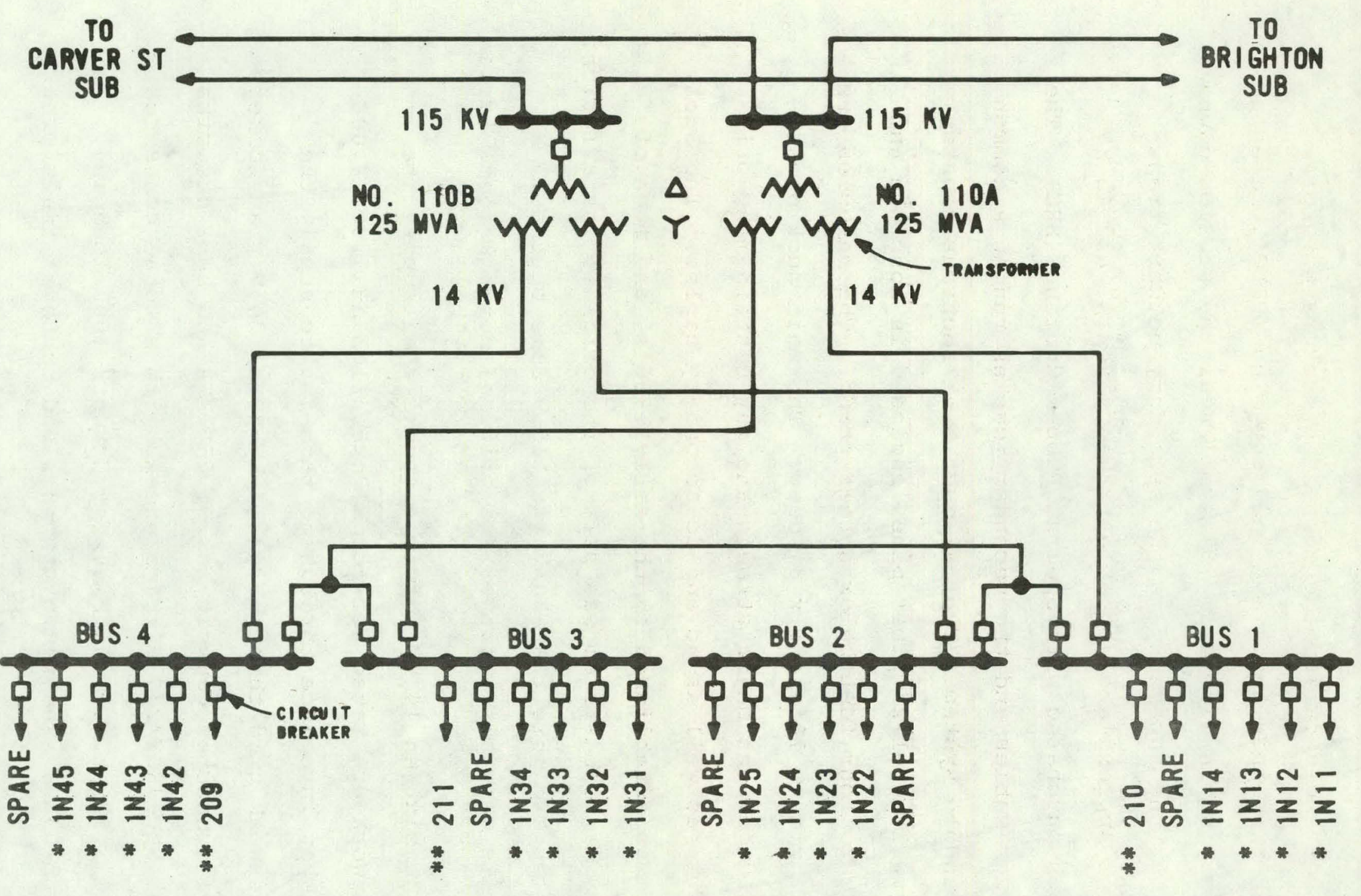

* back bay network feEders

** BEACON ST SUPPLY LINES

STATION 492 - SCOTIA STREET

CONNECTION DIAGRAM 
The feeder cables are copper conductors with oilimpregnated paper insulation and lead covering (PILC), rated at $15 \mathrm{kV}$ and varying in size from $750 \mathrm{kcmil}$ near the station down to 1/0 AWG for the taps serving the secondary network transformers. For approximately the last twenty years, all $15 \mathrm{kV}$ PILC has been purchased with Special Rubber coating (SRC). The network feeder cables and the secondary cables run in a common duct bank/manhole system. Typical duct bank sections consist of four to twelve 3-1/2" fiber pipe, enclosed in concrete and buried three to four feet below street grade. The manholes are typically $6^{\prime}$ wide $\times 10^{\prime}$ long $\times 8^{\prime}$ deep. The main duct banks usually run under the major streets and may contain many primary circuits, as well as ac and dc secondary cables. The Back Bay Network was established in the early 1930's, and much of the duct and manhole system was part of the original installation. Many dc cables are more than 50 years old. Some of the $14 \mathrm{kV}$ cable segments were also part: of the original network installation.

The sixteen $14 \mathrm{kV}$ network feeders that supply the Back Bay Network are rated for normal operation at 7,000-8,000 kVA each. They interlace throughout the area to supply the secondary network grid through $15214 \mathrm{kV}-208 \mathrm{Y} / 120 \mathrm{~V}$ transformers with a total connected capacity of 91,250 kVA and spot networks through $5014 \mathrm{kV}-480 \mathrm{Y} / 277 \mathrm{~V}$ transformers with a total connected capacity of 63,975 kVA. The Back Bay Network peak load was $63,800 \mathrm{kVA}$ in 1978. The ratio of peak load to total transformer 
capacity was 0.41 . The Back Bay Network has the highest percentage residential load of the five networks with 20 percent. A total of 11,000 customers are served by this network.

A single $240 / 120 \mathrm{~V}$ dc network system overlays all five ac networks in the downtown area, including the Back Bay Network. A total of 1,688 customers with a de load of less than 3 MW are supplied. The dc source is provided by thirty-four $250 \mathrm{~kW}$ solid state rectifiers. These rectifiers receive $208 \mathrm{~V}$ supply from the ac secondary mains. An cstimated 210 miles of dc cable are in service. Within the Back Bay Network area, the dc load is $\cdot$ about $800 \mathrm{~kW}$. Four rectifiers to convert ac to dc are located within this area.

The network is planned on the basis of single contingency outage criteria. This means that at peak load any single element such as a transformer, a feeder, or a bus section can be lost without any service interruptions or abnormal equipment overloads. A bus section outage at Substation 492 would result in four network feeders being out of service. Obviously, the bus section outage would remove 25 percent of the $14 \mathrm{kV}$ supply; and this is the most serious outage planned for without any electric service compromise. The network is also analyzed for double contingency failures. 
The Back Bay Network is unique because it is physically split into two approximately equal sections by the Massachusetts Turnpike and the Boston and Albany Railroad, which pass underground through the Prudential Center complex of buildings. Partly because of this barrier, the network is essentially composed of a North Grid and a South Grid. Loads north of the Turnpike, except for the Prudential Center are supplied by the North Grid, while the remainder of the area is supplied by the South Grid. This condition is shown by Exhibit 3.

There are sixteen $14 \mathrm{kV}$ circuits emanating from Substation 492 (Scotia Street) to supply the network. However, as a practical matter, there are eight circuits for the North Grid and eight for the South Grid, with only minor support available to either grid by a lew $208 \mathrm{y} / 120 \mathrm{~V}$ secondary circuits from the other. Power transfer by means of 208Y/120 V circuits is also impractical because of the absence of such circuits in the South Grid near its border with the North Grid. This is caused by the Turnpike and the large $480 \mathrm{Y} / 277 \mathrm{~V}$ spot loads of the Prudential Center, John Hancock Tower and large hotels in the area.

Thus, while the Back Bay Network is operated as a single entity, there are actually two networks because of the physical separation and lack of effective electrical connections between them. 
Of the sixteen $14 \mathrm{kV}$ circuits, twelve are routed along Boylston Street. Of these, eight serve the North Grid, while four serve the major Prudential Center spot loads along the south side of the street, which are part of the South Grid. Exlibit 5 shows the duct and manhole system along Boylston street from Substation 492 to Clarendon street. This exhibit also shows the number of $14 \mathrm{kV}$ circuits passing through each manhole. It can be observed that the numbers of $14 \mathrm{kV}$ circuits contained in manholes dlung Bölston street are as followo:

2 manholes contain 11 circuits

7 manholes contain 8 circuits

6 manholes contain 7 circuits

7 manholes contain 6 circuits

6 manholes contain 5 circuits

5 manholes contain 3 circuits

4 manholes contain 2 circuits.

The exposure to multiple outages from a single incident is evident. It is not practical to remove such exposure completely because of prohibitive cost; but efforts to minimize it can be made. Boston Edison has recognized this by routing North and South Grid feeders on both sides of the street.

DESCRIPTION OF OUTAGE

The Back Bay Network problems were initiated by a fire in Manhole 1456 at Boylston and Dartmouth Streets on 
oner dar metrom enchemim sTSTE

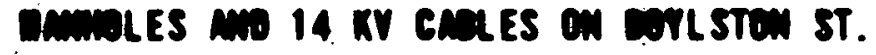

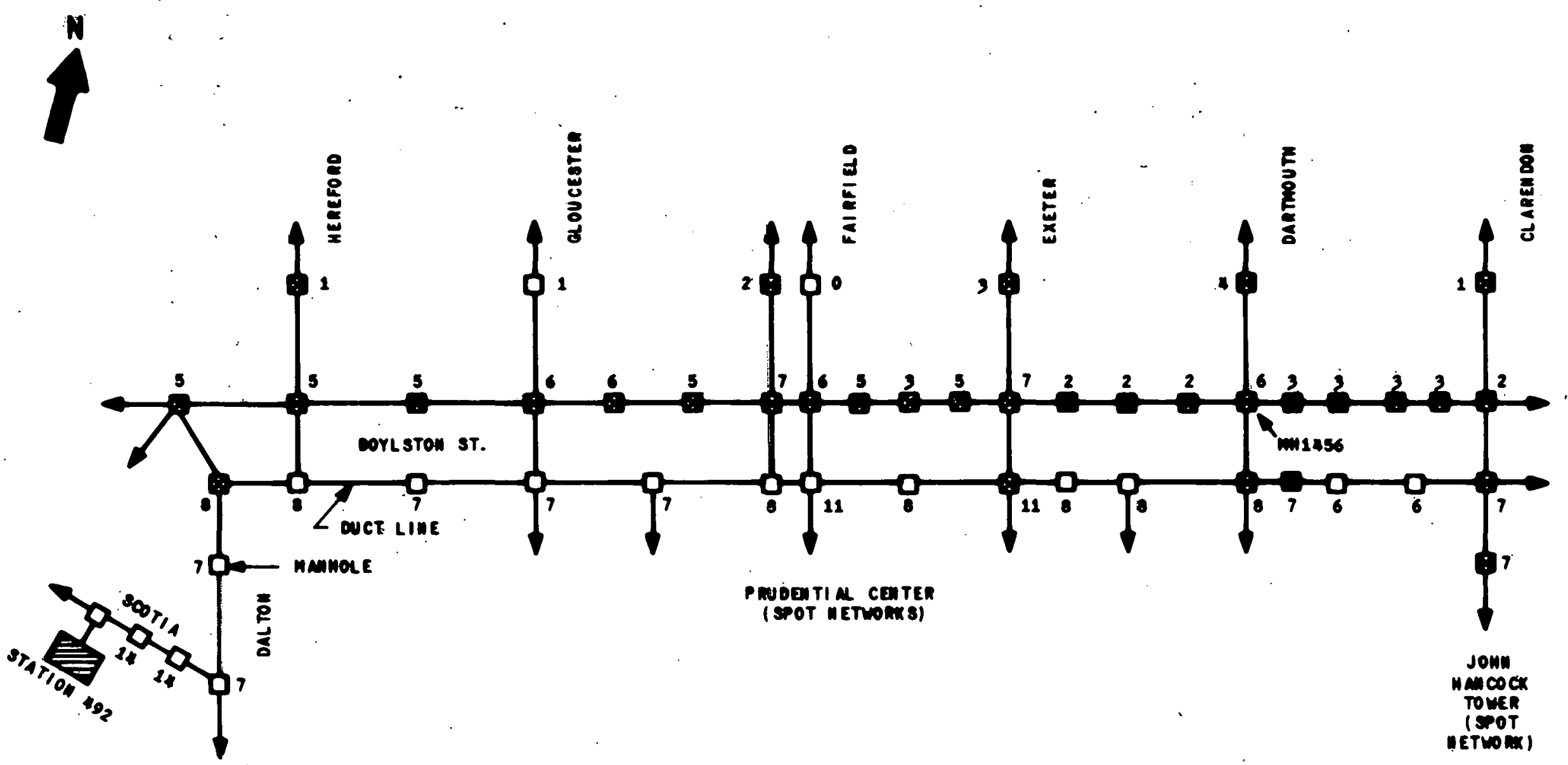

\footnotetext{
$\square^{7}$ MAMHOLE, WITM MUMOER OF $14 \mathrm{KV}$ CI RCUITS IMSTMLEO

8 manhole with dC cables installeo
} 
Sunday, April 1, 1979. An investigation by Boston Edison personnel indicated that the probable cause of the fire was the failure of a $240 / 120 \mathrm{~V}$ dc cable in Duct 11 (see Exhibit 6). The dc cable failed at or near the duct mouth, and the ensuing fire eventually destroyed all the cables within one to two feet of this location. Four $14 \mathrm{kV}$ network feeders (IN45, IN11, IN12, IN22) were damaged and sequentially relayed out of service within a 15-minute period just prior to 1 PM, Sunday, April 1 , 1979. Also at this time, a fifth $14 \mathrm{kV}$ feeder (IN25) was out of service because of scheduled maintenance at the John Hancock Tower. The estimated Back Bay Network load was 29,000 kVA; no secondary network customers were out of service at this time.

All five feeders out of service on April 1 supplied the North Grid. This grid was kept in service by the three remaining feeders, while the extent of damage to the other cables was being assessed.

Shortly after the extent of damage was assessed, a decision was made to cut and cap four of the five feeders which had been removed from service. This was faster than full repairs and would permit the return to service of a part of each of the circuits. In this way, as many transformers as possible could be made available prior to the Monday morning load. Electrical Operations Department personnel were dispatched to 46 network 


\section{DUCT FACE - MANHOLE 1456 \\ BOYLSTON MND DARTMOUTH STREETS \\ (FACING NORTH)}

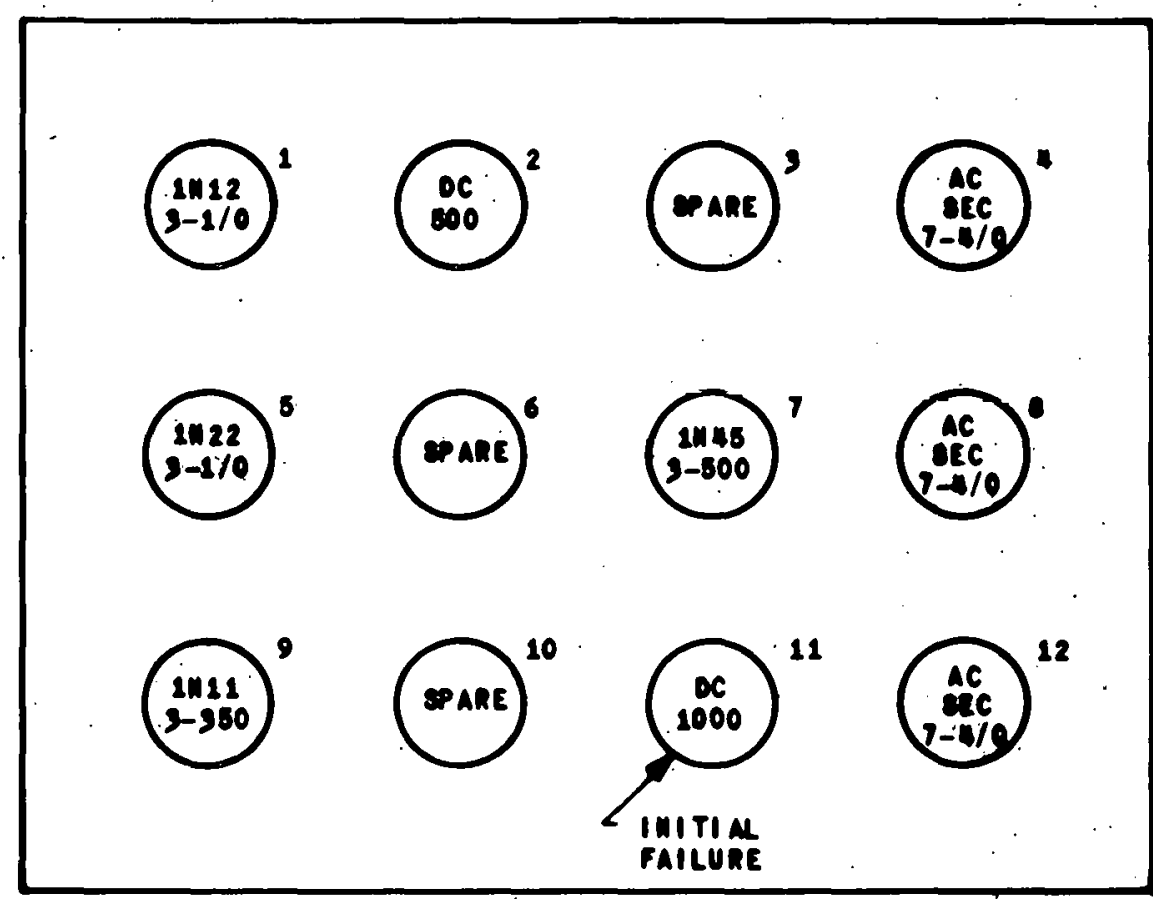

oucts 1,6,7,9 - 14. KV PRInAm cincuits

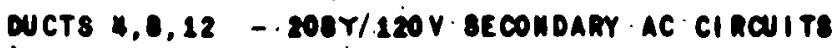

DuCTs $2.11-200 \_120 \mathrm{~V}$. OC CIRCuIts

WIRE SI ZES SHOWI ANE AWG OR KCHIL 
vaults to perform the necessary switching and tagging operations required to safely isolate the affected feeders prior to making repairs. In order to expedite switching time, additional offduty station operating personnel were used to assist. It took about seven hours to complete the entire operation. Switching personnel: were delayed for over an hour in one instance, waiting for an escort to a vault inside a building for seririty roacona. Anotlier delay was encountered because three feeders had contacted damaged secondary cables. These had to be cleared before the feeders could be safely grounded.

Betore 9 PM on Sunday; the Back Bay load had grown to an estimated $31,000 \mathrm{kVA}$. A second fire was reported in Manhole 1446 at Commonwealth and Exeter; and several minutes later $14 \mathrm{kV}$ feeder. IN31, relayed out of service at 9:01 PM, leaving: the North Grid supplied. by. only two of the original eight feeders. A later investigation of this fire revealed that the damage was caused by a $208 \mathrm{Y} / 120 \mathrm{~V}$ ac secondary cable that had overloaded, failed, and burned. Within a 40-minute period, between 10 and 11 PM, one secondary network vault and four additional manholes were reported smoking or afire. ro prevent further equipment damage, the $14 \mathrm{kV}$. transformer secondary breakers at station 492 were opened, de-energizing the supply to the entire Back Bay Network and to station 49, thus interrupting service to approximately 12,500 customers. 
The eight feeders serving the North Grid and the number of secondary transformers they each supply are summarized on Table I. The table also shows that the first five feeders out of service reduced the number of secondary transformers serving the North Grid by 63 percent, and the sixth feeder out brought the number of secondary transformers out of service to 81 percent.

The chronology of events of April 1-4, 1979, is summarized on Exhibit 7, following.

\section{CAUSES AND CONTRIBUTING FACTORS}

Three major factors contributed to the massive Back Bay area outage:

- The system is vulnerable to a manhole fire, because many feeders run in a common manhole/ duct system.

- The dc secondary grid is a potential source for a sustained manhole fire.

- The damaged network was operated beyond its capability for too long a period.

The Boston Edison system is more vulnerable to outages caused by a single manhole fire than some other utilities since many of the feeders supplying the networks are run in a common manhole/duct system. (See Exhibit 5.) A sustained fire in a. single manhole could conceivably take out as many as eleven 
TABLE I

BACK BAY NETWORK TRANSFORMERS OUT OF SERVICE

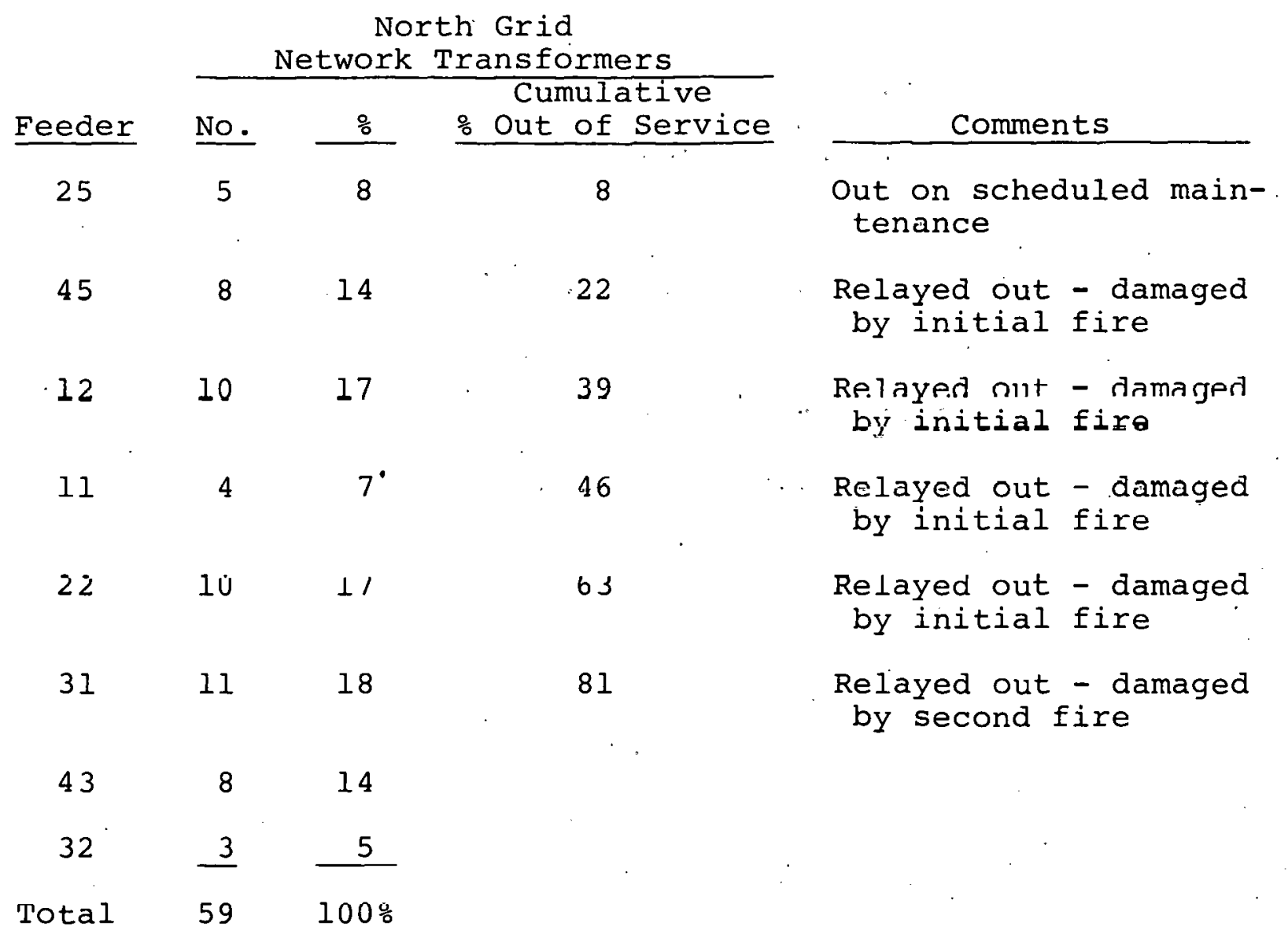


feeders. The concentration of feeders in a single-duct run has evolved for a number of reasons:

- Because of extreme congestion under the streets consisting of water lines, sewers, gas lines, steam lines, and telephone and electric cables, the city exerts considerable pressure to constrain the expansion of under-street facilities. On some streets, no additional width is available, and if expansion is required, it must be done vertically. If the electric utility requires more ducts, these must be built below existing duct lines. In some cases, even this is impossible due to the subways below the electric facilities. As a result, large main duct runs will usually be found under the major streets and thoroughfares.

- Boston is a very historical city with understandable pressures to preserve the historical qualities of many of the older sections of the city. It is very difficult to get permission to build through these sections and when permission is granted, it requires restoring the streets to their historical condition or repaving the entire street from curb to curb. In either case, extreme costs are incurred.

- All construction activities that would require closing streets are prohibited from Thanksgiving 
weekend until after the January lst holiday. Construction activities are also prohibited in areas near old wooden tunnels and underground subway structures in fear that the movement of the ground may weaken these structures.

- Near the source substation, the feeder cables must be concentrated to some extent to bring them into the station. Note that 14 of the 16 feeders serving the Back Bay Network are contained in single manholes near Substation 492 (Exhibit 5) .

The possibility of a fire in a manhole destroying all the cables is a rare occurrence, but has serious consequences. Usually, electrical faults are quickly cleared, limiting the damage to no more than one or two cables. In the Back Bay incident, four primary cables were damaged by the heat produced by a cable fault that did not clear. It is likely that the dc cable burned for more than thirty minutes. The fault occurred. on a very large cable protected with heavy fuses, and the fault current was not of sufficient magnitude to blow the fuses.

Direct current distribution systems are rare; mostly, only remnants of them remain in a few large cities. In Boston, as in other major cities, most dc customers have been converted to ac. In April, 1979, only 1,688 dc customers with a peak demand of about 2,300 kW remained in scattered locations 
throughout the city. It has been Boston Edison's policy for a number of years to encourage conversion of dc customers to ac and to simultaneously eliminate unnecessary dc equipment. The remaining dc load, however, has not exhibited significant decreases in recent years. This is essentially the "hard core" load, such as dc elevators and large industrial motors in old buildings which are costly to replace and where rewiring can lead to substantial expense. As a result, a rather substantial dc secondary grid remains. This system contains about 210 miles of cable occupying common facilities with all five ac networks in the two-square mile area in downtown Boston. For example, in Manhole 1456 where the trouble started, dc cables occupy 12 of the available 48 ducts, or 25 percent. This space used is completely out of proportion to the load served by the dc system. Moreover, it seriously hampers expansion of the ac network, which will be necessary to accommodate load growth. It also makes maintenance more difficult because of manhole congestion.

The dc grid is a major problem and expense for the Boston Edison Company. Because of age, lack of replacement parts or expensive special fabrication procedures, and diminishing use not reflected in proportionate system shrinkage, the dc grid has become extremely costly to maintain and operate. A recent review has revealed an annual operating deficit of approximately 1.25 million dollars. This averages $\$ 740$ per dc customer per year. 
Exhibit 8 shows electrical connections in a typical ac to dc rectifier station. Typically, the equipment is 8 ' long $\mathrm{x}$ $4^{\prime}$ wide $\times 7^{\prime}$ high and weighs about 13,000 pounds. A full-size vault is required for its installation. There are 34 such installations in the Boston Network area, four of them being in the Back Bay Network.

The 1,200 ampere fuses on the dc side of the rectifier must permit load current to flow without interruption, yet operate quickly for short circuits. For a maximum fault, this fuse would blow almost instantaneously so that heat generated would be negligible and that there would be no damage to adjacent cables. However, the speed of interruption decreases rapidly with reduction in fault current, which can be caused by arc resistance and/or distance between the fuse and the short circuit. For example, this fuse would require 10 seconds to blow for a 2,500 ampere short circuit.

One of the most difficult problems with the dc secondary grid is clearing faults. Arcing faults may not draw enough current to blow fuses as in the case of the Back Bay incident. This problem is compounded by the decreasing size of the dc system. As links in the dc grid are no longer needed and are retired and moved, the impedance of the grid increases.' This causes a decrease in fault currents and correspondingly increases the probability that faults will not be cleared by the fuses. 
TYPICAL ELECTRICAL CONNECTION

250 KW POWER RECTIFIER

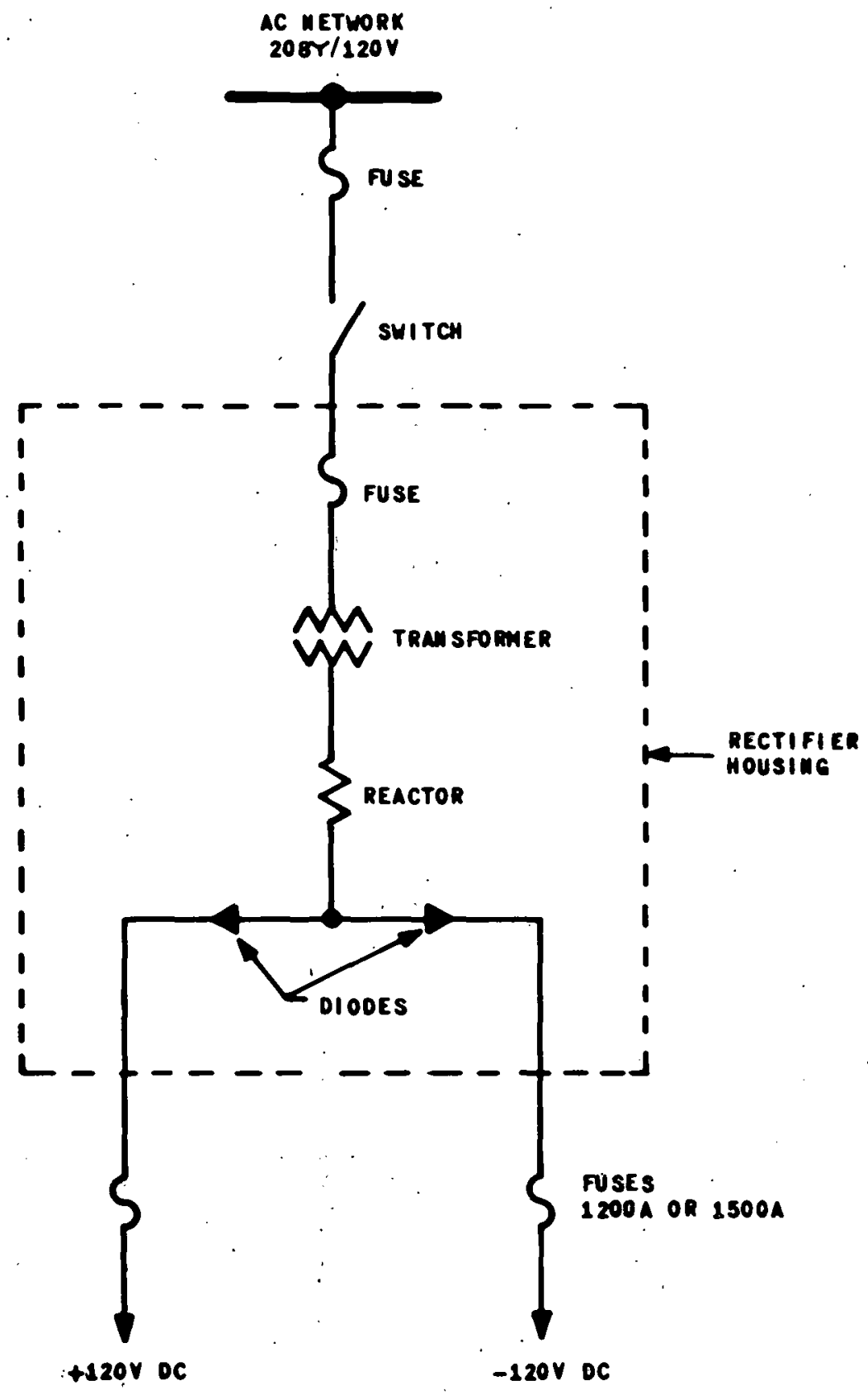


The cause of the dc fault that initiated the Back Bay incident is not known. The cable that failed was pilaced in service on November 22, 1922; it was 57 years old. Several weeks prior to the failure, this manhole was used to film a TV documentary on cable spiicing. Possibly, this cable was kicked or moved. If this happened, it could have been the cause of the fault. Cable insulation deteriorates with age, becomes brittle, and perhaps dry because of oil migration in impregnatedpaper insulated cables of the type used for the de system. However, particularly in the case of cables operating at low voltage as in this instance, satisfactory service can be rendered indefinitely, provided that the cable is not moved. However, movement can disturb this rather delicate balance with subsequent failure. The dc cable that failed occupied Position 11 , a bottom position, in Manhole 1456 (Exhibit 6) and might have been more vulnerable to accidental movement than some other cables in the manhole. The fault current completely destroyed the cable, leaving little evidence to determine how the cable initially failed. However, none of the fuses in the dc systeli blew, indicating that the initial problem was a high-resistance dc fault that failed to clear.

This incident occurred on a sunday afternoon in April, a time of light system loads. The Back Bay Network was carrying about 29 MVA at the time. (The 1978 summer peak demand on the network was 64 MVA.) The situation facing the operators was the 
operation of a lightly loaded, but badly damaged network. Periodic load readings were taken at selected network transformers. Loadings were within acceptable emergency limits; however, low voltage problems were being reported.

The North Grid of the Back Bay Network is characterized by large commercial customers south of Boylston Street and small commercial and residential customers north of Boylston street. The large commercial customers (notably the John Hancock Tower and the Copley Plaza Hotel) are supplied by $480 Y / 277 \mathrm{~V}$ spot networks, and other commercial and the residential customers are served by the $208 \mathrm{Y} / 120^{\circ} \mathrm{V}$ secondary grid. The loss of five $14 \mathrm{kV}$ feeders severely impacted this $208 \mathrm{Y} / 120 \mathrm{~V}$ secondary grid, since only three remained in service. This grid was being operated very near it.s limits. By sunday evening, the Back Bay Network load had slightly increased to $31 \mathrm{MVA}$, and the load demand within the network was probably shifting with more residential load coming on. Approximately eight hours after the initial fire, a second manhole fire was reported within this residential area caused by overloaded secondary cables. This, in turn, was caused by unavailability of network transformers. Burning secondary cables damaged one of the remaining three feeders supplying this area. Consequently, the sixth feeder tripped out. Within two hours, one transformer and four additional manholes were reported smoking or afire. The situation at that time was that the North Grid was being supplied by only two $14 \mathrm{kV}$ circuits (of eight normally available) and eleven 
network transformers (of 59 normally available). It was evident that the load could not be sustained. A decision was then made that the network be shut down to prevent further equipment damage.

The severity of the situation was now apparent and emergency restoration procedures were initiated.

The network system is composed of three major components, each of which must be adequate to supply the load and transfer power as required. These components are:

- Primary Circuits $(14 \mathrm{kV})$

- Network Transformers (14 kV - 208Y/120 V)

- Secondary Network $(208 \mathrm{Y} / 120 \mathrm{~V})$

During the emergency, an accurate assessment of the status of primary circuits and network transformers was known. The loads on the primary circuits were readily, determinable from substation instrumentation. The number of transformers in service was determinable from system reçurds and knowledge of "cut-and-cap" locations on damaged primary circuits. Transformer loads were monitored by field forces, and unacceptable overloads were not experienced during the emergency. Upon loss of a transformer (due to primary circuit outage) the $208 \mathrm{Y} / 120 \mathrm{~V}$ circuits transfer power from remaining transformers to loads normally served by transformers out of service. These loads 
are not easily monitored, and such power transfers can exceed the overload capabilities of the cables, with resulting failures. Low-voltage conditions are also experienced. Inability of the secondary grid to make the necessary power transfers, with ,resultant overloads, smoking, and fires was the cause of all subsequent outages to primary circuits serving the network.

It can be observed that six of the eight primary feeders that normally supply the North Grid were out of service simultaneously during the emergency. However, all of the outages were caused by damage from fires on low-voltage systems the dc cables in the case of the initial outages and the ac cables in the cases of subsequent outages.

RESTORATION MEASURES

The following steps were taken to restore service to the affected customers:

- The three $14 \mathrm{kV}$ feeders that supply Beacon Street Station 49 were reclosed, restoring service to approximately 1,500 customers after a 25-minute outage between 2242 and 2307, on Sunday, April 1. Service to Beacon Street was briefly interrupted for switching operations on six occasions prior to the end of the emergency on the morning of Wednesday, April 4. 
- Four interconnecting secondary mains were cut and a switch was opened to separate the Back Bay North and South Grids. The undamaged South Grid was re-energized, restoring service to approximately' 5,000 customers, after a 4-hour, 34-minute outage from 10:42 PM Sunday night until 3:16 AM Monday morning. Six brief interruptions for switching operations were experienced prior to Llie end if Llie emergency.

- The damaqed North Grid was repaired and reenergized to restore service to the remaining customers out of service. The total outage time was 38 hours and 10 minutes at various times between 10:42 PM on Sunday, April 1, and 6:32 AM on Wednesday, April 3.

- The dc customers were out of service for varying intervals with the final restoration occurring on Friday, April 5.

Three of the four feeders damaged by the initial fire and the feeder out on maintenance were cut and capped, and switching was performed, isolating the damaged equipment. After an outage of 8 hours and 10 minutcs, the undamaged parts of six feeders were used to energize the North Grid. Several hours later, the undamaged portion of a sevienth feeder was returned to service. Throughout the day of Monday, April 2, all customers were in service while repairs were being made. 
At approximately 9 PM, a manhole fire was reported, and shortly thereafter a $14 \mathrm{kV}$ feeder tripped out. Several reports of further manhole fires were received, and at approximately 11 PM the North Grid was de-energized to prevent additional damage. Additional repairs were undertaken, and an unsuccessful attempt was'made to energize the North Grid on April 3. More repairs were made, and the North Grid was successfully energized on April 4.

The series of problems that occurred on April 1-4 resulted in service interruptions to approximately 12,500 customers for various parts of the four days as summarized in the following table.

Number of Hours-Minutes Out of Service Customers $4 / 1 \quad 4 / 2$ 4/3 $4 / 4$ Total Beacon Street Station $\quad 1,500 \quad 0-25 \quad 0-4 \quad 00-5 \quad 0-1 \quad 0-35$ Back Bay South Grid $\quad 5,000 \quad 1-18 \quad 3-18 \quad 0-5 \quad 0-1 \quad 4-42$ Back Bay North Grid $\quad 6,000 \quad 1-18 \quad 7-59 \quad 22-21 \quad 6-32 \quad 38-10$

The three $14 \mathrm{kV}$ distribution supply lines to Beacon Street Station 49 are not directly involved in the network system, but outages of these three lines cannot be avoided when energizing the Back Bay Network. since they are connected to the same $14 \mathrm{kV}$ buses that supply the network. For the same reason, an outage of the South Grid is necessary when re-energizing the North Grid. In any secondary network, each feeder is connected to the entire network load via the transformers and secondary 
grid. If only one feeder is energized, it will attempt to carry the entire network load and will be overloaded. Therefore, to energize a network, all feeders must be energized simultaneously. This is accomplished by de-energizing the $14 \mathrm{kV}$ bus, closing all feeders onto the de-energized bus, and. then re-energizing the bus. All of the outages to Beacon Street Station 49 and those to the South Grid after isolation from the North Grid were of this nature.

During the restoration effort, Boston Edison received good cooperation from the police and fire departments. The fire department was usually the first called by citizens reporting manhole fires. The fire department was quick to respond and immediately called Boston Edison. The fire department stood by to assist Boston Edison personnel. The police department designated a single liaison to serve as a contact point for Boston Edison. This liaison directed police units to close streets or move parked cars, as necessarỵ to facilitáte the restoration efforts.

Boston Edison made space available near the system Control Center and scheduled frequent press conferences. The news media could see the activity in the control center directed toward restoring service. The direct observation by the news media reinforced the utility's statements that action was being taken and resulted in better press briefings than would have been obtained in a "sterile" conference room away from the action. 
Since the outage was localized and required a number of repairs in the streets, Boston Edison repair crews were highly visible in the affected area. The people in the blacked-out area could see for themselves the effort being made to restore their service.

Another measure found useful in expediting the restoration effort was to provide coffee and meals in the streets for the repair crews. Arrangements were made with vendors to take food directly to the repair crews so the crews could rest, eat and return to work with a minimum of lost time.

A problem involving access to facilities was encountered during initial phases of the emergency. It was necessary to perform switching operations in a vault located in the John Hancock Tower. Boston Edison personnel had to wait for more than one hour for an escort required by building security regulations.

Special effort was made to restore service to hotels and very large commercial buildings during the emergency, although outages of substance were also suffered by these facilities. A North Grid feeder was made available to the John Hancock Tower at 1135 on Tuesday, April 3. Partial service was restored at 1652 to the Copley Plaza, Lenox, and Copley Square Hotels.

MITIGATIVE MEASURES

Following the Back Bay incident, the Boston Edison ' $:{ }^{\prime}$, Company embarked on several field programs: 
- Inspection of the 444 manholes in the North Grid, with repairs to electrical facilities as required.

- High voltage testing of each $14 \mathrm{kV}$ feeder serving the Back Bay Network.

- Inspect the 58 network vaults, to assure that all equipment is in good condition and to replace all limiters that might have blown during the emergency.

- Inspect the 7 dc junction boxes in the North Grid, making repairs and replacements as required.

In addition to field programs, a Network Task Force has been formed with the following objectives:

- Provide a detailed investigation of the trouble experienced on the secondary network system April 1-4, 1979 .

- Review how company supporl forces could be utilizea to more effectively assist restoration.

- Review secondary network design criteria.

- Review communication systems employed during network system problems. 
- Consider developing a different system to modify and coordinate the temporary removal of customer load and a system to control restoration of same.

- Establish an emergency plan to address major secondary network disturbances.

- Review methods and procedures to speed up the grounding, phase identification and live capping procedures on both live and dead network systems.

- Review number, size and estimated connection time for emergency generators.

- Re-evaluate the Company position concerning future disposition of the dc system. 
BRIGHTON AREA INTERRUPTION, MAY 21-22, 1979

Brighton Station 329, located at 150 Lincoln Street, Brighton, Massachusetts, is a major $115-24-14 \mathrm{kV}$ bulk power and distribution station in the Boston Edison System. This station, a manned station built in the mid-1950's, presently includes the following equipment:

$$
\begin{aligned}
& 8-115 \mathrm{kV} \text { line terminations } \\
& 2-115-24-14-14 \mathrm{kV}, 100 \text { MVA transformers } \\
& 1-115-14-14 \mathrm{kV}, 100 \mathrm{MVA} \text { transformer } \\
& 2-24 \mathrm{kV} \text { bus sections with } 4-2.4 \mathrm{kV} \text { fepiers } \\
& 6-14 \mathrm{kV} \text { bus sections, tie bus, and } 30-14 \mathrm{kV} \text { feeders }
\end{aligned}
$$

DESCRIPTION OF OUTAGE

On Monday evening, May 21, 1979, Station 329 was supplying a load of approximately $125,000 \mathrm{~kW}$ when a fault occurred on $14 \mathrm{kV}$ feeder $202 \div 90$.

The circuit breaker protecting this feeder opened in accordance with the relaying scheme. However, although the circuit breaker contacts opened, the electric arc was not interrupted and the fault was not removed. This sustained arcing inside the circuit breaker continued, and developed into a bus fault on $14 \mathrm{kV}$ Bus section 3 of the station. (See Part A of Exhibit 9.) All other circuit breakers connected to this bus opened, in correct accordance with the bus differential 
relaying scheme. The elapsed time after the initial cable failure was 2.19 seconds. A $14 \mathrm{kV}$ circuit breaker had failed, but subsequent circuit breaker operation was correct; except that an undesired operation of transformer $14 \mathrm{kV}$ circuit breakers occurred, removing power supply Transformer C from service. Subsequent investigation revealed incorrect relay calibration on the Transformer $\dot{C} .14 \mathrm{kV}$ circuit breakers. The load was now being supplied by Transformer $B$ and half of Transformer A (again - refer to Part $A$ of Exhibit 9). The original cable fault had not been cleared because the circuit breaker at Station 202 had not opened and power was being supplied from Bus section 6 through $14 \mathrm{kV}$ Circuit 202-160.

The next event occurred five seconds later when an insulator flashover occurred on a $14 \mathrm{kV}$ circuit breaker connected to Bus Section 5. An explosion and fire in the switchgear occurred at this time. Bus section 5 was isolated by correct operation of all $14 \mathrm{kV}$ circuit breakers connected to the bus section (see Part B of Exhibit 9). Note that the original cable fault still had not been cleared.

After another three seconds other circuit breakers opened, including one of the three $14 \mathrm{kV}$ Cambridge tie lines. The initial cable fault was finally cleared - 10.27 seconds after its occurrence - by the circuit breaker at Station 202. (See Part $C$ of Exhibit 9.). The Cambridge ties constitute an interconnection with the Cambridge Electric Light Company. 
By this time the situation had deteriorated to the point where no service could be maintained, and all power supply transformers and all $14 \mathrm{kV}$ Cambridge ties opened because of excessive currents. (See Part D of Exhibit 9).

Service had been interrupted to 50,600 customers by this series of events. In addition, substantial damage had been caused to equipment in the substation by the explosion and fire.

The durations of outages to customers were as follows:

Time

$7: 25 \mathrm{PM}-10: 50 \mathrm{PM}$

$7: 25 \mathrm{PM}-12: 18 \mathrm{AM}$

$7: 25$ PM - 12:31 AM

$7: 25 \mathrm{PM}-3: 38 \mathrm{AM}$
Duration

Hrs - Min Number of Customers

$3-25 \quad 20,200$

$4-53 \quad 30,400$

$5-06$

$8-13$
1 (commercial)

9 (commercial)

\section{CAUSES AND CONTRIBUTING FACTORS}

The Brighton incident was caused by a cable fault, followed by a circuit breaker failure, a bus fault, and incorrect relay settings that, when combined; resulted in the loss of the $14 \mathrm{kV}$ portion of the station. The initial failure occurred when a $14 \mathrm{kV}$ circuit breaker failed to interrupt a cable fault. The arc across the circuit breaker degenerated into a bus fault. Proper relay action cleared the faulted bus 'section, but overcurrent relays caused $14 \mathrm{kV}$ circuit breakers protecting a transformer to open, consequently isolating a transformer supplying two bus sections. This was attributable 
to incorrect calibration of the relay. Five seconds later, an insulator failed, resulting in another bus fault. An explosion and fire followed, completely destroying one circuit breaker. More circuit breakers tripped, de-energizing all six $14 \mathrm{kV}$ bus sections. The entire sequence from initial cable fault to shut- : down occurred within seventeen seconds.

Except for the incorrect relay setting, the problems in this incident were essentially equipment failures. This station was built in the mid-1950's, and this is the first incident of a circuit breaker failing to interrupt a cable fault. These circuit breakers are maintained on a regular four-year schedule. This particular breaker was last overhauled in March, 1976.

The second bus fault was caused by the failure of an insulator in a circuit breaker cubiclë. The suspected reason is that a voltage surge from the first bus fault caused further damage to an already weak insulator.

The feeder circuit breakers at this substation are General Electric, Type AM-13.8-500-2. There are many such circuit breakers on the Boston Edison system. The breaker that failed has been returned to General Electric for detailed investigation by the manufacturer to determine the cause of the failure. It has not been possible to establish a pattern of 
frequent failures of this type breaker through EEI records or by a limited inquiry to other utilities. However, Westinghouse has discovered a design flaw in similarly rated breakers of their design and manufacture, whereby the arc might not be interrupted in case of a fault of low magnitude. A modification kit has been offered for the Westinghouse equipment to correct this situation. It has been suggested by Boston Edison that the initial circuit breaker could have failed because the power arc might have evolved outside the arc chutes, thus resulting in the bus fault. A vigorous joint effort should be undertaken with the General Electric Company to ascertain whether design or manufacturing defects exist in this type of circuit breaker.

The Boston Edison Trouble Analysis Report for the cable fault that triggered this major disturbance concluded that the fault was of extremely long duration, and had probably burned for some time before relay action was initiated at Brighton station. A total of 8 inches of all three copper conductors and 33 inches of lead sheath had been completely burned away before the trouble was cleared. The fault occurred in a duct between Manholes 19449 and 19448, which was reported to be wet. The cable was of an obsolescent belted (nonshielded) construction and was 42 years old at the time of failure. Traces of moisture were found in the outer layers of insulation near the fault. However, this was not fixed as the cause of failure because of the damage. 
The second circuit breaker which resulted in the explosion could easily have been caused by a fault beyond the interrupting rating of the breaker on Feeder 506-73. The circuit breakers have an interrupting rating of $500 \mathrm{MVA}$, while the theoretical maximum three-phase bus fault is about 1328 MVA under conditions when the fault occurred. Current-limiting reactors are inserted in each feeder exit so that feeder faults will always be within breaker ratings. However, there is a short distance (a few feet) between the breaker terminals and the reactor where fault reduction is not accomplished. This is where the fault occurred. Such faults are extremely rare, and this situation is regarded as an acceptable calculated risk by many (if not almost all) utilities.

A good protective scheme for a $14 \mathrm{kV}$ system such as that supplied from the Brighton station is very difficult to achieve without establishment of expensive communications circuits between all of the substations involved. Instead, a scheme using overcurrent relays was adopted. It is difficult to calibrate the relays so that fault interruption will occur quickly, yet have proper selectivity so that circuit breakers will not be opened unnecessarily. The result is usually a compromise, with fault interruption being slower than desired. This is especially true of relaying for three-phase faults such as occurred on $14 \mathrm{kV}$ Feeder 202-90. Even so, two seconds is an excessively long clearing time for a cable fault. The relaying scheme for this area should be reviewed in detail to provide faster protection if at all possible. 


\section{RESTORATION MEASURES}

Bus taps, a switchgear cubicle and a circuit breaker were completely destroyed by the second bus fault. The explosion caused by this fault severely damaged a partition wall between two bus sections, aspestos-cement barriers covering the bus section and louvers and doors on the enclosed bus section. Brighton is a manned substation, and the fire and smoke caused by the explosion forced evacuation of the station operator's office. Supervisory personnel and the fire department arrived within fifteen minutes. A smoldering fire was extinguished, and fans were used to clear smoke from the office area and bus section aisles.

Immediate priority was given to restoration of customers' service. 'Visual inspection of the station equipment was made, and damaged equipment was isolated. Undamaged equipment was re-energized, restoring service to most customers within three and one-half hours. Restoration of service to the last customer was complicated by the fart that both feeds to this customer had been damaged. A temporary arrangement at the station was made to bypass damaged equipment, and the service to the last customer was restored in approximately eight hours.

\section{MITIGATIVE MEASURES}

As a result of this incident, the Boston Edison Company initiated the following actions:

- The overcurrent relays protecting $115-14 \mathrm{kV}$ transformers at Brighton station have been 
reset to not overreach and operate incorrectly

for $14 \mathrm{kV}$ bus faults. The protective relay

settings for other transformers at stations of similar design were reviewed.

- The circuit breaker that failed was returned to the manufacturer for additional analysis.

- All insulators at this station were inspected for signs of weakness or stress. No problems were found. 
CHELSEA/EAST BOSTON AREA INTERRUPTION, JUNE 2, 1979

The Chelsea and East Boston areas, including Logan International Airport, are supplied by $14 \mathrm{kV}$ distribution systems emanating from Substations 445 and 488 . Power supply is from the Mystic Generating Plant, which feeds station 488 by means of a $115 \mathrm{kV}$ underground cable and station 445 by means of two $25 \mathrm{kV}$ underground cables. There is also a $14 \mathrm{kV}$ connection between Stations 445 and 488 to station 14, which, in turn, is fed from Mystic at $14 \mathrm{kV}$. These connections are shown by Exhibit 10. There are approximately 10,000 customers in this area, with a total load in the order of $36,000 \mathrm{kVA}$ at the time of the service interruption. A second $115 \mathrm{kV}$ source has already been planned for support to this area; before occurrence of the outage.

DESCRIPTION OF OUTAGE

On Friday, June l, one of the $14 \mathrm{kV}$ lines feeding Station 14 from Mystic Generating Plant failed. The other circuit was removed from service to prevent overload; and the Station. 14 load was distributed among other stations. Of this load, approximately $4000 \mathrm{~kW}$ was transferred to stations 445 and 488 .

On Saturday, June 2 , testing and laboratory work was scheduled on $115 \mathrm{kV}$ underground cable 250-518 at Mystic and a 115-14 kV transformer 110A at station 488. Thus, the entire area load was being supplied by means of the two $25 \mathrm{kV}$ lines between Mystic and Station 445. The 25-14 kV transformers at Station 445 have nameplate ratings of $20,000 \mathrm{kVA}$ each. 


\section{SIMPLIFIED DIAGRAM CHEL SEA/EAST BOSTON INCIDENT (NOT ML FACILITIES ARE SHOWN)}

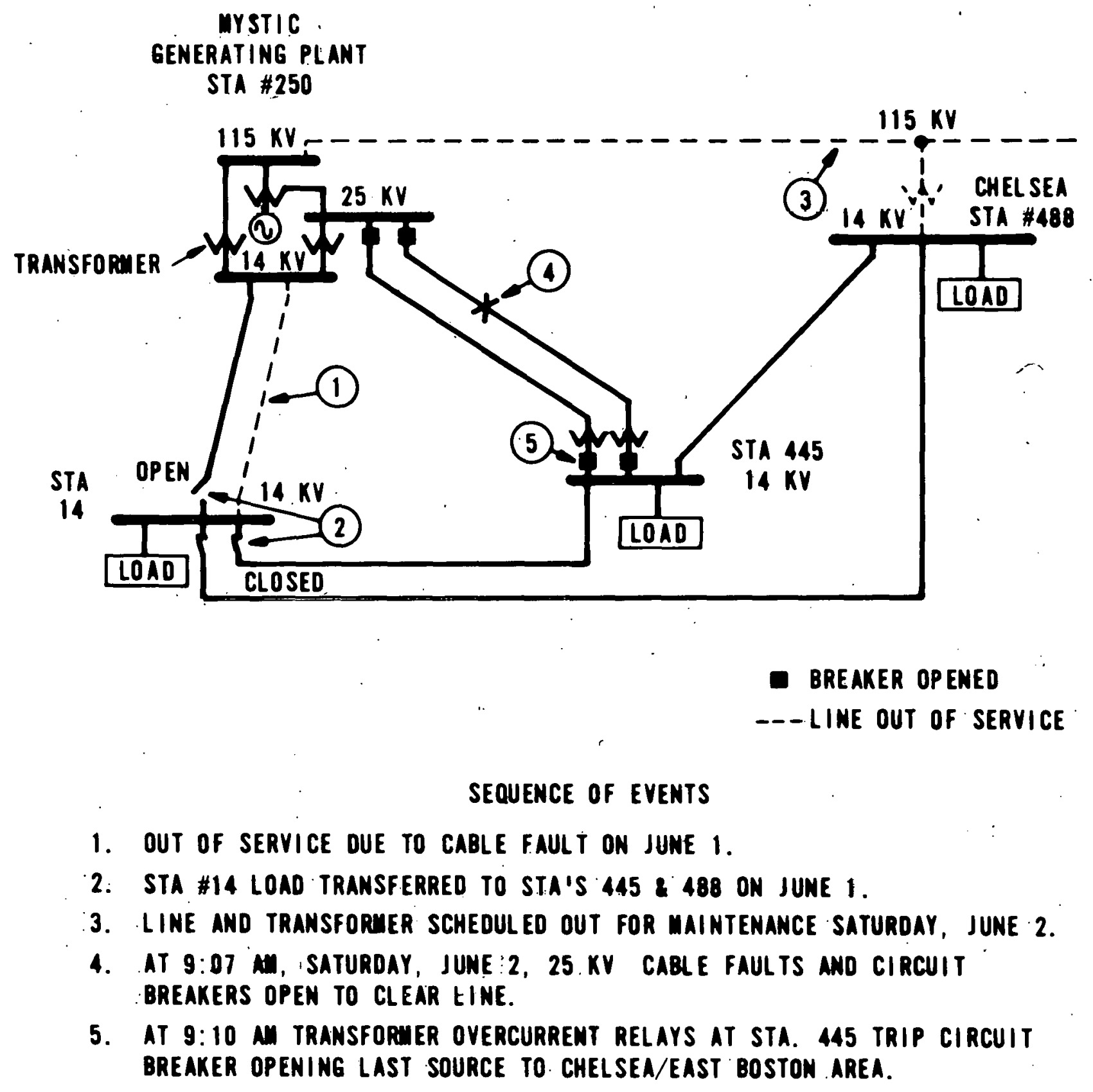


Overcurrent relays controlling the $14 \mathrm{kV}$ circuit breakers on each transformer are set to cause the breaker to open when the transformer load reaches $36,000 \mathrm{kVA}$.

At 9:00 AM on Saturday, June 1, the total load on the two $25 \mathrm{kV}$ circuits was $29,000 \mathrm{~kW}$ as measured at Mystic Generating Plant. This corresponds to about $31,500 \mathrm{kVA}$. At 9:07 AM one of the $25 \mathrm{kV}$ cables failed, thus transferring the entire load to the other. The station operator at Mystic reported that meter readings on the remaining $25 \mathrm{kV}$ circuit to Station 445 were "off-scale," or in excess of $32,000 \mathrm{kw}$, corresponding to more than $34,800 \mathrm{kVA}$. The summer emergency rating of each of the $25 \mathrm{kV}$ cables is $26,000 \mathrm{kVA}$, and the overload rating of the $25-14 \mathrm{kV}$ transformers is $28,000 \mathrm{kVA}$ each.

At 9:10 AM the $14 \mathrm{kV}$ transformer breaker opened at Station 445, with the operation initiated by overcurrent relays. This removed the remaining power source and the load served by Stations 445 and 488 was interrupted. This substantially included the towns of Chelsea and East Boston, including the Logan International Airport. Geographic location of these areas as related to the remainder of the system is shown by Exhibit 2 .

The scheduled maintenance work, on $115 \mathrm{kV}$ line 250-518 at Mystic Generating Plant and 115-14 kV Transformer 110A at Station 488 was immediately cancelled. Some work had begun, but it was possible to re-energize stations 445 and 488 at 10:24 AM when the transformer was switched back into service. 
The outage duration was 1 hour and 17 minutes to most customers. One station was not re-energized until 11:18 AM, so that its customers experienced a 2 hour and 11 minute outage. This added time was caused by failure of remote supervisory control to operate properly, which resulted in a requirement to send an operator to a normally-unattended station.

\section{CAUSES AND CONTRIBUTING FACTÓRS}

It has been determined by Boston Edison that testing requiring removal of the $115-14 \mathrm{kV}$ transformer at Station 488 from service should not have been undertaken on Saturday, June 1 , 1979. The reason for this was that any additional problems on the system could result in overloads and possible interruptions. (This determination was made immediately after the incident, and was not prompted by this investigation.)

Boston Edison's review of this incident determined that the dispatcher directing the switching of the Chelsea $115-14 \mathrm{kV}$ transformer had not reviewed previous load readings for typical Saturday and sunday conditions prior to scheduling the work. Such a review would have indicated that the second contingency (loss of a Mystic-Station $1425 \mathrm{kV}$ line) could have been handled on sunday whereas on Saturday it could not. In addition, load readings were not taken before and after switching to make sure that circuit loadings were within acceptable limits. Such checks are standard Boston Edison operating procedúre. It was particularly important in this case, since additional load aggregating $4000 \mathrm{kVA}$ had been transferred into this area as a result of the $14 \mathrm{kV}$ cable fault in the Mystic area the previous day. 


\section{RESTORATION MEASURES}

The scheduled maintenance work was cancelled, and the 115-14 kV transformer was returned to service. Service to all customers was restored within $1-1 / 2$ hours.

\section{MITIGATIVE MEASURES}

- This incident has been throughly reviewed with the personnel involved, dealing particularly with the scheduling of outages and the responsibilities of the permit coordinator and the dispatcher.

- In the course of repairing the damaged $25 \mathrm{kV}$ cable, one manhole was rebuilt.

- To further st.rengthen this area, a second 115-14 $\mathrm{kV}$ source has been authorized. This source will be provided by tapping an overhead $115 \mathrm{kV}$ line. It is scheduled to be in service by June, 1981.

- Boston Edison Company "Guidelines for Scheduling Equipment Outages" has been revised to emphasize the importance of consideration of secondcontingency outages. Scheduling of such outages for Sundays rather than Saturdays was directed for cases where risk of interruption would be less. 
TOWN OF WELLESLEY ABNORMAL SYSTEM CONDITIONS JUNE 18-23, 1979

The Boston Edison Company supplies at wholesale all of the Town of Wellesley's requirements via five $14 \mathrm{kV}$ supply lines. Four of the five originate at Newton Highlands station 292 and run underground in a common duct line to the Wellesley border. The fifth is an overhead spacer cable that originates at Needham Station 148 and goes underground at the Wellesley border.

The capacity of this cable system, as determined by Boston Edison is as follows:

\begin{tabular}{|c|c|c|c|c|}
\hline \multirow[b]{2}{*}{ Line } & \multicolumn{2}{|c|}{ Summer, kVA } & \multicolumn{2}{|c|}{ Winter, kVA } \\
\hline & Normal & Emergency & Norma I & Emergency \\
\hline $41-210$ & 7,750 & 9,750 & 9,000 & 10,750 \\
\hline $4 I-212$ & 7,750 & 9,750 & 9,000 & 10,750 \\
\hline $41-213$ & 9,250 & 11,500 & 10,625 & 12,750 \\
\hline $378-89$ & 9,250 & 11,500 & 10,625 & 12,750 \\
\hline $378-90$ & 8,000 & 8,750 & 8,750 & 8,750 \\
\hline & 42,000 & $39,750 *$ & 47,250 & $43,000 *$ \\
\hline
\end{tabular}

*Largest line out of service.

Line 378-90 originates at Needham, the other four at Newton Highlands.

The four supply lines from Newton Highlands Station run along Worcester Street, Route 9, approximately 5,800 feet in 18 manhole sections. The duct and cable are owned and maintained by Boston Edison. At the Wellesley border, the duct line 
splits into two separate lines and extends 13,000 feet into Wellesley in 35 manhole sections. This duct system and two of the cables are owned by Wellesley. The two Wellesley cables then extend an additional 16,000 feet in a wellesley-owned duct system. The Needham supply line is owned and maintained by Boston Edison in Needham and by Wellesley inside the Town of Wellesley. (See Exhibit il.)

The four Newton Highlands supply cables are fed from separate $14 \mathrm{kV}$ bus sections and are dedicated lines supplying no load other than Wellesley. The Needham line serves both Boston Edison and Wellesley loads.

The 1978 wellesley summer peak load was 31.9 MVA, well under the cable system rating.

DESCRIPTION OF OUTAGE

On Monday, June 18, at 2:22 PM, when the first of a series of cable faults occurred on the $14 \mathrm{kV}$ supply line from Newton Highlands Station, the Wellesley load was 31.1 MVA. Crews, dispatched to investigate, found another of the supply lines damaged. At 5:17 PM, at another location, a second supply line failed. This put two of the four supply lines out of service, and a third, though operating, was badly damaged. Both supply lines to Wellesley's Cedar Street Station were out, causing an interruption of service to approximately 1,000 customers. Throughout the week of June 18-23, problems on 


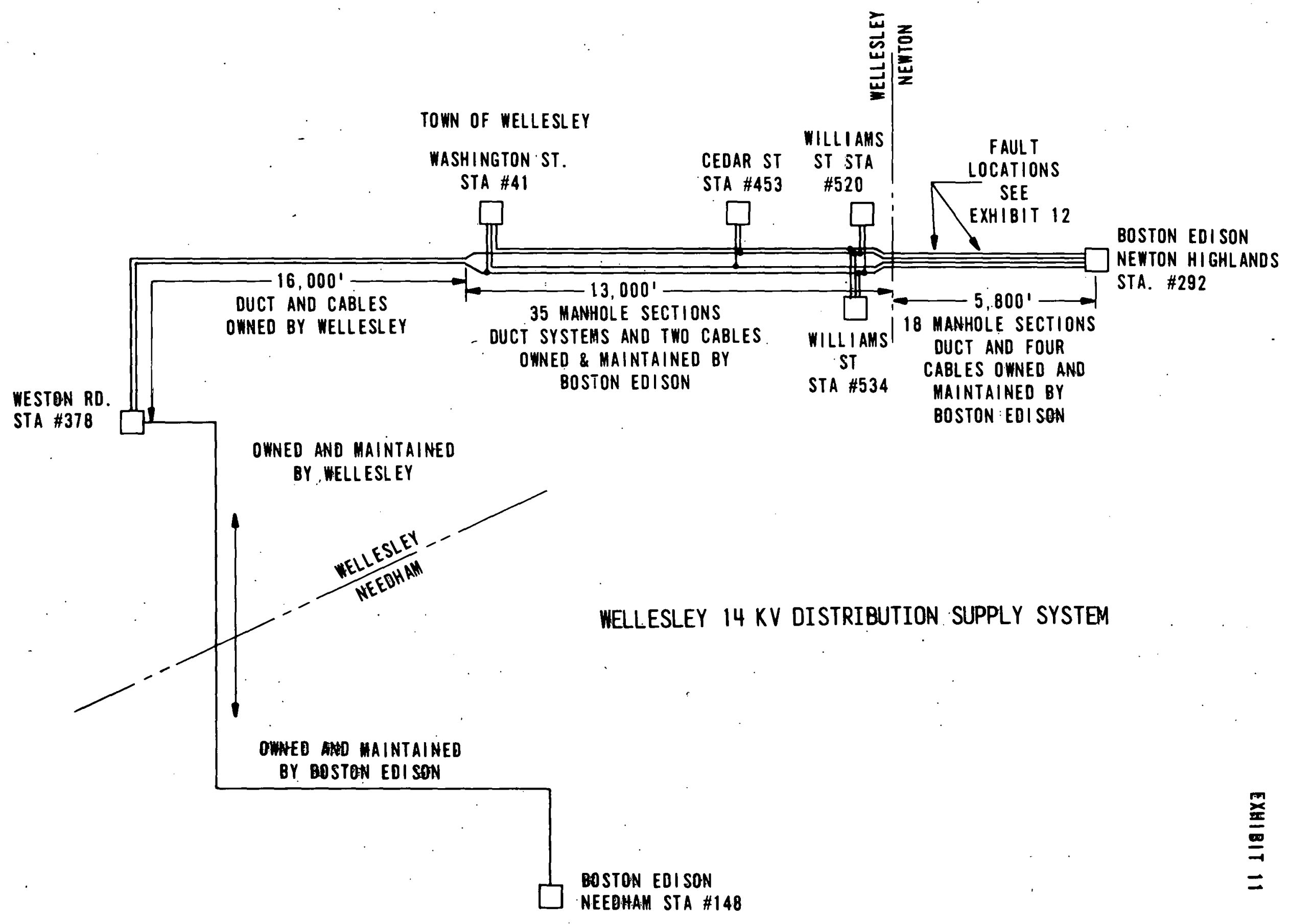


these lines continued with one or two cables being out of service. Exhibit 12 shows a chronological record of the week's events. By the end of the week, repairs had been made on all four of these lines. The following table provides a summary of the hours of service interruption:

\begin{tabular}{|c|c|c|c|c|}
\hline Date out/In & Hour & Out/In & $\begin{array}{c}\text { Duration } \\
(\mathrm{Hr}-\mathrm{Min}) \\
\end{array}$ & $\begin{array}{l}\text { Number of } \\
\text { Customers }\end{array}$ \\
\hline $6 / 18-6 / 19$ & $5: 17 \mathrm{PM}$ & $-1: 05 \mathrm{PM}$ & $19-48$ & 1,000 \\
\hline $6 / 19-6 / 20$ & $1: 20 \mathrm{PM}$ & $-1: 44 A M$ & $12-24$ & 1,000 \\
\hline
\end{tabular}

The sequence of troubles is depicted on Exhibit 12 .

CAUSES AND CONTRIBUTING FACTORS

The first fault was a joint failure on Circuit 378-89. The joint was a short distance from the duct on the downward side of the manhole. There was a one-inch slit at both ends of the wipes on the joint, and signs of moisture. When this joint faulted, it damaged an adjacent cable, circuit 41-212. The fault blew a hole about the size of a half-dollar in the sheath of the adjacent cable. In spite of the damage, this circuit remained in service.

The second fault occurred on Circuit 41-210, approximately three hours after the first failure. This fault was located within the duct. It is suspected that thermal expansion and contraction of the cable over a long period of time caused a crack in the sheath, allowing moisture to enter the cable. The third fault, also on Circuit 41-210, occurred at the old cable end of a new joint completed approximately thirty minutes earlier. The 
original analysis of the old cable end indicated acceptable levels of moisture. Later analysis, outside this failed joint, found the old cable insulation to be very wet, indicating that a cracked sheath had absorbed moisture. This third fault also caused damage to an adjacent joint on Circuit.41-212. The lead sleeve of the joint was slit and leaking oil.

The paper-insulated, lead-covered cables in this system have been in place for many years $\mu$ and are of an obsolescent, nonshielded design. There is strong evidence that the lead sheath ruptures which led to moisture ingress and/or oil leakage were caused by fatigue rather than wear. Modern lead alloys (such as arsenical or tellurium) are much more resistant to fatigue cracking. Available records indicate that the lead sheaths on the Weliesley cables were of arsenical alloy, which indicates that no unusual vulnerability to fatigue cracking was present.

The fact that subsequent cable failures occurred after the first one, even though the load was well within cable ratings is significant. This indicates that all of the cables are in poor condition, might have cracked sheaths and moisture in the insulation, and are thus extremely vulnerable to failures when sudden load changes are imposed. Exhibit 13 shows that none of the cables were overloaded during the week of June 18-23, 1979, based on thermal ratings which have been assigned to them.

Upon closer examination of the four supply cables, both outside and inside the town of Wellesley, additional cracks were found. This is a hilly area and most cracks were found in 
ESTIMATED LOADS

WELLESLEY SUPPLY CABLES

CKT

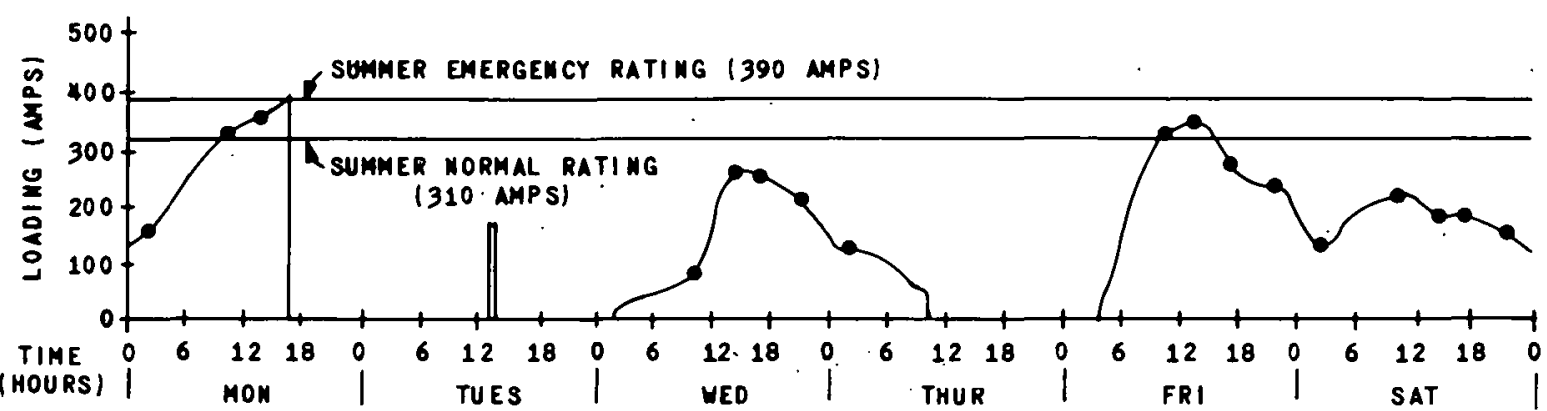

CKT

41-212

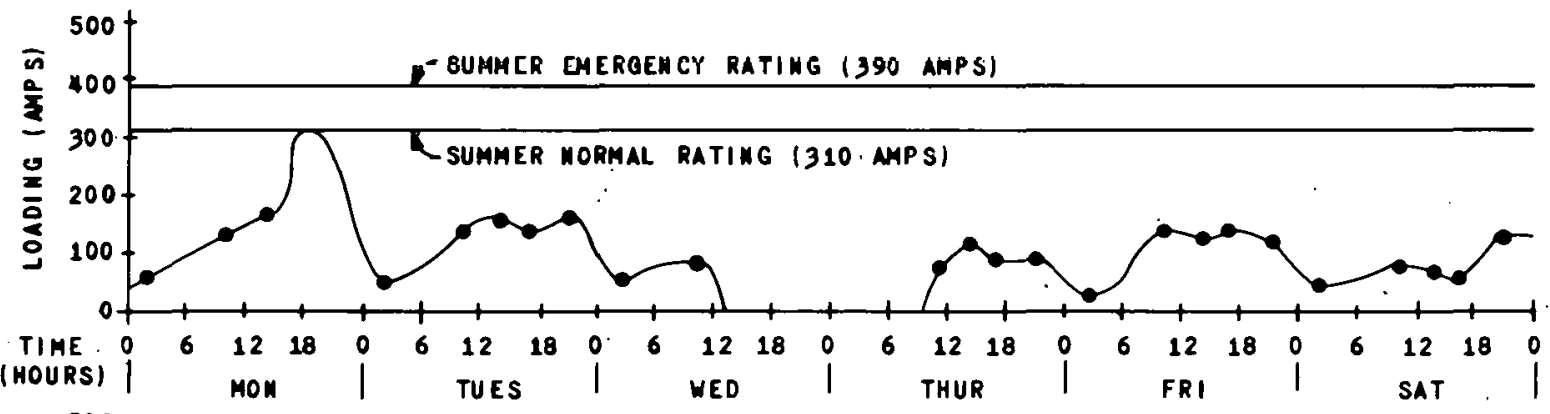

CKT

41-213

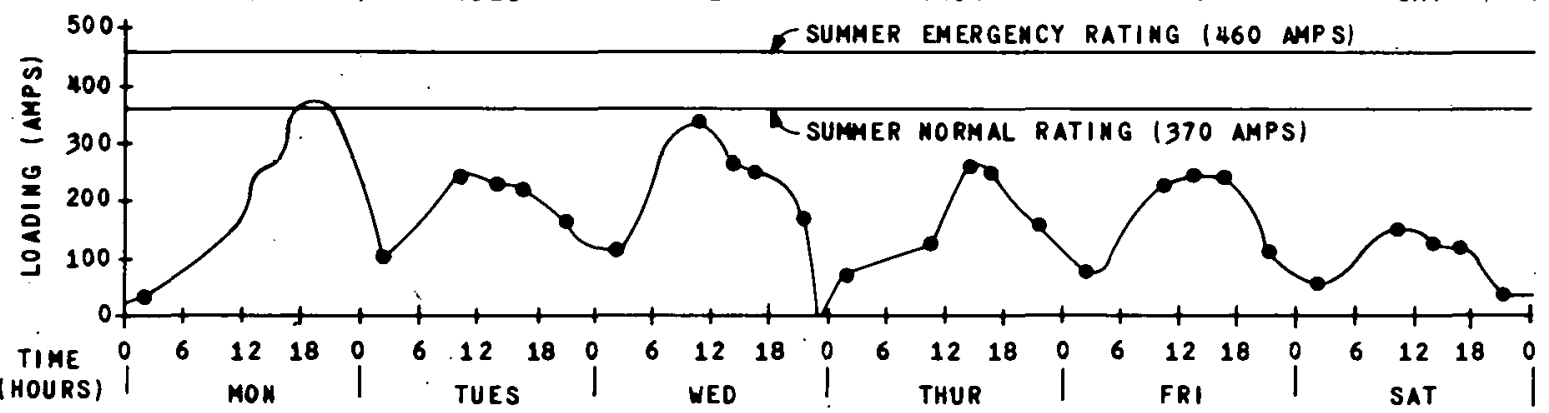

CKT

378-89

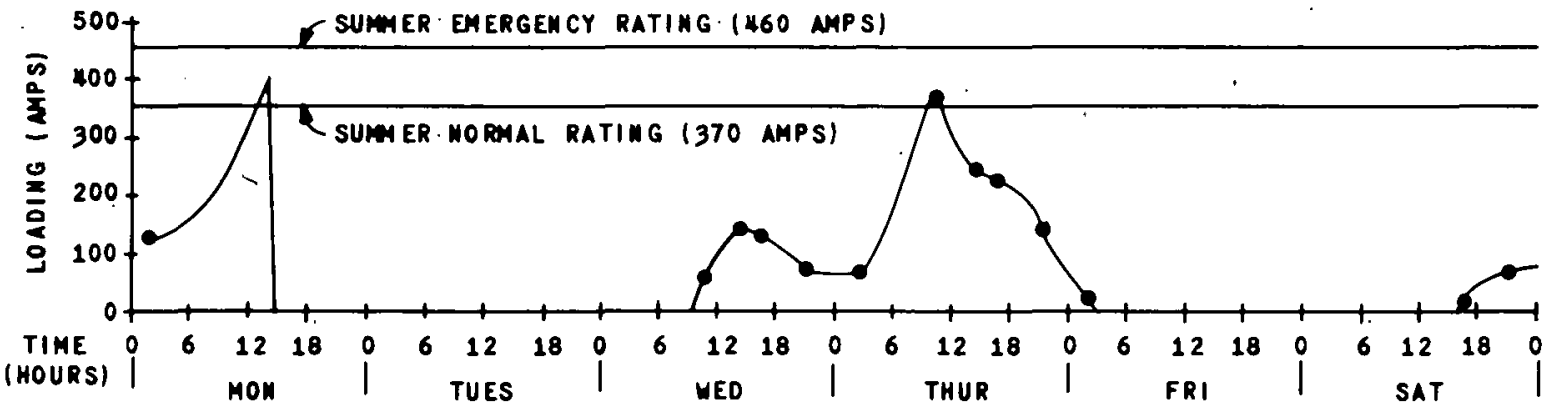

CKT

378-90

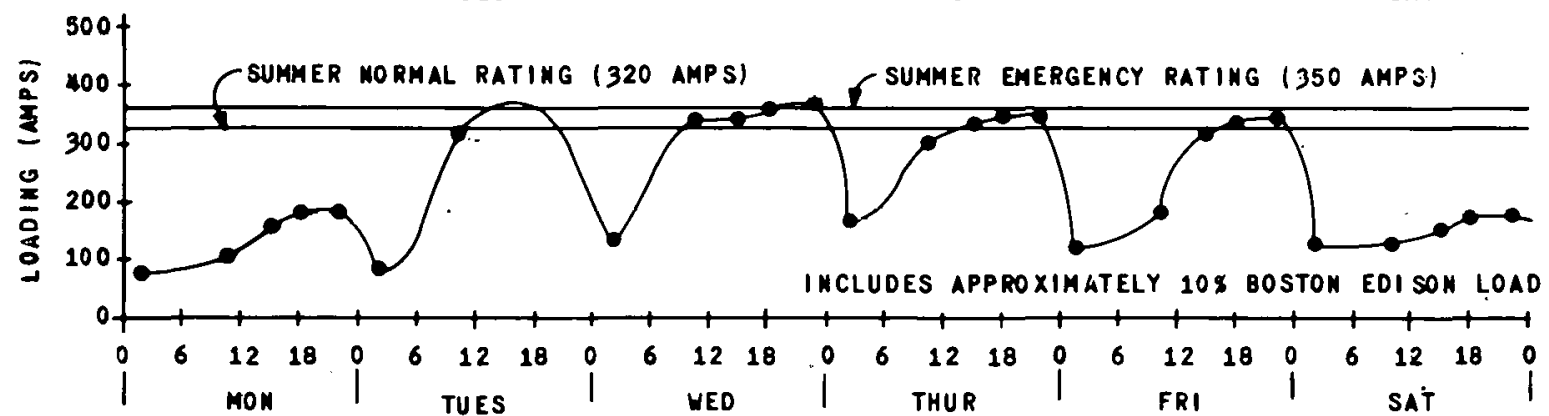


this area. Boston Edison has hypothesized that the cracking of the cable sheath may be caused by the combination of the steep grades and thermal cycling. The cables, on expansion, may be moving in the downhill direction, but upon contraction, there may be less movement back uphill. Through many cycles of thermal expansion and contraction, the cable movement may have caused stress and cracking of the cable sheath.

Compound migration can also occur in such an environment. The oil impregnant can drain from a cable end at high elevation, leaving it dry and relatively more likely to fail. This problem can be greatly reduced by the use of high viscosity compound (thick oil) that is migration-resistant when the cable is manufactured. Boston Edison states that high-viscosity compound was used in the Wellesley cables (desireable for hilly terrain). Since failures occurred at both high and low points, it does not appear that cable impregnant migration was the cause.

Another measure that can help is the use of a lead sheath covering (such as neoprene) with a relatively high coefficient of friction for cable in hilly areas.. In this way the tendency of the cable to move through the duct would be somewhat reduced. Records indicate that much of thecable serving Wellesley has such a covering.

RESTORATION MEASURES

Service to most customers in the town of Wellesley was maintainted by switching stations to the undamaged circuits. However, the very delicate nature of the supply situation was 
apparent. Special measures were instituted by Boston Edison to. secure the wellesley supply system, as follows:

- Consultations between Boston Edison and the Town of Wellesley were initiated to communicate the severity of the problem and to discuss and jointly agree on measures to be undertaken.

- Public appeals to reduce load were made with the best results coming from commercial customers.

- Temporary overground "jumpers" were installed, bypassing damaged cable in two locations. This permitted energization of the circuit while damaged sections were being repaired. Good cooperation was received from authorities in obtaining permission needed to install the overground cables.

- Two overhead ties were installed to back up the Wellesley supply cables. One was a temporary line; the other tie had been scheduled for installation on a permanent basis later in the summer. The temporary tie was in place by late Tuesday, and the permanent tie was available for use by Wednesday morning. Fortunately, neither tie was needed. Since the permanent 
tie had been planned, necessary permits were

in hand, and some facilities were already

installed prior to the incident. No difficulties

or delays were encountered in putting in the two overhead ties.

\section{MITIGATIVE MEASURES}

Following the incident, Boston Edison made a thorough inspection of all manholes outside the town of Wellesley, and a joint. Boston Edison and Wellesley inspection was conducted on the manholes inside the town. Additional repairs were made. Also, all four cables were tested. Boston Edison is presently considering design changes, such as the use of wedges and restraints to minimize cable movement.

In addition to the measures taken, which essentially amounted to inspection and repair of existing facilities, the following is suggested:

- Consider replacing all of the old belted cable showing signs of sheath fatigue (in the hilly areas) with new shielded cable with arsenical or tellurium lead-alloy sheath, migrationresistant compound, and neoprene covering overal1. Support the cables in areas of steep grades by means of wire basket grips in the manholes. 
- Adopt a rigorous program of annual high-voltage testing of all cables supplying the Town of Wellesley.

- Consider (jointly with the Town of Wellesley) establishment of power supply feeders using different routes, with probable reinforcement of the Wellesley distribution circuits to make it more able to transmit power across the. system. 
ROSLINDALE AREA INTERRUPTION, JUNE 23-26, 1979

The Roslindale area is supplied by three $14 \mathrm{kV}$ underground circuits $(13-76 \mathrm{H}, 13-75 X Y \mathrm{H}, 13-79 \mathrm{H})$ from station 13 (Roslindale). Two of these extend to Station 143 (Humboldt Avenue), and are operated open at that location. This system serves several large institutional loads and about 6,200 other customers. Two circuits are connected to every load, so that loss of one would not result in a service interruption. In addition, the Roslindale station can be removed from service, and $a \perp \perp$ of the load transterred to Humboldt Avenue station. There would be no load interruption provided that Circuits 13-76XYH and 13-79H remain in service. See Exhibit 14.

At 8:27 AM on Saturday, June 23, 1979, circuits 13-76H and 13-79H failed simultaneously in Manhole 1601. It is postulated that one of the circuits failed, damaging the other, resulting in failure of both. Circuit 13-75XYH remained in service. The loads supplied exclusively by the two tailed circuits lost electric service. These were:

Comm. of Mașsachusetts Health Laboratorł Southwest High School

Because the incident occurred on a Saturday, loss of service to these institutions was much less disruptive than it would have been on a weekday . 


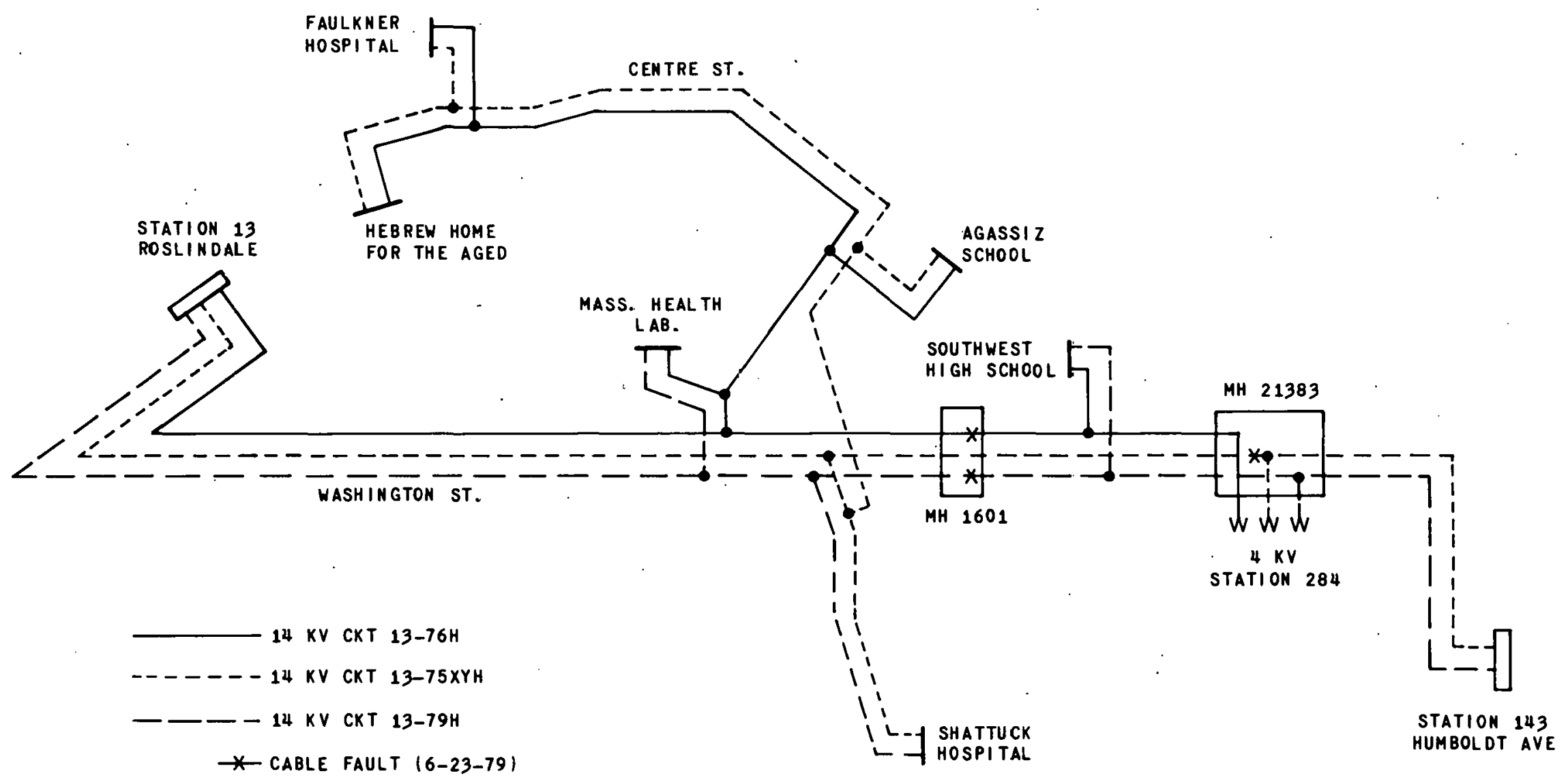

ROSL INDALE AREA

14 KV DISTRIBUTION SYSTEM 
All remaining load was automatically transferred to Circuit 13-75XYH, which was operating well within its rated capacity. Thus, the initial outage was limited to the loads cited above.

At 10:49 AM, Circuit 13-75XYH failed in Manhole 21383 (at Station 584). This caused an interruption to all of the load originally supplied by the three $14 \mathrm{kV}$ circuits. This included:

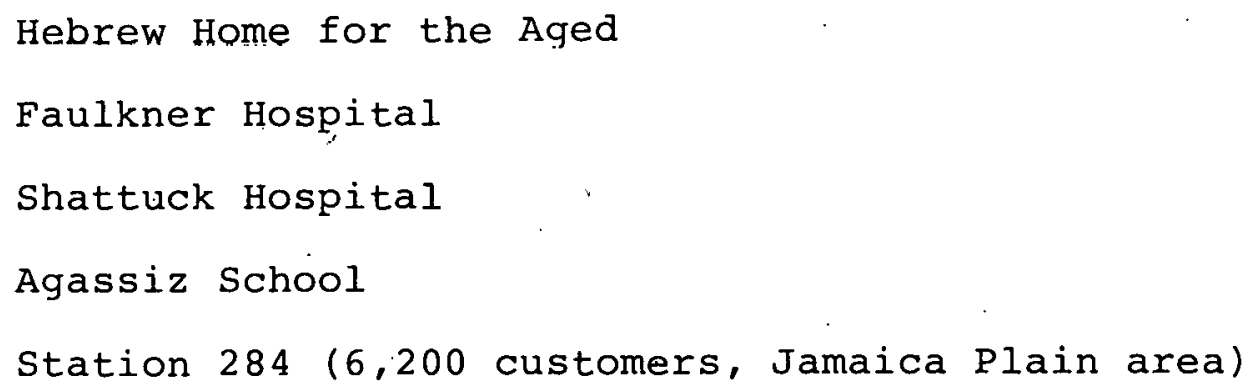

The duration of the outage and the number of customers affected were as follows:

$\begin{array}{cccc}\text { Time } & \begin{array}{c}\text { Duration } \\ \text { (Hr-Min) }\end{array} & \frac{\text { Number of Customers }}{\text { Hospitals/Institutions }} \\ 8: 27 \mathrm{AM}-2: 54 \mathrm{PM} & 4-05 & & 3,200 \\ 10: 49 \mathrm{AM}-12: 45 \mathrm{PM} & 1-56 & 3,000 \\ 10: 49 \mathrm{AM}-4: 37 \mathrm{PM} & 5-48 & -\end{array}$

The manner of restoration is discussed in another section of the report.

CAUSES AND CONTRIBUTING FACTORS

The cable in service on the Roslindale area $14 \mathrm{kV}$ system is of an unshielded, belted construction, which has 
been obsolete for several years. It has been in service for many years. The cable does not have a rubber or plastic jacket over the lead sheath.

There have been 49 cable failures on the three $14 \mathrm{kV}$ circuits since 1970. Of these, 12 occurred in 1979. The failures have been classified according to cause by Boston Edison as follows:

$$
\begin{aligned}
& 10 \text { - moisture } \\
& 10 \text { - corrosion } \\
& 3 \text { - deleriurated cable (ağe) } \\
& 3 \text { - workmanship } \\
& 5 \text { - other } \\
& \frac{18 \text { - unknown }}{49 \text { - total }}
\end{aligned}
$$

The total length of the three circuits is 84,748 feet. From this, an average failure rate of 30.53 per 100 miles per year for the 10-year period can be calculated. This is more than twice the Boston Edison Company system average (see Appendix D). Of the failures with assigned causes, 32 percent each have been caused by corrosion and by moisture ingress.

All three circuits are located in a duct system under Washington street for a distance of about 1:.5 miles. The Massachusetts Bay Transport (MBT) system operates an elevated 
rapid-transit system along the same street, using a third-rail dc power supply system. This suggests that the MBT could have contributed to the cable failures by causing corrosion on the lead sheaths. Vibrations from the trains could also have contributed to cable failures by causing cracks in the lead sheath. These would normally be expected to occur at duct mouths and at the joints between splices and the cable sheath.

The cable sheaths in this area were not protected against corrosion by a cathodic protection system.

As in many other areas of Boston, the manholes and ducts are often filled with water. This affords ample opportunity for water ingress into the cable insulation should there by any cracks, worn-through areas, or excessively corroded areas in the lead sheaths.

RESTORATION MEASURES

Station 284, which is supplied from the Roslindale $14 \mathrm{kV}$ system, provides service to customers by means of nine $4 \mathrm{kV}$ circuits. After the interruption, it. was possible to restore service to all or parts of six of these circuits by switching them to other power sources. This restored service to about 3,200 customers after an interruption of about two hours.

At the same time, steps were being taken to "cut-andcap" the faulted $14 \mathrm{kV}$ circuits, then energizing the system from both Station 13 (the normal power supply) and Station 143. 
At $2: 54$ PM, part of Circuit 13-75XYH was energized from station 13, restoring power to:

Comm. of Massachusetts Health Laboratory Shattuck Hospital

Faulkner Hospital

Hebrew Home for the Aged

Agassiz School

At 4:37 FM, part of c1rcuit 13-75XYH was energized from Station. 143 to Station 284. This made possible restoration of service to the remaining 3,000 customers served from the Station $2844 \mathrm{kV}$ system.

At this time, all of the load except southwest High School was restored and being supplied by Circuit 13-75XYH.

Permanent repairs were then underway on circuits 13-76H and 13-79H. Repairs were completed on Circuit 13-79H by 1:24 PM on Sunday, June 24. Southwest High School was then re-energized. It had not been considered necessary to devise a special temporary source for the school on a week-end.

After Circuits $13-76 \mathrm{H}$ and $13-79 \mathrm{H}$ had been repaired; Circuit 13-75XYH (which had been cut-and-capped) was removed from service for permanent repairs at 6:55 AM on Monday, June 25. Those repairs were completed at 6:27 PM on Tuesday, June 26. During this time all of the $4 \mathrm{kV}$ circuits which had been switched to alternate supply sources were restored to normal. 
MITIGATIVE MEASURES

As a result of this incident, Boston Edison initiated action to improve the reliability of $14 \mathrm{kV}$ lines $13-75 \mathrm{XYH}$, 13-76H and 13-79H. These actions included the following:

- Determine the feasibility of separating the circuits at station 13 .

- Consider replacement of all belted cable on these three circuits.

- Investigate alternative connections for serving critical loads on these circuits. (A new $14 \mathrm{kV}$ circuit for Faulkner Hospital and the Hebrew Home for the Aged. is being considered.)

- Inspect and upgrade manholes (work completed). Perform high voltage testing of cables (work completed). (Repairs made after some cables failed on test.)

- Perform electrolysis tests (results indicated definite electrolysis; a protection system is being designed and will be installed.)

- Determine whether an increase in capability to switch $4 \mathrm{kV}$ loads to alternate feeders is practical.

- Review of history of failures to determine which sections of cables have experienced the 
most faults, thereby determining priorities for cable replacements. 


\section{MITIGATIVE MEASURES}

Mitigative measures are those actions that can be taken to prevent or reduce the probability of an outage, or to reduce the impact of outages on customers. The measures outlined in this section are specifically aimed at mitigating outages of underground cable distribution systems, typically used to serve residential and commercial metropolitan loads.

DESIGN

There are many different distribution design practices, and though different, all are well established with proven reliability. In most cases, major design changes would be difficult, costly, and unjustified. However, some incremental changes to the design may make significant improvements in system reliability. The procedure for making these changes consists of (a) identifying where a particular design is most vulnerable, and (b) concentrating resources to improve these weakest links. Specific design changes are listed below:

- Limit the number of network feeders allowed in a common manhole.

- Eliminate dc secondary cables in all manholes with a large number of ac network feeders.

- Upgrade manholes and redesign cable supports and restraints to minimize cable failure caused by thermal cycling: 
MAINTENANCE

- Inspection of every manhole on a three-to-five year cycle is practiced by some utilities. rritical manholca may need inspection more often. Crews in the field should routinely inspect manholes. Inspection reports can be computerized to summarize the findings of the inspection and to keep a resord of the frequency that each manhole is inspected. The computer reports can list priority work and can keep track of manholes that require routine work to be completed the next time the crew is in the area.

- High voltage testing of primary feeder cables each year can minimize the number of "in service" cable failures. Annual testing of every primary cable has been instituted by some utilities, who report that the total number of failures (on test and in 'service) remain about the same as before. However, service is improved because test failures occur'at times under control of the utility when customer interruptions do not occur while repairs are being made.

- Attention to routine equipment maintenance is a must. Good results have been obtained in using computers to maintain schedules and track actual maintenance performed: 
- Older cables - particularly those with non-shielded belted construction - should receive special attention, with more frequent inspection than newer cables. Replacement should be made when such cables fail a voltage test and/or when general condition indicates a possibility of failure.

QUALITY OF MATERIAL AND WORKMANSHIP

- Stringent specifications and quality control measures should be continued to insure the use of only the highest quality cable.

- The quality of the workmanship to install cables and make splices and terminations is a function of training and constant attention to the work being performed. Inspections, dissection ミand analysis of failed splices, records of each craftsman's failures, and the use of x-rays are techniques of measuring the quality of work being performed.

OPERATION

- Even a system adequately maintained and welldesigned with quality material can fail if it is operated improperly or beyond its capability. Under emergency conditions, the system operators have a very limited amount of information on the status of the distribution system. Sophisticated 
systems to monitor the state of these systems are, at the present time, technically feasible but prohibitively expensive. To make up for lack of actual data, the system operators need to have a good understanding of how the system will behave under abnormal system conditions. One method of achieving this understanding is the greater use of simulation techniques to study the distribution systell for probable emergency̆ situations. Uperating procedures and guidelines can be developed from these studies. Training programs on a regular basis would encourage system operators to keep up-to-date on new procedures and guidelines.

- High priority should be assigned to activities to preserve ability to sustain an outage without interruption to customers. When a feeder is out of service, immediate action should be taken to return that feeder to service even if all customers are being supplied. Also, while the feeder is out of service, the system operators should be anticipating actions to be taken, should a second contingency occur.

IMPACT ON CUSTOMERS

Cooperation is required between electric utility and public agencies. The utility can help public agencies prepare for major outages by: 
- Keeping appropriate agencies informed of the potential for an outage,

- Identifying areas served by a given distribution system and the number of people in these areas, and

- The potential duration of a màjor outage.

Public agencies should have contingency plans to deal with major electrical outages. For example; the police department, which is responsible for personal safety and the protection of property, should have plans for providing emergency street lighting, traffic control, and the removal of people trapped in elevators and subways. All public agencies whose headquarters may be in the blacked-out area should have plans for performing their vital services from alternate locations.

The utility should be aware of all.critical loads served by each distribution system so that priority attention can be given. These loads should be identified on the system operator's maps, diagrams, mimic boards, or CRT displays. Explicit plans should be prepared documenting actions the system operators should take, such as:

- Give priority for installing portable generator, or

- Contact police department for possible evacuation of elderly invalids. 
70

During an outage, it is extremely important for the utility to keep the public informed on the effort being made to restore service and the expected duration of the outage. This requires the use of the utility's customer information center for smaller outages and the skillful use of public news media for major area outages.

All utility equipment should be available to its employees at all times.' Prior arrangements should be made with building owners, and others on whose property such equipment is located, so that no delays will be encountered in an emergency situation. 


\section{RESTORATION MEASURES}

Restoration measures are those actions necessary to return the system to normal after an outage has occurred. It is most important to be prepared and to react quickly.

Outages on radial distribution systems will usually result in the customer being out of service until a fuse or a faulty piece of equipment can be replaced. If a major piece of equipment fails, temporary measures are improvised to service the customer while permanent repairs are being made. Some of the measures that can be used are:

- Switching to alternate feeders

- Using portable generators

- Installing temporary lines and cables to bypass damaged sections, and

- Cutting out damaged sections of cable and reenergizing undamaged sections

Network distribution systems are extremely reliable; however, when an outage does occur, service restoration is difficult. The mobilization and coordination of many different departments within the utility is required to efficiently restore service. Following the Back Bay Network outage, Boston Edison recognized the need for an emergency restoration plan for this situation. 
Example pages from their recently developed plan follow as Exhibit 15. Ten different departments are involved in the restoration effort. Key functions of each department are summarized on the chart included as Sheets 5 and 6 of the exhibit.

Boston Edison also has restoration procedures for dealing with other types of outages. Exhibits 16, 17, and 18, respectively, show the Major Emergency. Plan of Operation, Major System Outage Plan of Restoration, and Steam Deficiency - Steam Emergency Plan of Operation. 
EXHIBIT 15, SH. 1 OF 6

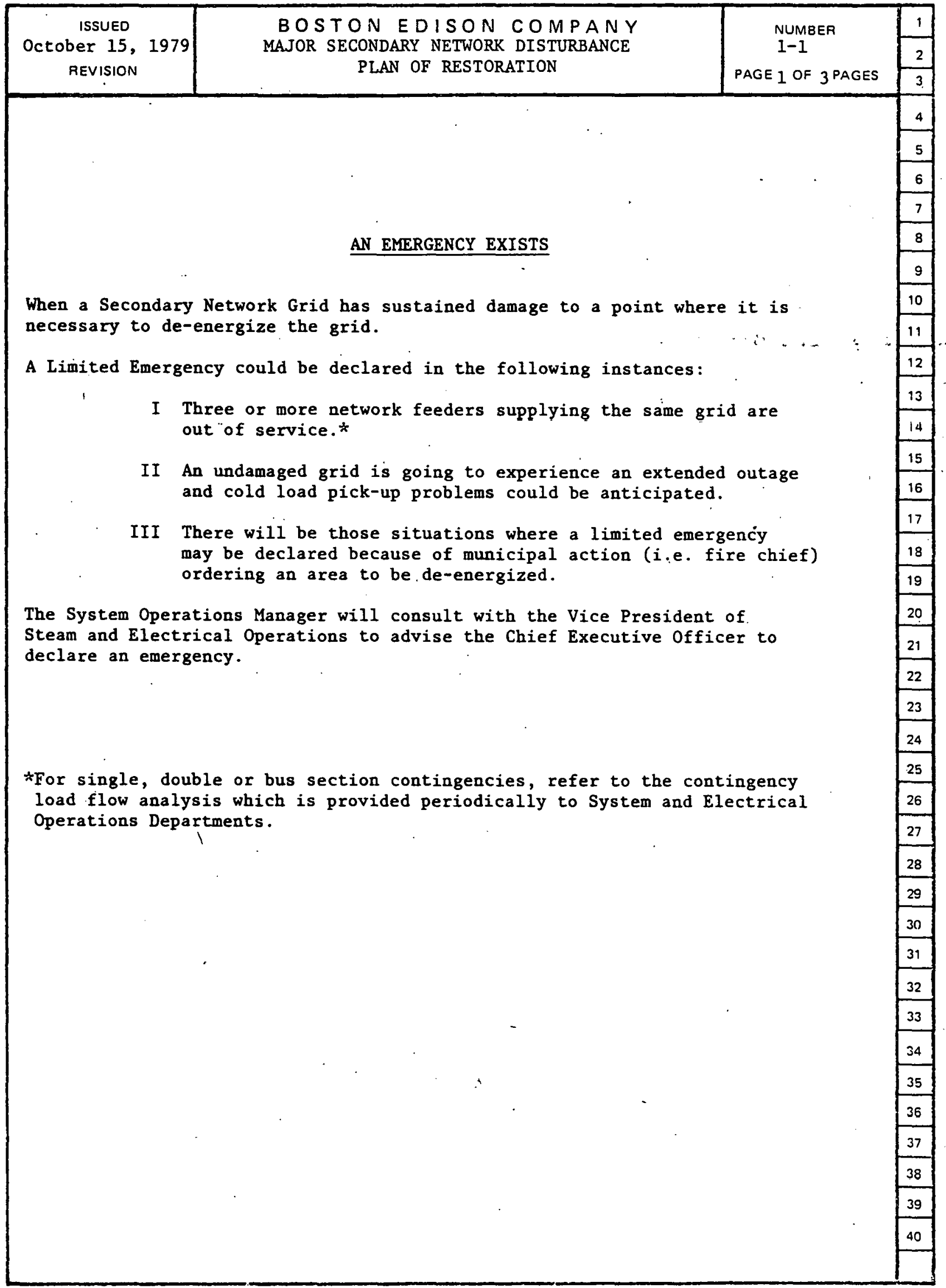


EXHIBIT 15, SH. 2 OF 6

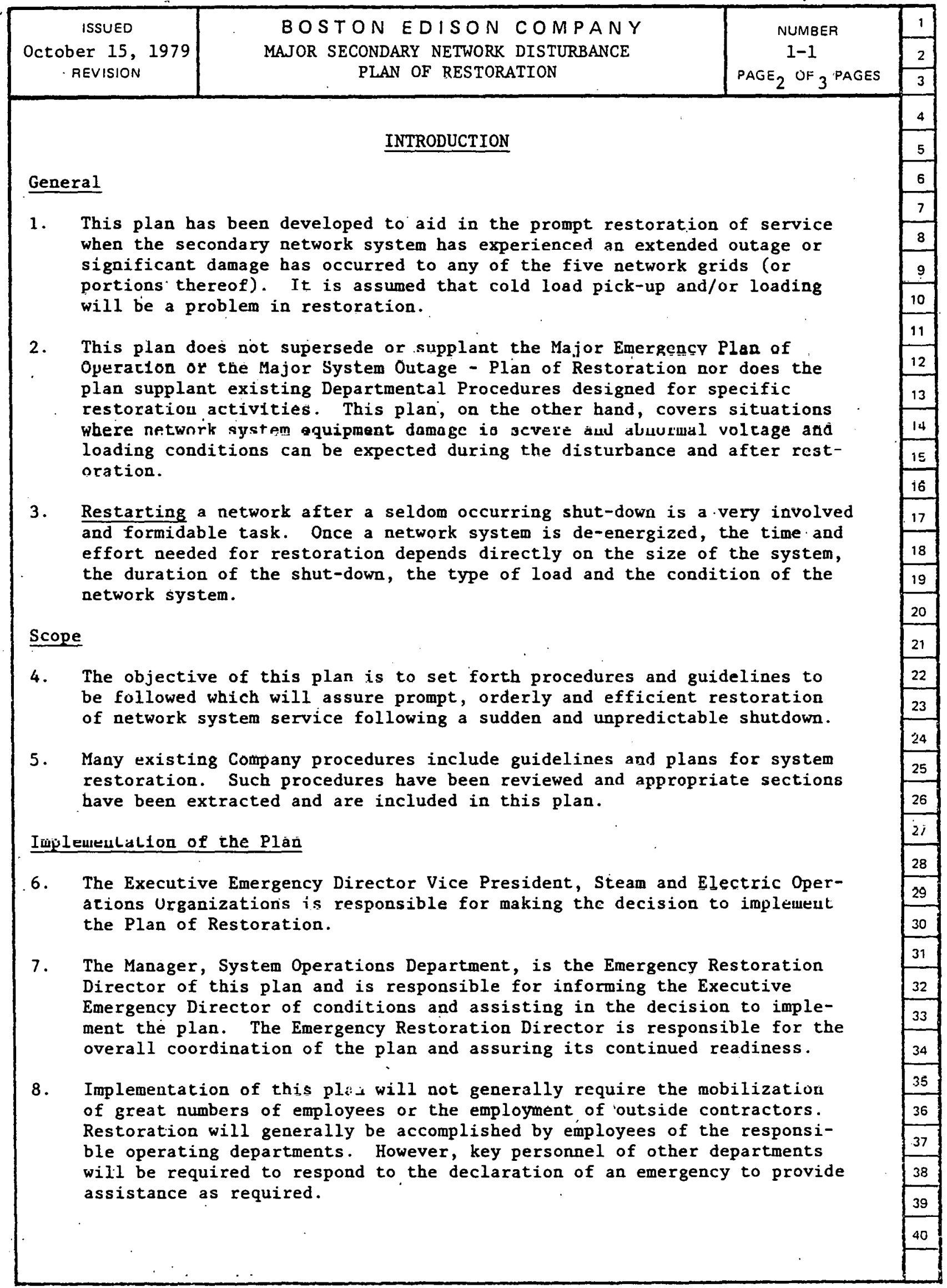

FORM 2584 
EXHIBIT 15, SH, 3 OF 6

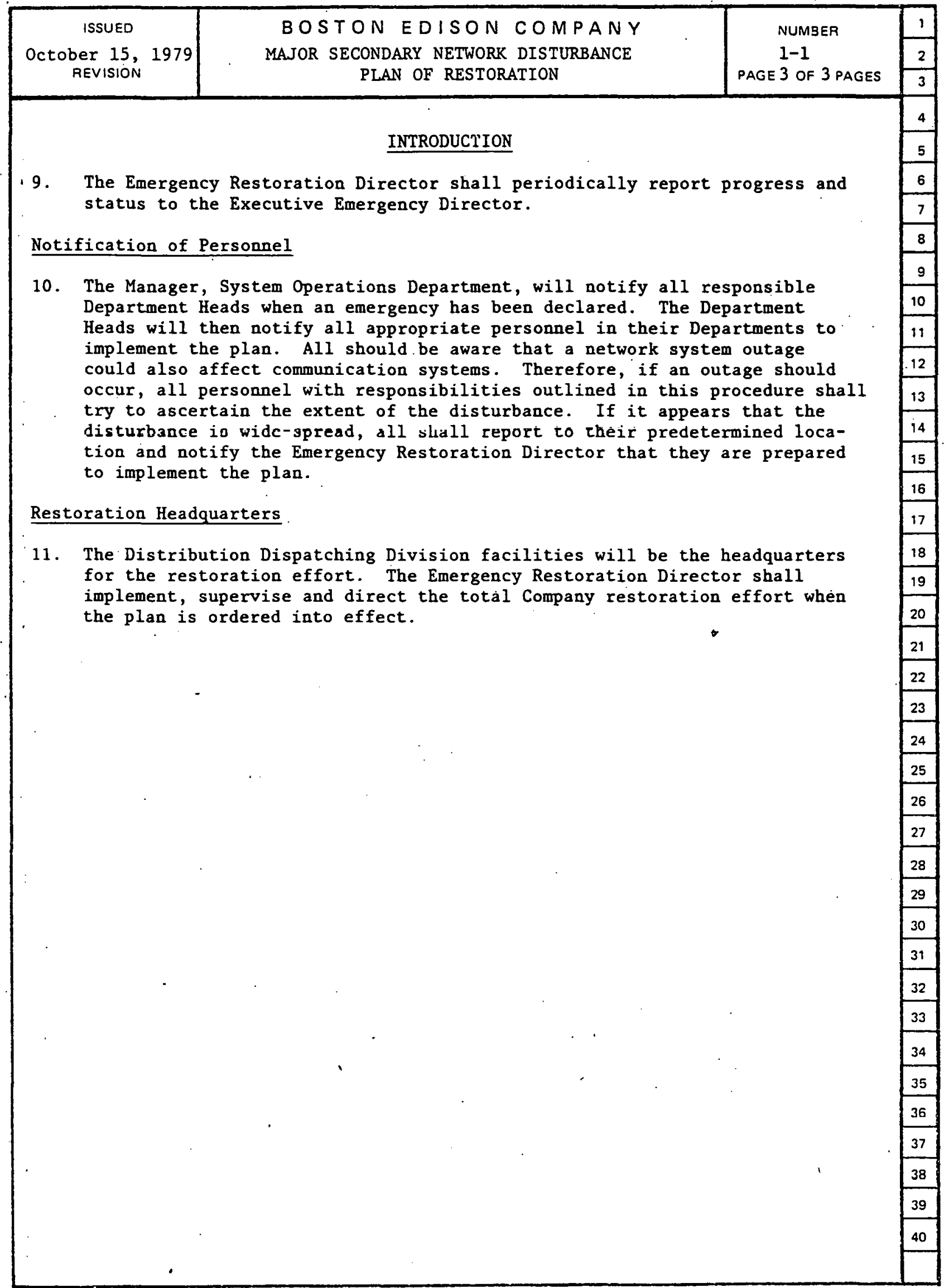




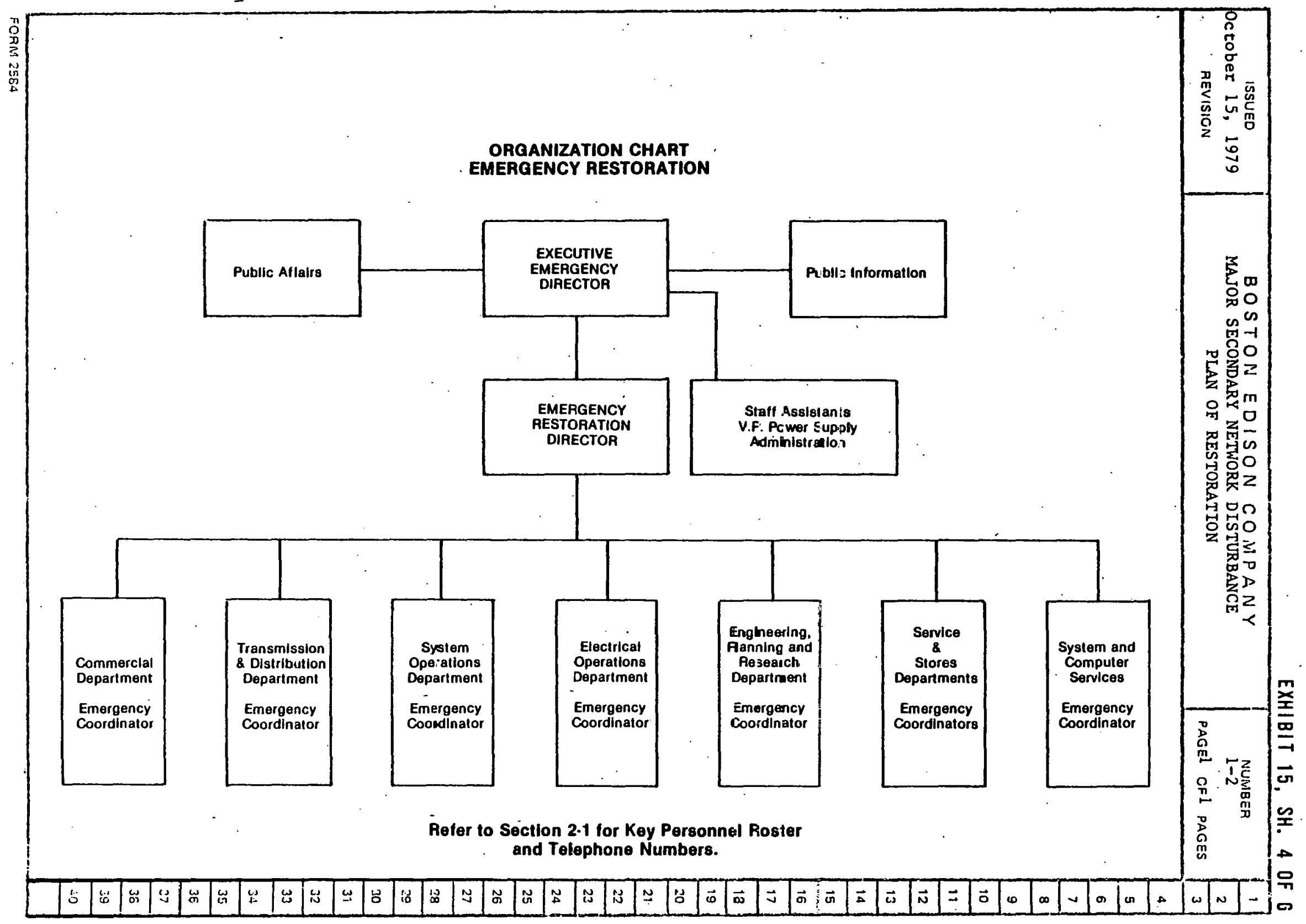


EXHIBIT 15, SH. 5 OF 6

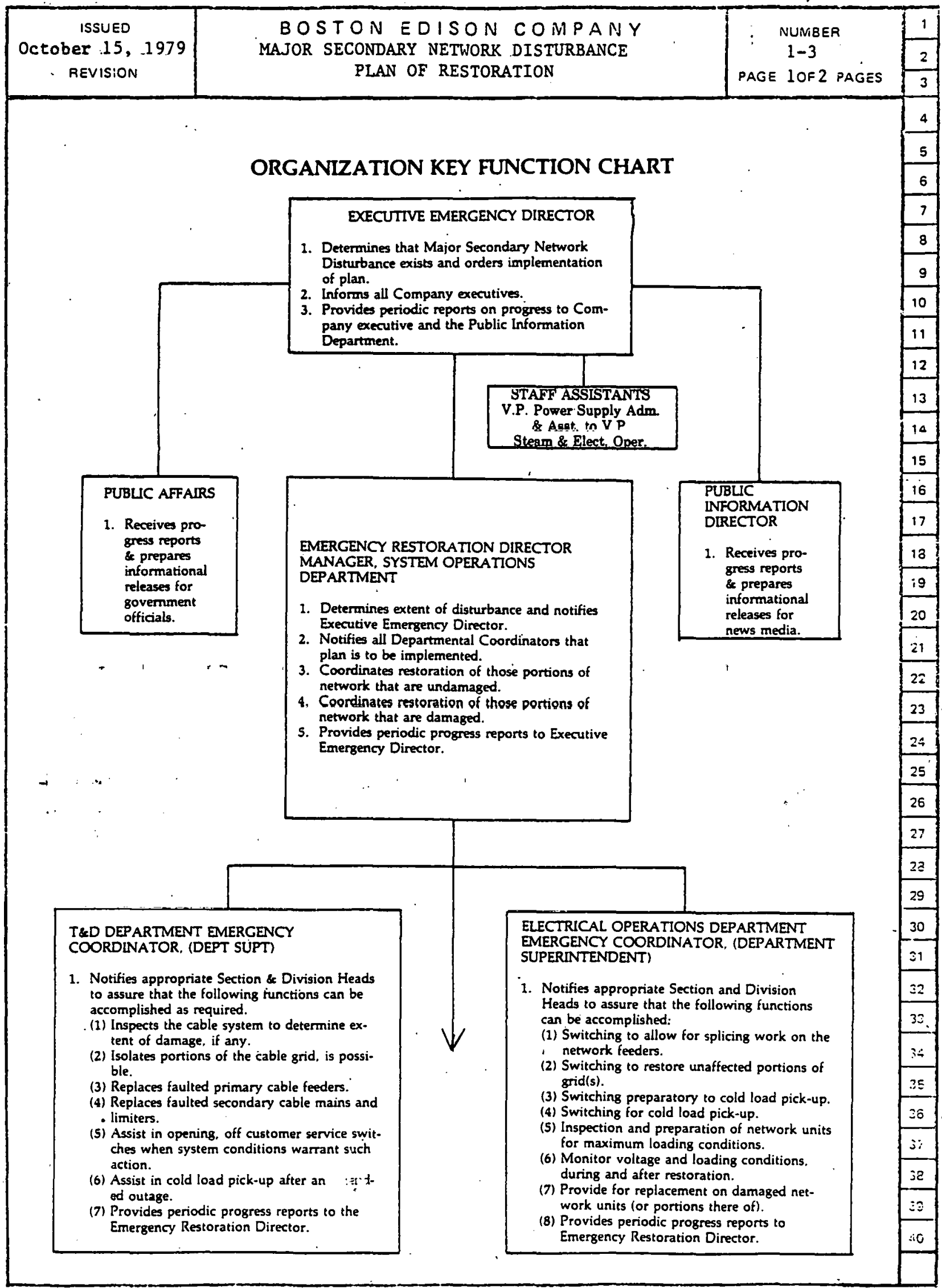


EXHIBIT 15, SH. 6 OF 6

\begin{tabular}{|c|c|c|}
\hline $\begin{array}{c}\text { ISSUED } \\
\text { October } 15,1979 \\
\text { REVISION }\end{array}$ & $\begin{array}{c}\text { BOSTON EDISON COMPANY } \\
\text { MAJOR SECONDARY NETWORK DISTRUBANCE } \\
\text { PLAN OF RESTORATION }\end{array}$ & $\begin{array}{l}\text { NUUMBER } \\
1-3 \\
\text { PAGE } 20 F 2 \text { PAGES }\end{array}$ \\
\hline
\end{tabular}

\section{CONTINUED FROM PAGE 1}

\begin{tabular}{|c|c|}
\hline 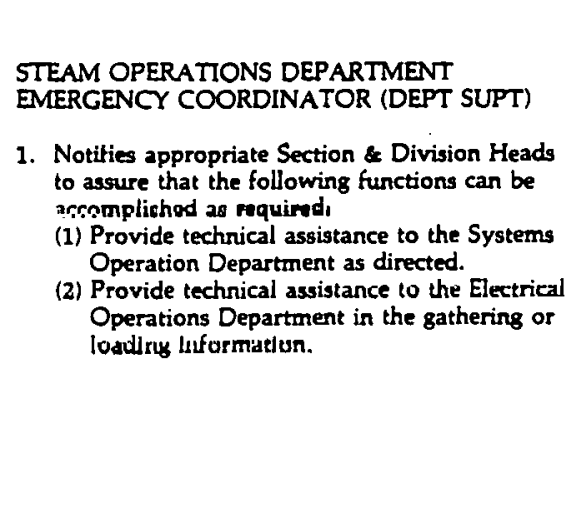 & 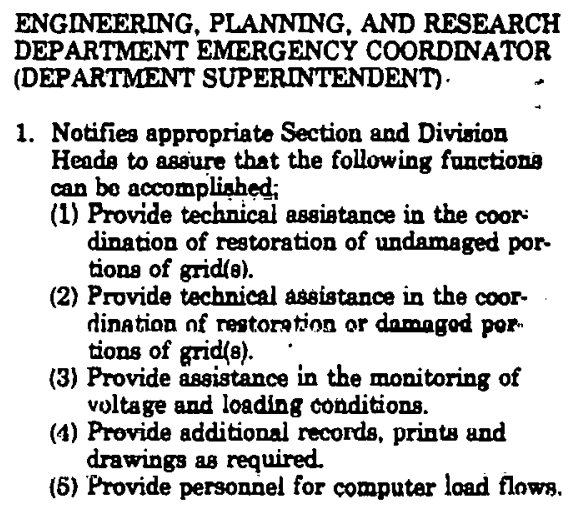 \\
\hline
\end{tabular}

STORES DEPARTMENT EMERGENCY COORDINATOR (DEPARTMENT MANAGER)

(1) Provide necessary access to existing network stock supplies for issuance to field personnel.

(2) Provide periodic stock level reports to the Emergency Restoration Director.
SYSTEMS \& COMPUTER SERVICES DEPARTMENT EMERGENCY COORDINATOR (DEPARTMENT MANAGER)

1. Notifies Computer Division Head to provide technical assistance as required for network load flow simulations.

\section{COMMERCIAL DEPARTMENT}

EMERGENCY COORDINATOR (DEPARTMENT MANACER

1. Notifies Government and Major Accounts Division to be prepared to communicate with major consumers.
SERVICES DEPARTMENT EMERGENCY COORDINATOR (DEPARTMENT MANAGER)

1. Provides necessary maintenance of vehicles and generators.

2. Provides necessary housekeeping and services

Refer to Section 2-1 for Key Personnel Roster and Telephone Numbers. 
EXHIBIT 16, SH. 1 OF 5

March 1963

REVISION

April 1976

BOSTON EDISON COMPANY

INTRODUCTION

The Major Emergency Plan of Operation is a pattern of action whereby established operating procedures are augmented and superseded whenever the system or property may suffer major damage. Its purpose is to co-ordinate the personnel and facilities of Boston Edison Company and to utilize assistance from other utility companies and contractors.

The objective of the Plan is to restore electric service to the maximum number of customers in the shortest possible time, with special consideration being given to those services which are essential to the public welfare.

The Plan will be put into operation upon \& declaration of an emergency by the Chief Executive Officer. He is assisted by the Emergency Administrator who controls and co-ordinates all emergency functions, and by an Emergency Operations Council that makes recommendations concerning the administration and implementation of the Plan, both prior to and during the emergency.

The Plan broadly covers four phases of activity:

1. Pre-Emergency Requirements

This is the planning and training phase in which records are checked and brought up-to-date, training programs are scheduled and carried out, and inspections of equipment and supplies are made.

2. Emergency Declared - Condition I

This phase of the Plan alerts designated Company personnel to report to their emergency work locations, set up equipment and supplies and prepare for restoration activity as specified in Section 19-1.

3. Emergency Declared - Condition II

The provisions of the Plan will be put into operation for one or more Divisions as specified in Section 19.

4. Emergency Declared - Condition III

The provisions of the Plan will be put into operation for all Divisions of the Company.

One of the main features of the Plan is the decentralization of operations. During a major emergency, the territory normally covered by the six major Service Centers will be sub-divided into 38 Areas, with a headquarters located in each Area. The six Service Centers become emergency Division Hcadquarters. Specially organized crews will be assigned to the Areas and pre-trained Company personnel will perform administrative, commercial, municipal and survey functions. 
EXHIBIT 16, SH. 2 OF 5

\begin{tabular}{|c|c|c|}
\hline $\begin{array}{l}\text { ISSUED } \\
\text { March } 1963\end{array}$ & BOSTON EDISON COMPANY & $\begin{array}{l}\text { NUMBER } \\
1-1\end{array}$ \\
\hline $\begin{array}{l}\text { REVISION } \\
\text { Ap }=i 11976\end{array}$ & ENTRODUCTION & PAGE $2^{\text {OF }} 2^{P A}$ \\
\hline
\end{tabular}

As soon as field conditions permit, crews will make hazardous conditions safe and restore critical-service customers in accordance with established Restorntion Sehedules. After critical-service customers are restored. general restoration will be undertaken in order of predetermined circuit priority lists. The area restoration forces work under the general dirnntinn of an Area Crew Supervisor and Group Crew Supervisors.

The focal point of the restoration effort is the Company Restoration Control Center. Here the Assistant Superintendent of the Transmission and Distribution Department and his staff appraise the damage, request additional -assistance if necessary and direct the restoration operation. The Control Room Director supervises the restoration and Control Center operations. The periodic reports from the Divisions are posted and compiled into Company totals. The oharte indicate the progrces of ourveying and restoration, and provide the data necessary to determine if crews should be shifted between Divisions or Areas or if additional crews are necessary. Reports of circuits out are received and immediately despatched to the fleld. All Division Headquarterş are linked to the Control Room by teletype as well as. by special telephone lines. Information is received from many sources and despatched to the field.

Many additional employees provide supporting services without which the Plan would not be functionally cohesive. The success of the Plan depends upon the close cooperation of all assigned personinel and the desire to see a difficult job done efficiently, safely and speedily. 


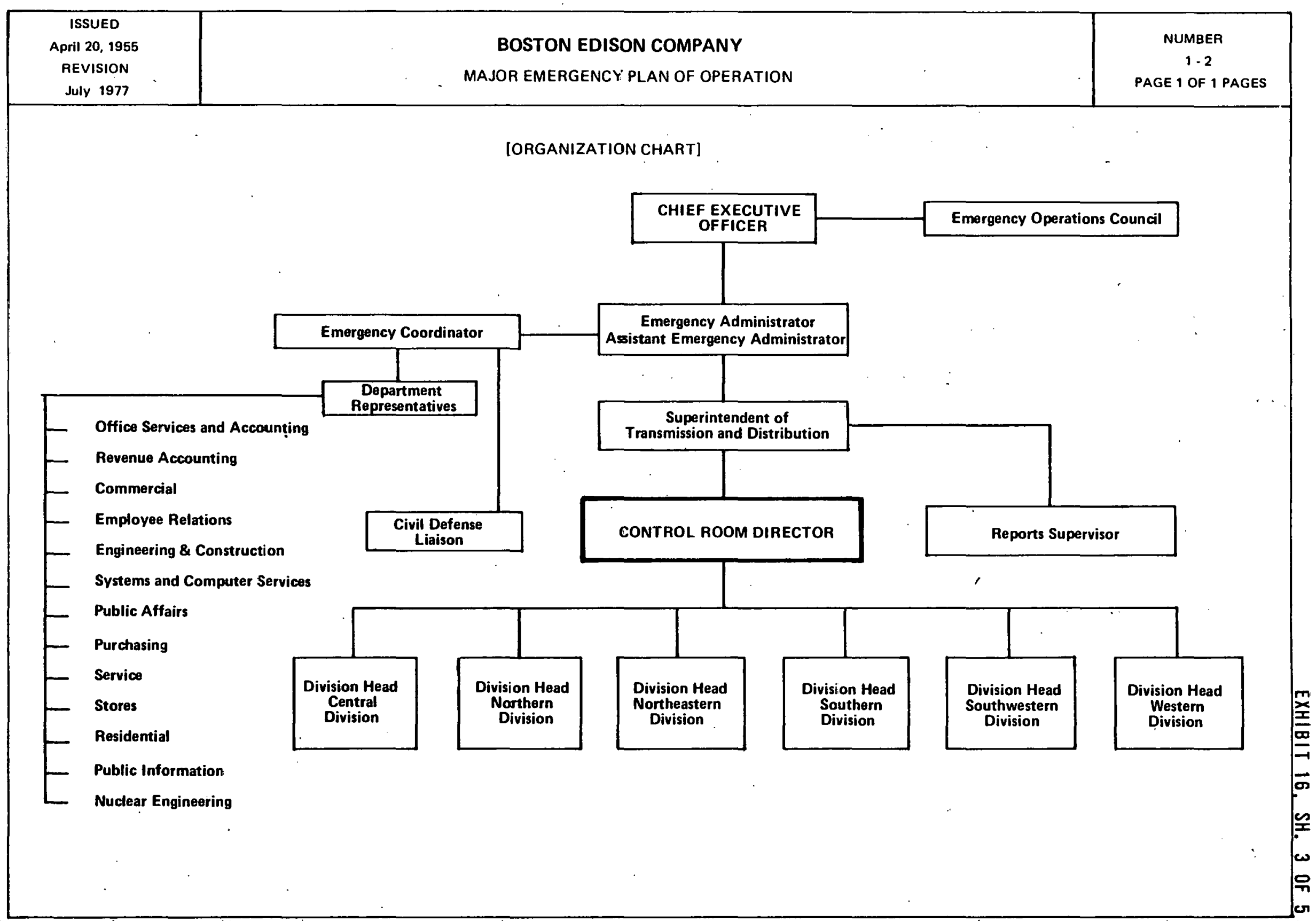


EXHIBIT 16, SH. 4 OF 5

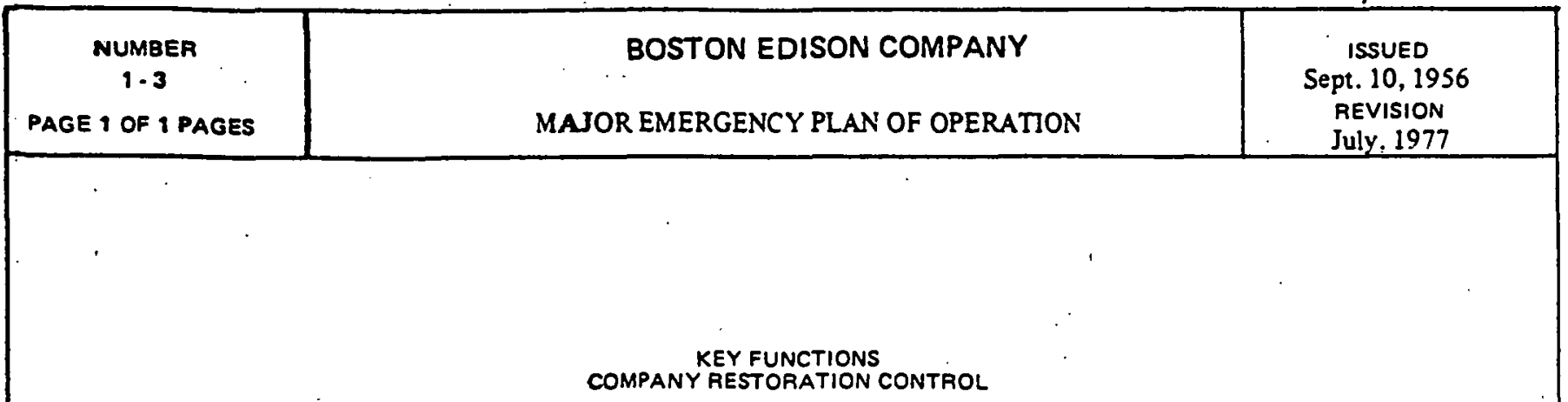

\begin{tabular}{|l|}
\hline EMERGENCY AOMINISTRATOR \\
\hline Control and Coordinate all Operations \\
Modity Procedures to fit Conditions \\
\hline
\end{tabular}

Program Pian Procadures, Training

Produles and Assis Modity Procedures to fit Conditions

Coordinaw Functions Allied with Pertaretion through Department Pepresentatives
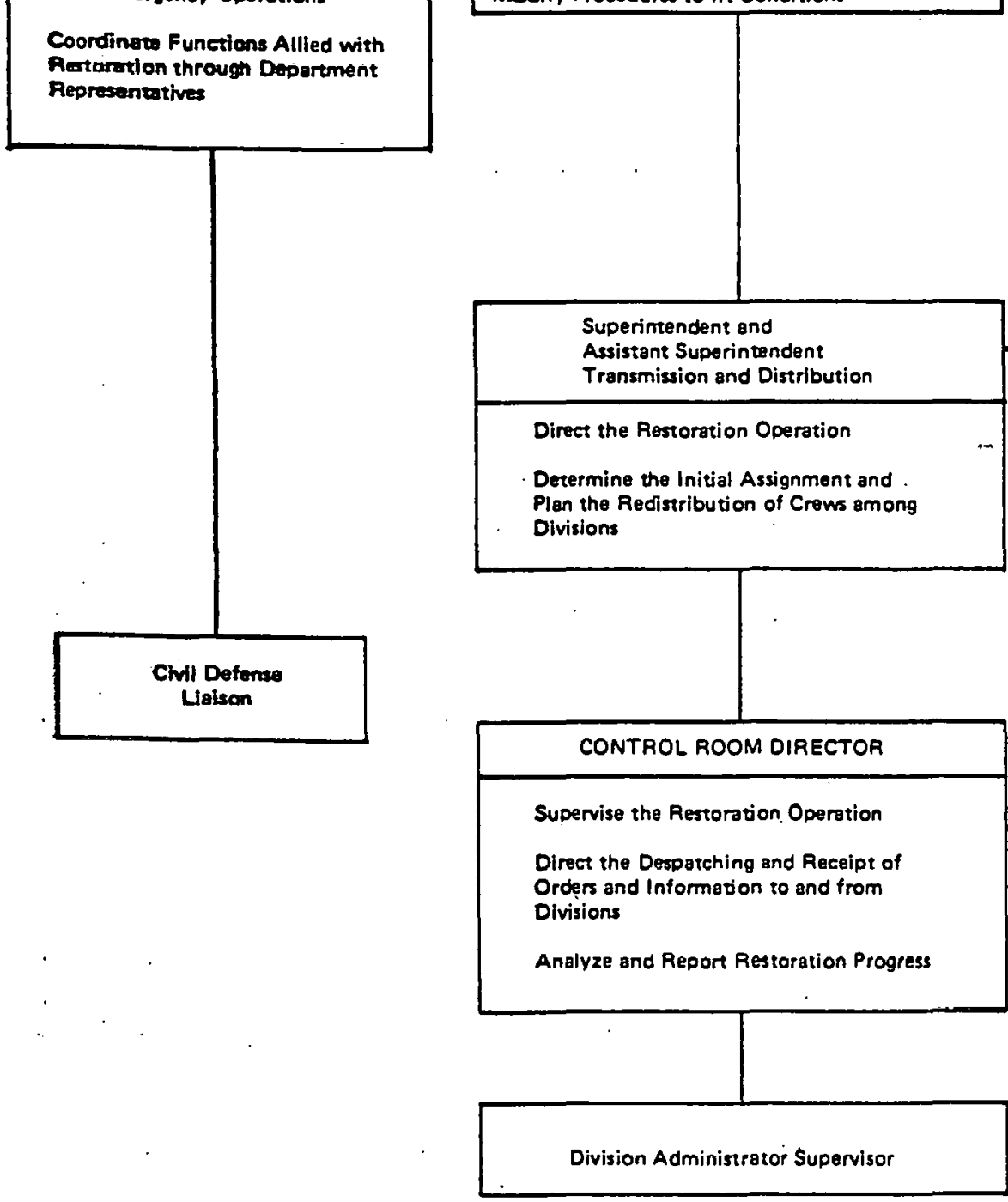

REPORTS SUPERVISOR

Supply Data on Weather, Load, and Station Operations 


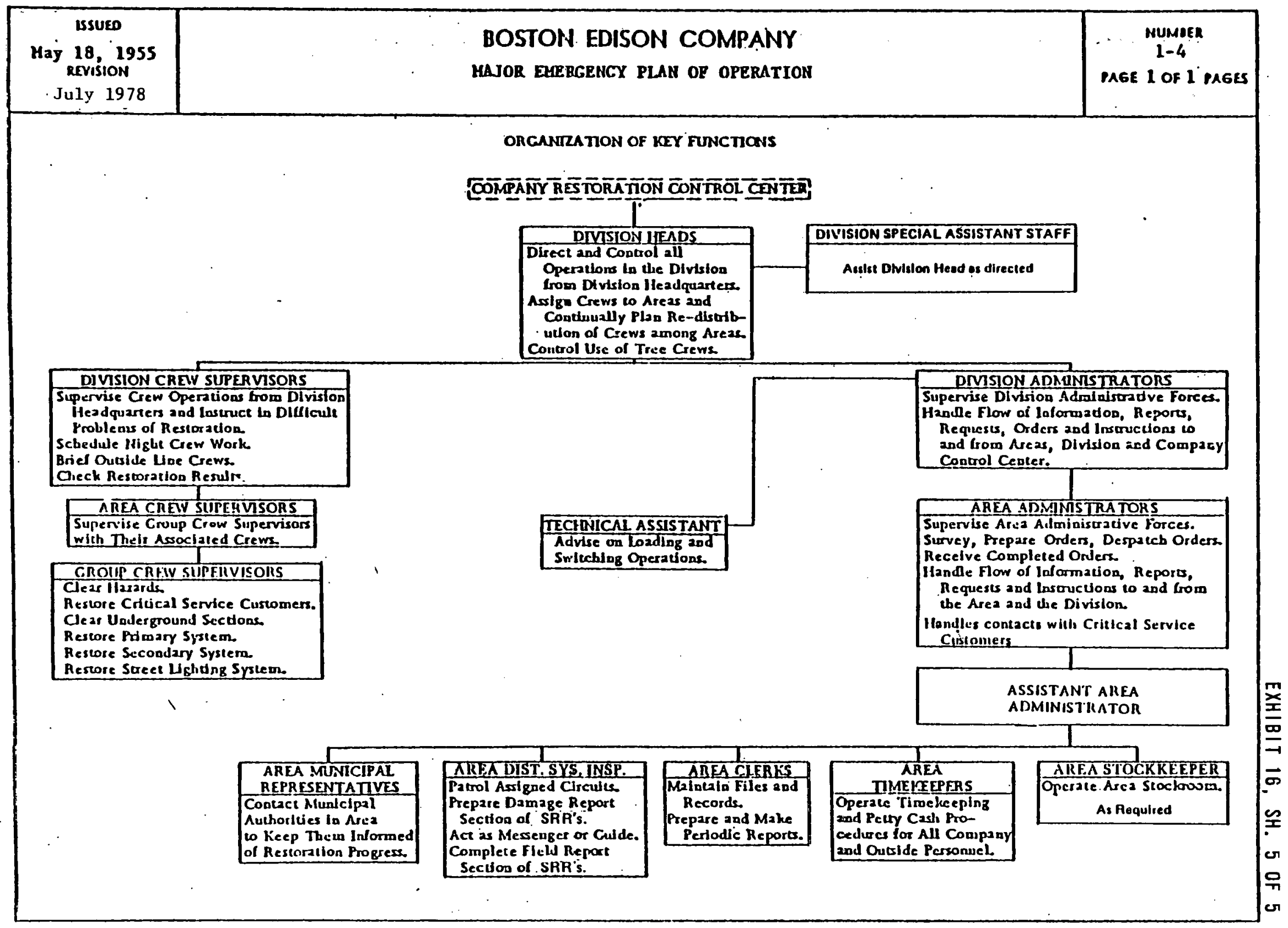


EXHIBIT 17, SH. 1 OF 5

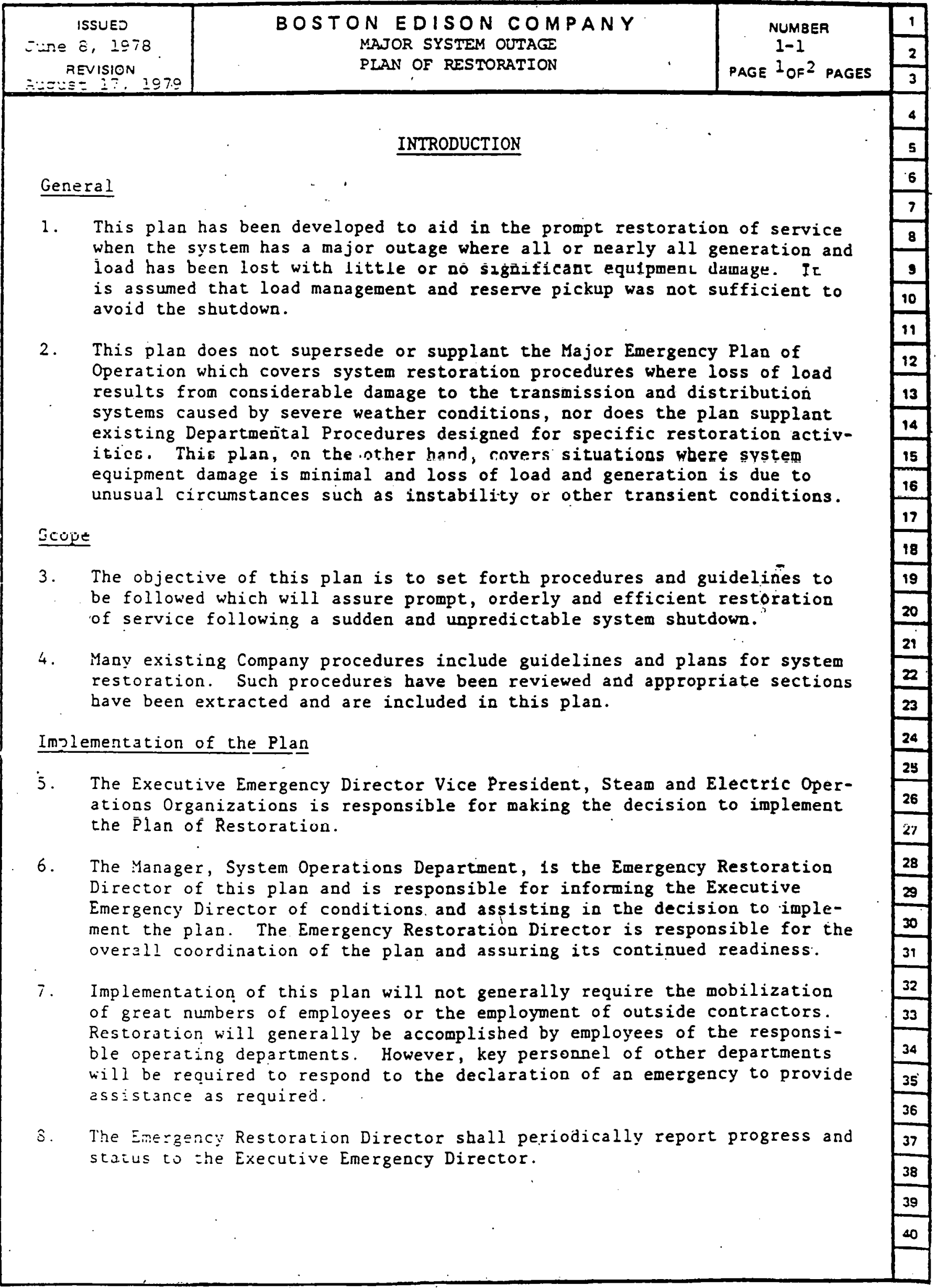


EXHIBIT 17, SH. 2 OF 5

\begin{tabular}{|c|c|c|}
\hline $\begin{array}{l}\text { ISSUED } \\
\text { JLre } 8,1978 \\
\text { REVISION } \\
\text { S. }\end{array}$ & $\begin{array}{c}\text { BOSTON EDISON COMPANY } \\
\text { MAJOR SYSTEN OUTAGE } \\
\text { PLAN OF RESTCRATION }\end{array}$ & $\begin{array}{c}\text { NUMBER } \\
1-1 \\
\text { PAGE } 2 \text { OF } 2 \text { PAGES }\end{array}$ \\
\hline
\end{tabular}

\section{INTRODUCTION}

9. REMVE will retain operational control of the transmission and generating facilities. In the event of the loss of REMVEC communications the Emergency Restoration Director shall assume operational control and direct all generation and load start-up activities.

\section{Notification of Personnel}

10. The Manager, System Operations Department, will notify all responsible Department Heads when an emergency has been declared. The Department Heads will then notify all appropriate personnel in their Departments to implement the plan. All should be aware that a system outage could also affect communication systems. Therefore, if an outage should occur, all personnel with responsibilities outlined in thie procedure shall try to ascertain the extent of the outage. If it appears that the outage is wide-spread, all shall report to their predetermined location and notify the Emergency Restoration Director that they are prepared to implement the plan.

\section{Restoration Headquarters}

11. The Distribution Dispatching Division facilities will be the headquarters for the restoration effort. The Emergency Restoration Director shall implement, supervise and direct the total Company restoration effort when the plan is ordered into effect. 


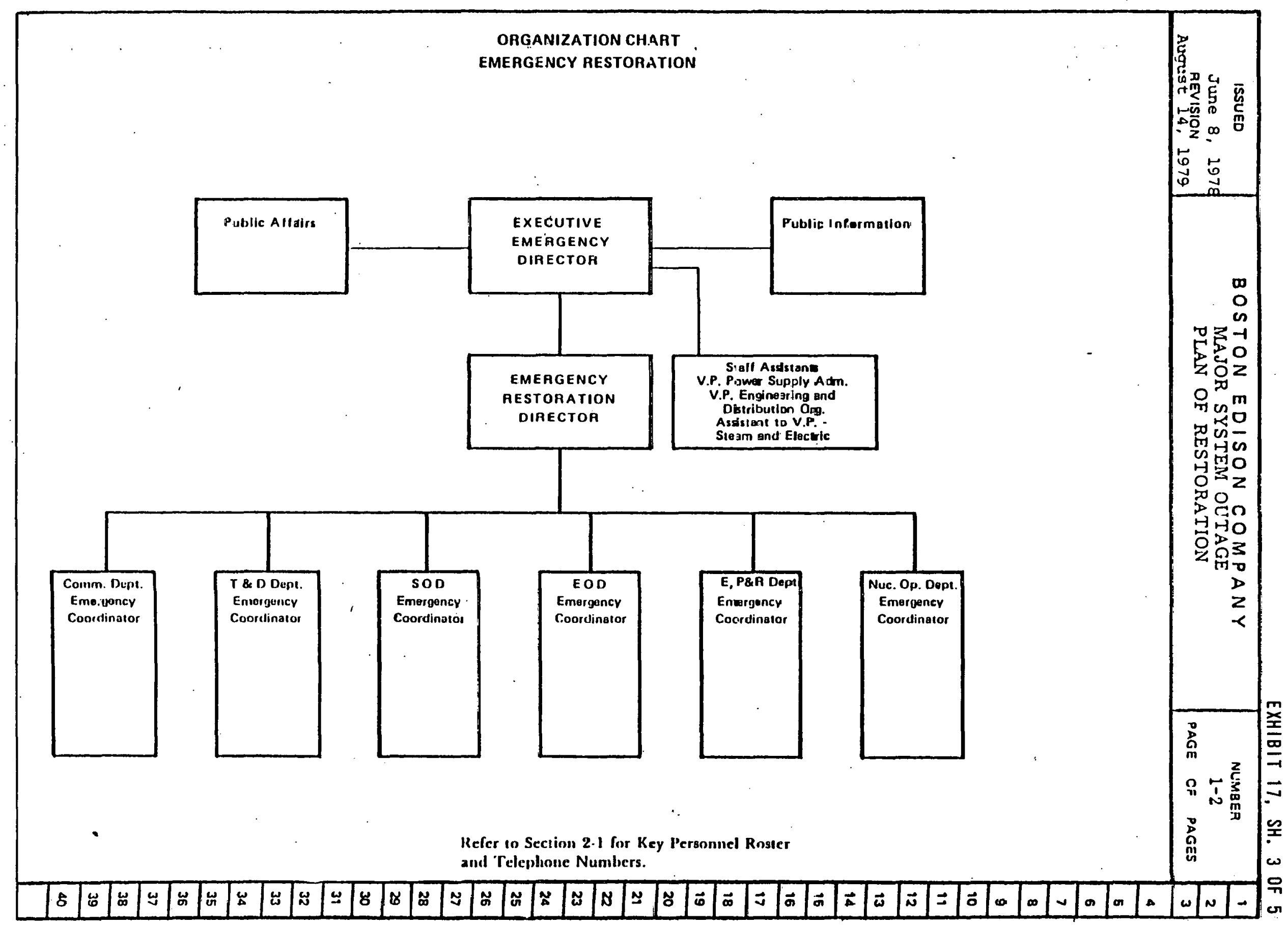


EXHIBIT 17, SH. 4 OF 5

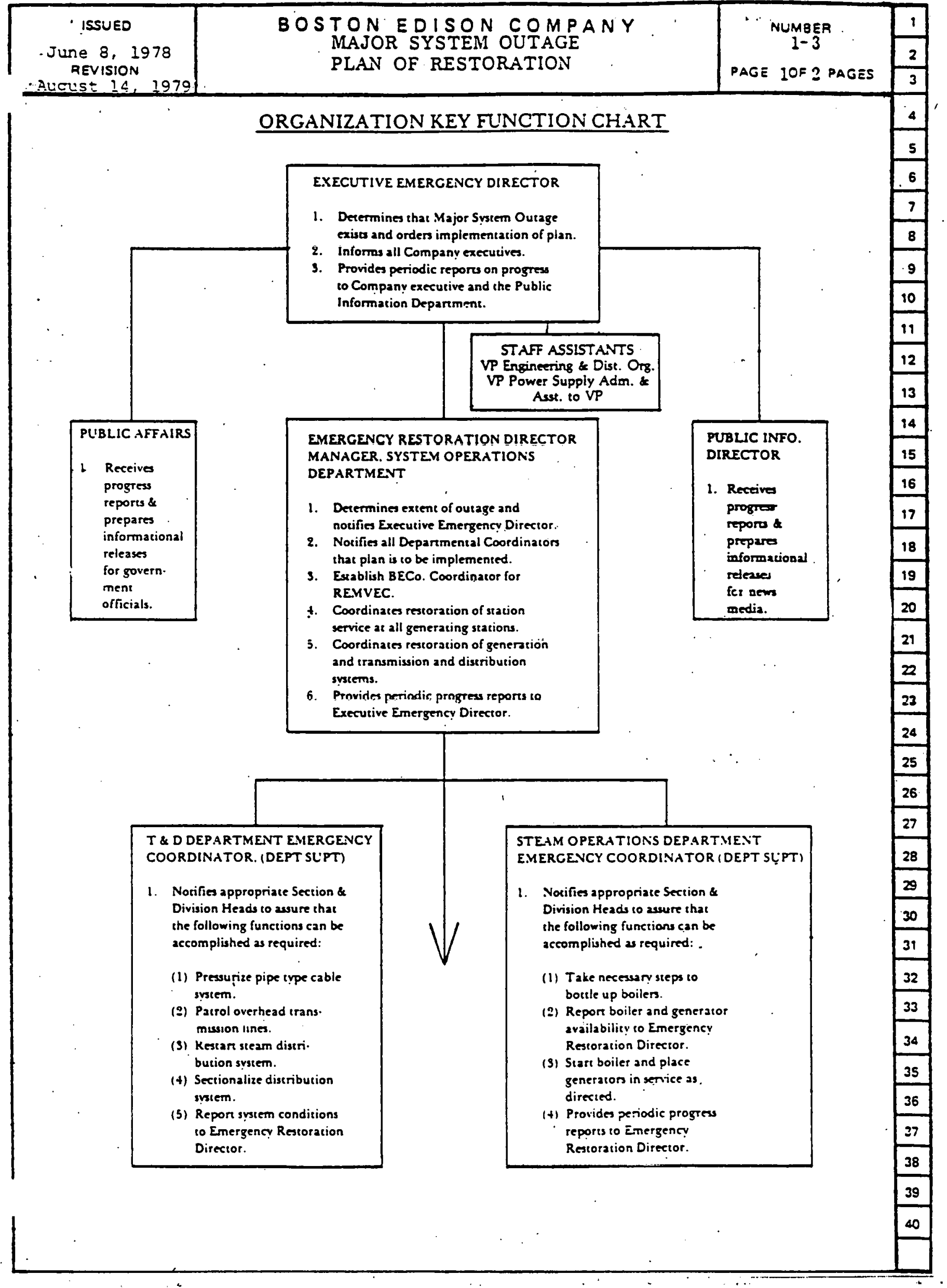


EXHIBIT 17, SH. 5 OF 5

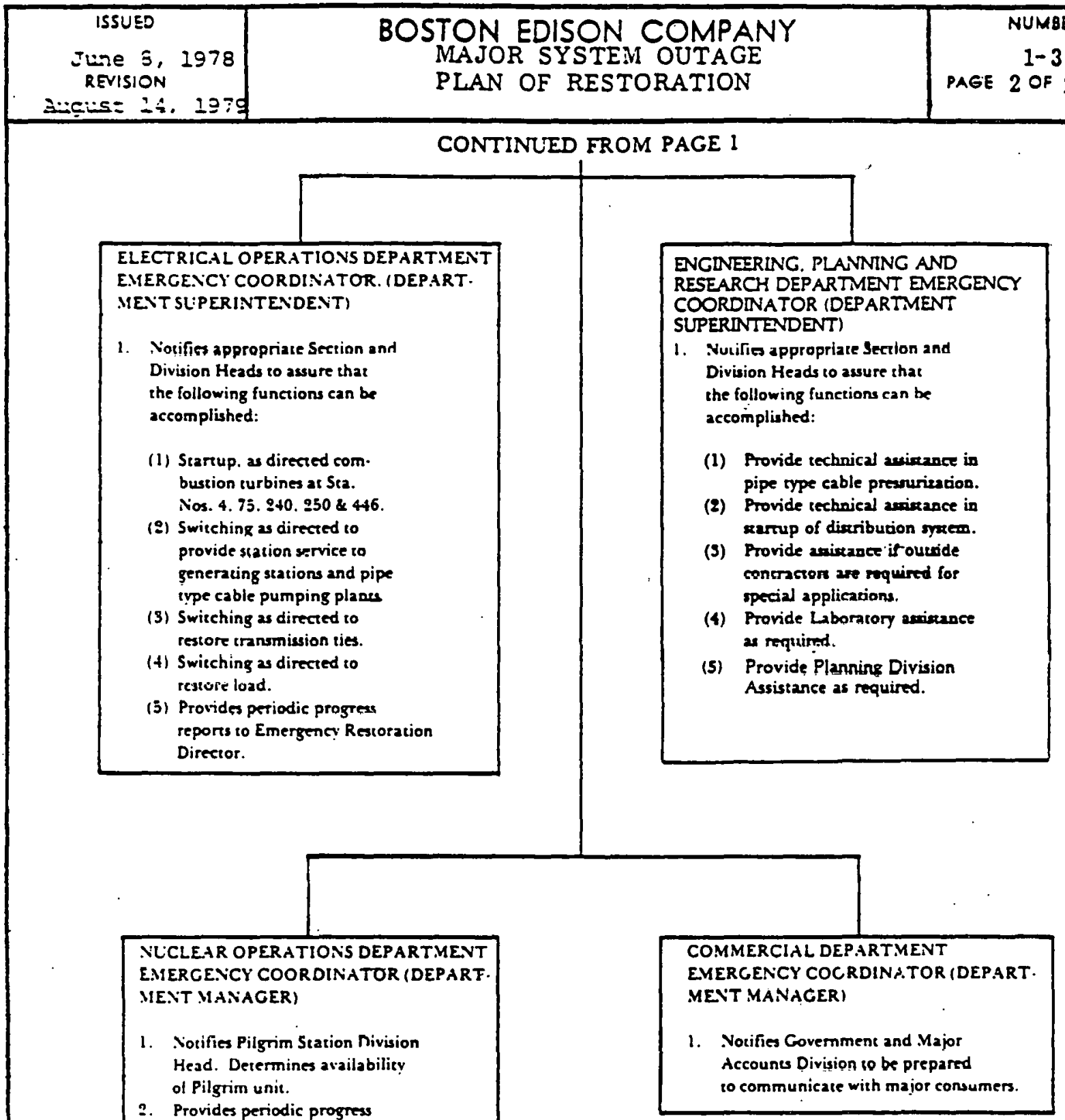

Refer to Section 9.1 for Key Personnel Roster and Telephone Numbers. 
EXHIBIT 18, SH. 1 .OF 5

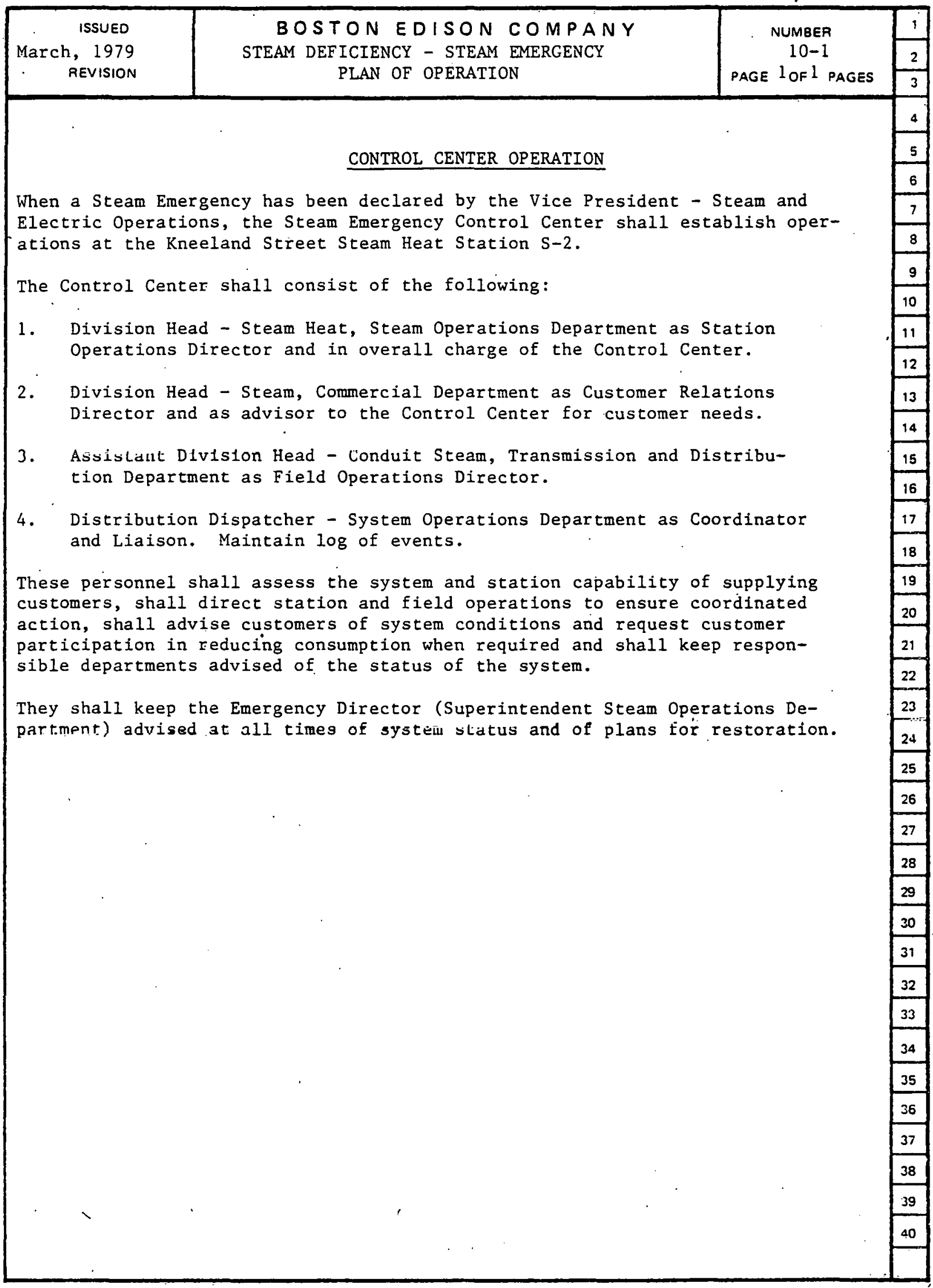


EXHIBIT 18; SH. 2. OF 5

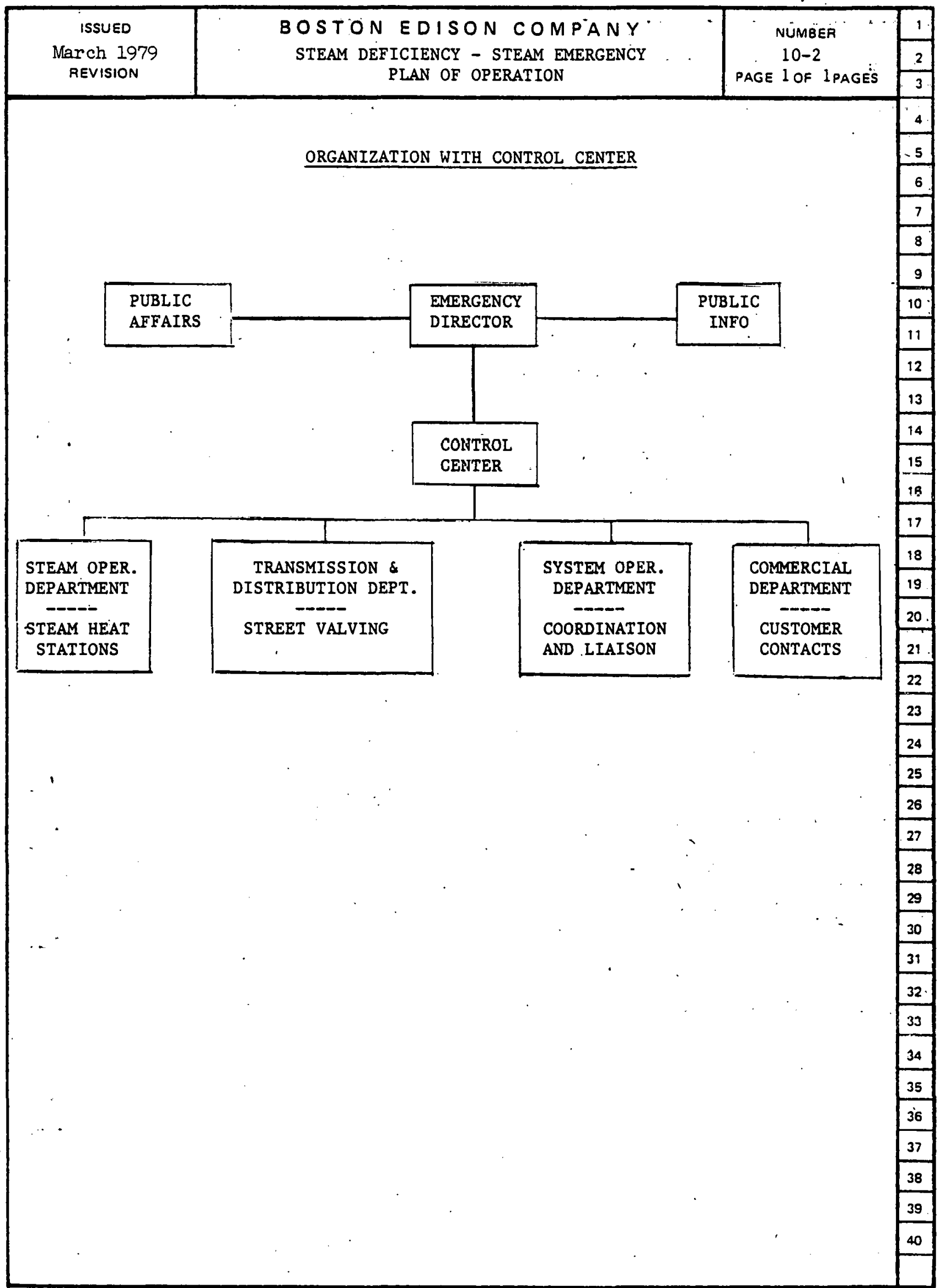




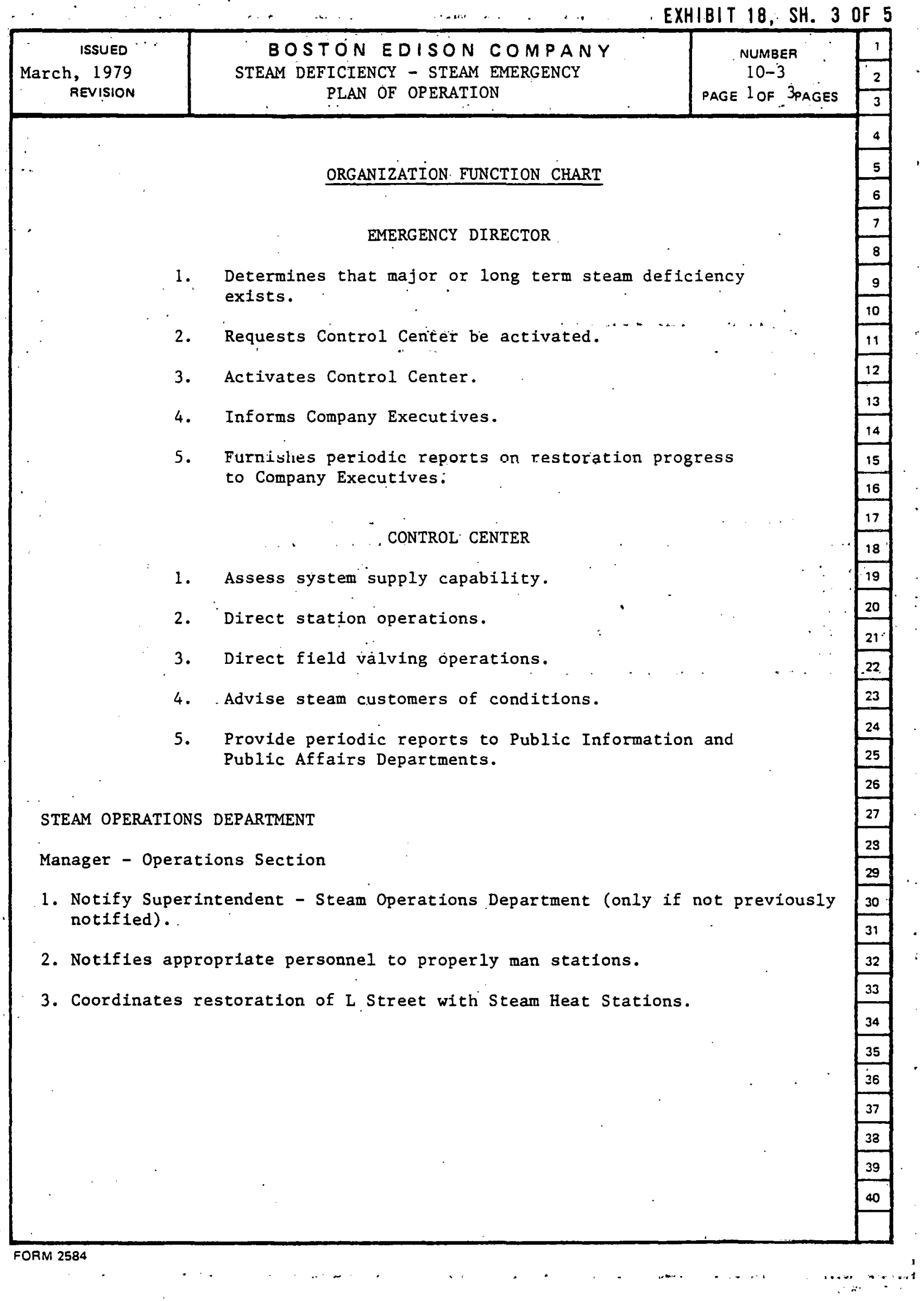


EXHIBIT 18, SH. 4 OF 5

\begin{tabular}{|c|c|c|}
\hline $\begin{array}{r}\text { ISSUED } \\
\text { March, } 1979 \\
\text { REVISION }\end{array}$ & $\begin{array}{l}\text { BOSTON EDISON COMPANY. } \\
\text { STEAM DEFICIENCY - STEAM. EMERGENCY } \\
\text { PLAN OF OPERATION }\end{array}$ & $\begin{array}{l}\text { NUMBER } \\
\text { 10-3 } \\
\text { PAGE } 2 \text { OF } 3 \text { PAGES }\end{array}$ \\
\hline
\end{tabular}

TRANSMISSION AND DISTRIBUTION DEPARTMENT

Head - Conduit-Steam Division

1. Obtains necessary personnel for street valving.

2. Contacts Cable Division for possible assistance for pumping.

3. Contacts Meter Service Division for possible use of Steam Meter Mechanics as helpers for valving.

4. Advises Superintendent - Transmission \& Distribution Department of conditions.

SYSTEM OPERATINNS NF.PAR.TMENT

Head - Distribution Dispatching Division

1. Obtains necessary personnel for Control Center by calling Division Head, Steam Heat Division, Steam Operations Dept; Assistant Division Head, Conduit Steam, Division, T\&D Dept; Division Head, Steam Division, Commercial Dept; and assigns Distribution System Dispatcher or Coordinator.

2. Notifies Director or alternate of Public Information Department of steam emergency.

3. Notifies and periodically advises the Manager of System Operations Department and Customer Information Division of system steam conditions.

COMMERCIAL DEPARTMENT

Head - Steam Division

1. Notffies Manager - Commercial Department of system conditions.

2. Contacts necessary personnel for making customer cuntacrs.

3. Notifies appropriate Clty and State officials (Coordinate with Public Affairs Department).

4. Notifies Customer Information Division.

PUBLIC AFFAIRS DEPARTMENT

1. Receive perlodic system status reports for releases to government officials. 


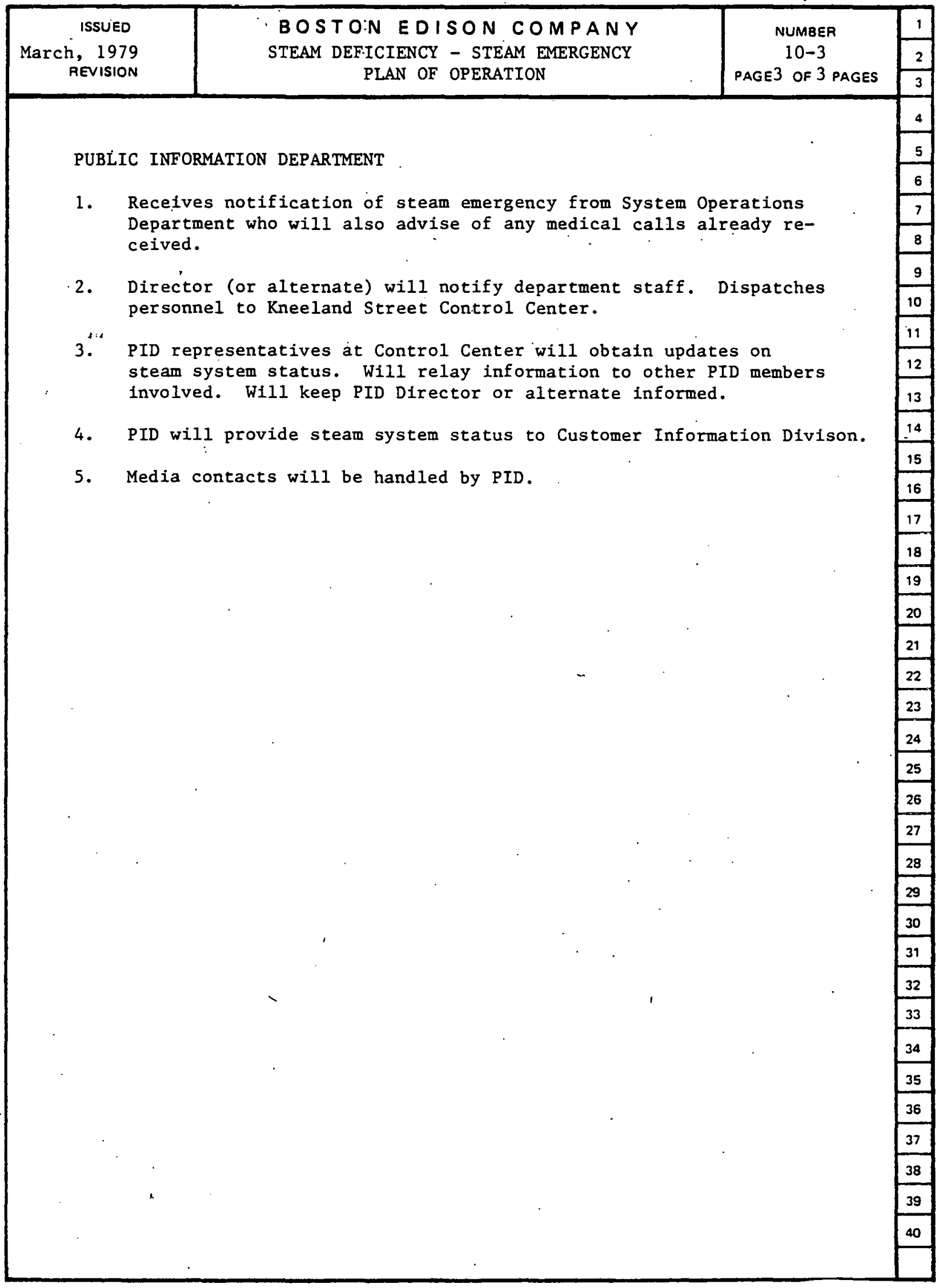




\begin{abstract}
APPENDIX A
FOUR UTILITIES' EXPERIENCE WITH

METROPOLITAN DISTRIBUTION SYSTEMS
\end{abstract}

Four electric utilities that operate underground distribution systems to supply large metropolitan loads were visited to discuss their experiences and practices. The companies visited were:

Commonwealth Edison Company, Chicago, Illinois Consolidated Edison Company, New York, New York The Detroit Edison Company, Detroit, Michigan Philadelphia Electric. Company, Philadelphia, Pennsylvania

All four companies serve at least a portion of their downtown load via secondary networks, but their network designs and practices are quite varied. The networks in Philadelphia and Detroit serve a smaller percentage of the total load than the networks in Chicago and New York. In Philadelphia, three networks each supply about 15 MVA of load and in Detroit, fourteen networks supply a total demand of 88 MVA. Eighteen networks are operated in downtown Chicago to supply more than 600 MVA of load. Fifty-two major networks and fifteen smaller networks supply 82 percent of the coincident demand in New York City or more than 7000 MVA of load.

\title{
PHILADELPHIA
}

The three networks in Philadelphia are each connected to a different source substation. Each network has three 13.2 $\mathrm{kV}$ feeders that loop back to the originating bus. These feeders 
are dedicated to serve only network load. The feeders are segmented by vacuum circuit breakers, and a network transformer is connected to each segment. The feeder segment and transformer combination is protected by a differential relay scheme. The secondary is a $240 / 120 \mathrm{~V}$ two-phase, five-wire design.

The network is designed on a single contingency basis. However, with the looped feeder, a fault on a feeder will only take out one network transformer. A second fault on another feeder will result in the loss of only one additional network transformer. Only the combination of two faults on the same feeder can cause multiple network transformer outages. In the event of a source station failure, normally open switches can be closed to pick up the network from an alternate source. This switching could take as long as 10 to 12 hours for the worst case but can be accomplished much quicker in most cases.

The downtown Philadelphia area is also served by $13.2 \mathrm{kV}$ radial distribution system. Most new large customers are supplied $13.2 \mathrm{kV}$, three phase rather than from the low voltage network and, as a result, the network load has remained about the same for the past several years, and very little additional growth is anticipated in the future.

DETROIT

The fourteen Detroit networks are supplied from six source substations via a total of forty-nine dedicated radial 
$4.8 \mathrm{kV}$ primary feeders. Approximately $90 \%$ of the network transformers are platform-mounted on steel columns. The secondary is $208 \mathrm{Y} / 120 \mathrm{~V}$.

For purposes of analysis and planning, each network is subdivided into several smaller areas. There are a total of 110. of these sub-areas. A sub-area is served by three to ten network transformers, each supplied from a separate feeder, and each feeder is connected to a different bus at the substation: The feeder branch into a sub-area is equipped with a pad-mounted disconnect switch that permits rapid manual isolation of a faulted cable section and restoration of the remaining undamaged sections of the feeder. Each sub-area is evaluated and planned on the basis of single outage criteria.

In recent years the downtown Detroit load has grown, but the load on the network has declined. In areas where old buildings have been demolished and new high-rise buildings are constructed, the secondary network has been completely eliminated and replaced with either radial secondary service fed from a. sectionalized primary network or primary service to customerowned equipment. New load additions. are made to the network only when it is cost-effective to do so. Many new customers are being served by a $13.2 \mathrm{kV}$ radial distribution system that also permeates the downtown Detroit area. 
CHICAGO

The eighteen networks in the downtown Chicago area each serve from $40^{\circ}$ to $60 \mathrm{MW}$ of load. The maximum load is limited to $60 \mathrm{MW}$. If the network grows beyond $60 \mathrm{MW}$, it is split into two networks of approximately $30 \mathrm{MW}$. Each network is fed by four to twelve $12.5 \mathrm{kV}$ dedicated radial feeders. The source station is designed with dual ring buses identified as a "red" bus and a "blue" bus. The ring buses are connected by a normaliy-open circuit breaker. Each ring is composed of six bus sections with, typically, three feeder per bus section. Each network feeder comes off a different bus section, and half the feeders are from the red bus and half from the blue bus. In a secondary transformer vault with two transformers, one would be supplied by a "red feeder" and the other by a "blue feeder."

The network is planned on a single contingency basis. for the summer peak load months and a double contingency basis for off peak. Maintenance is performed during off-peak periods. The double contingency criteria is based on the assumption that one element is on maintenance and another element is forced out of service. The source station is built with a minimum of three transformers, although allowable loading has historically been based on single contingency. From 1930 until 1972, the load on the network grew at a rapid rate, but since 1972 the network load has remained nearly constant. This leveling off is 
attributed to customer conservation efforts and to changes in the characteristics of new load. Much of the new load is from large buildings that are supplied via radial $12 \mathrm{kV}$ primary feeders rather than the secondary network.

NEW YORK

Almost all the load in New York City is supplied by secondary networks. Typically, the network source substation is connected to the $138 \mathrm{kV}$ transmission system by five 65 MVA, 138-13.2 kV transformers. These transformers supply up to 8 bus sections connected in a double bus arrangement. A maximum of four feeders are allowed per bus section, thus providing for as many as 32 feeders per substation: The networks are supplied by 8 to 24 feeders. A typical network will have 12 feeders. Primary voltages in use are $13.2 \mathrm{kV}, 27 \mathrm{kV}$ and $33 \mathrm{kV}$. The secondary voltage is $208 \mathrm{Y} / 120 \mathrm{~V}$, with some spot networks at $460 \mathrm{Y} / 265 \mathrm{~V}$.

The average network in Manhattan will serve about 18,000 customers with a demand of more than $100 \mathrm{MW}$. The maximum load permitted on a network is determined by computing the customer service voltage during cold pickup. The voltage available for motor start-up should not drop below $85 \mathrm{~V}$. All the feeders are radial and run in pairs with not more than two "associated" feeders per duct bank or manhole, whenever possible. "Associated" feeders serve a common area. It is sometimes necessary to violate this scheme in very high loaddensity areas, but the effort is made. 
In 1961, the city mandated that the Manhattan distribution system be planned on a double contingency basis. This system can withstand the loss of a pair of associated feeders or two adjacent network transformers, but for the most part, the distribution in the rest of the city is designed on single contingency criteria.

\section{RELIABILITY MEASURES}

Reliability measures used by the four companies havc been summarized and are discussed under the categories of System Design, Cable Considerations, Maintenance Practices, and Management.

\section{Sýstem Design}

The system design practices of the four companies varied considerably. The larger networks (30-100 MW) were designed with radial feeders supplying many network transformers. Considerable effort is made to separate feeders and to plan some components on double contingency basis. The smaller networks (5-15 MW) were designed with circuit breakers or switches located at strategic locations along the feeder. There is less concern for separating cables or providing redundancy, and the planning is based on single contingency basis.

Two major concerns are addressed in the design of manholes and duct runs: dissipation of cable heat, and allowance for cable expansion and contraction. Arc-proofing is selectively applied at cable joints and limiters are provided to minimize damage to adjacent cables, should the joint or cable fail. 


\section{Cable Considerations}

Good results were reported by two companies on the use of solid dielectric cables. These cables are less susceptible to cracking, absorbtion of moisture, and corrosion. Commonwealth Edison uses cable with PVC or polyethylene sheaths; while Consolidated Edison uses cable with lead sheaths with a jacket overall. The lead sheath provides superior protection against moisture ingress, but is substantially more expensive (25-35 percent). All companies have programs to analyze cable faults and maintain records on cable failures. Other programs cited as significantly improving cable reliability were (1) stringent cable specifications and attention to manufacturing details, (2) analysis of corrosion failures and application of preventive measures, and (3) careful rating of cables, taking into account heating effects of adjacent cables. Quality workmanship is also an important consideration. Failed joints are dissected, and if poor workmanship is found, the splicer may be reprimanded or required to take additional training. One company is $x$-raying new joints, thereby detecting faulty joints before they fail.

\section{Maintenance}

The practice of routinely inspecting manholes is implemented by some utilities. The utilities operating the larger networks routinely inspect every manhole once every three to five years. High voltage testing of network feeders on a routine basis is very important. Some utilities are increasing the frequency of testing and are now testing each 
feeder once per year. Computers are being used to document maintenance. Monthly or weekly schedules of required maintenance are generated, and follow-up reports are printed on actual maintenance performed. The scheduling of maintenance during off-peak load conditions is generally practiced. One utility studies these off-peak conditions with multiple con-" tingency to take into account facilities out-of-service for maintenance. Another utility has found it possible to decrease feeder restoration time and thereby increase network reliability. Feeder down-time is minimized by (1) giving. immediate attention to a feeder that trips out even during week-ends and off-peak periods, and (2) stressing to the repair crew the importance of quickly returning the feeder to service, and by recording and comparing repair times to determine efficient and inefficient practices.

\section{Mänágement}

Management programs can have a significant effect on system reliability. Performance standards and control measures need. to be established. One method is to compare the performance of operating divisions and use this data to establish goals and minimum acceptable performance standards. If comparisons are made on a quarterly basis, substandard performance can be detected early, and corrective measures can be implemented. Another method, already discussed, was the program to minimize feeder repair time. This program establishes standards and control measures that allow utility management to track the performance of the repair effort. 
Two-way communication and cooperation among utility divisions and between the utility and outside entities are always important. Specifically mentioned by one utility was the need for cooperation between engineering and purchasing departments so that quality and control could be maintained in the purchase of cable. Other communication channels that are especially critical are between planning and operations, and operations and maintenance. Open communication channels between utility and customers, regulators, and public agencies are sometimes difficult to establish.

Many research and development programs, and other programs with the ultimate purpose to improve system reliability, are underway. These programs include experimental instrumentation of distribution systems, cable fault. locating techniques, development of distribution data bases, corrosion mitigation, greater use of prefab cable joints, application of new material and equipment, detection and-containment of cable fires, and greater use of computers for data handling and power system control.

DC DISTRIBUTION

All four utilities have had dc distribution systems. All except New York have converted the dc load to the ac system and have eliminated the dc distribution system. This was accomplished by either replacing customer-owned dc equipment 
with ac or by installing a rectifier on the individual customer's site. Commonwealth Edison, the most recent company to eliminate their dc distribution, did so in 1972. Prior to installing a rectifier, the utility offered the customer the choice of the rectifier or the equidalent in cash to be used to replace equipment. The removal of the dc distribution made available valuable duct space for expansion of the ac system; and there was significant salvage value in the junk cable.

A large dc load is present in New York. This load is composed of elevator motors and industrial motors, such as those used in the garment industry's sewing machines. $\bar{A}$ substantial dc distribution grid is in place to serve this load. No significant decrease in dc load or in the distribution system is foreseen. The dc cables are protected by limiters, run in common facilities with ac cables, and have not been a major problem or liability to the reliability of the system. (In this regard, the practice is similar to that of Boston Edison.) 
TABLE A-I

COMPARATIVE STATISTICS

FIVE UTILITIES WITH UNDERGROUND SYSTEMS

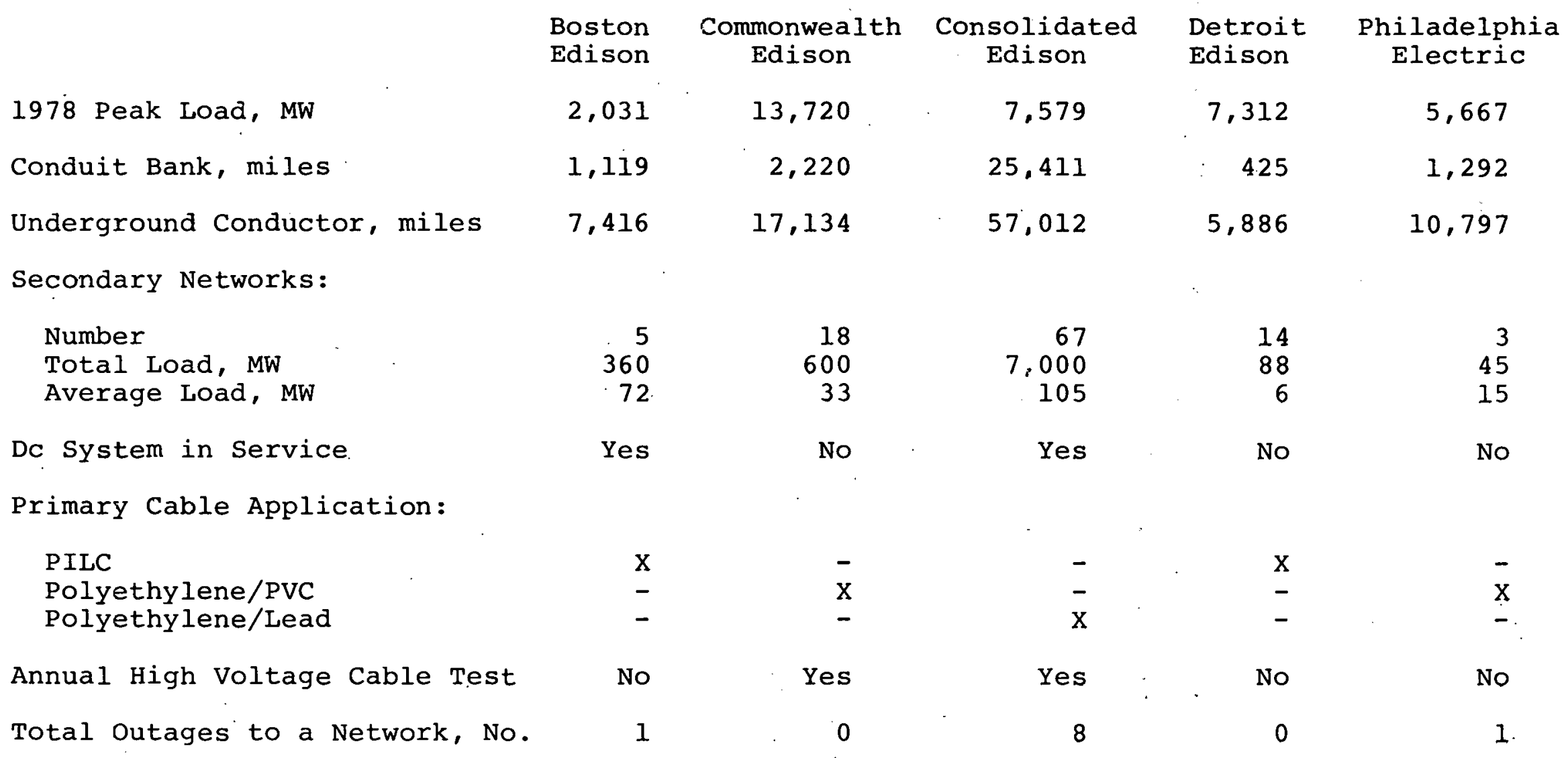




\section{APPENDIX B \\ BOSTON EDISON'S TROUBLE INFORMATION MANAGEMENT SYSTEM}

Distribution systems, unlike transmission systems, are not normally monitored by sophisticated communication and telemetering apparatus that provides the system operators with instant information on the status of the distribution facilities. Much of the needed information to operate the distribution system comes from customers who telephone to report outages. During system emergencies with multiple facilities out of service, the telephone communication channels are usually quickly overloaded, and the information, critical to the system operators, becomes extremely difficult to efficiently separate from the miscellaneous and extraneous outage data. Boston Edison has installed a Trouble Information Management System to alleviate this problem.

The Trouble Information Management System (TIMS) provides Boston Edison's Customer Information Center with a powerful tool for handling customer trouble reports. When a trouble call comes in, the telephone operator is trained to obtain information such as:

- Are your lights on or off?

- Are your neighbors' lights on?

- Can you see any damage to the wire coming into your house?

- Can you see any damage to poles or wires along the street? 
The trouble information is coded and entered into the computer. TIMS summarizes the trouble information by street address, keeping the highest and lowest street address and the address of the last customer who has called in trouble. Duplicate information is automatically deleted. The summarized trouble information is available almost instantly to the other telephone operators and to the System Control Center.

As the System Control Center monitors the trouble information coming to them, they keep the data file updated as to the action being taken, such as:

- Crews not dispatched

- Crews dispatched

- Line repaired

This information is provided to the telephone operators in the Customer Information Center so they can keep the customers informed as they call in, or they may verify that service has been restored by calling back the last customer reporting trouble.

The advantages of TIMS are:

- It summarizes trouble information

- It eliminates duplicate reports

- It eḷiminates paper work

- It speeds communications from customer to system dispatchers back to customer 
Work is in progress to further improve TIMS by linking street addresses to circuit numbers and map coordinates. A long-range hope is to have the computer actually predict which part of the circuit is damaged, and which switches should be opened to isblate the damaged sections, or predict which fuse has blown and its 'location.

Boston Edison's Customer Information Center is equipped with thirty-seven stations consisting of a telephone and video computer terminal. Approximately 850 calls per hour can be handled at the Center. During emergencies, overflow calls can be directed to additional telephones. Also, taped messages can be played to the customer while he is waiting for an available operator. The Center is manned from $8 \mathrm{AM}$ to midnight during normal periods and "as needed" during emergency periods. When the Center is not manned, incoming calls are directed to the system Control Center. 


\section{APPENDIX C \\ OPERATING AND MAINTENANCE EXPENSES}

The purpose of this section is to make a statistical review of operation and maintenance expenses for the underground distribution system since 1967. This period is appropriate, since it represents about a 5 -year period before and after the 1973 oil crisis.

Expenses considered include the cost of labor, materials and those incurred in operation as reported on Federal Power Commission (FPC) Accounts 584 (operation) and 594 (maintenance). These expenses are also compared to underground system investment as reported on FPC Accounts 366 (underground conduit) and 367 (underground conductors and devices).

This data was compiled for five companies, as follows:

$$
\begin{aligned}
& \text { Boston Edison Company } \\
& \text { Commonwealth Edison Company } \\
& \text { Consolidated Edison Company } \\
& \text { The Detroit Edison Company } \\
& \text { Philadelphia Electric Company }
\end{aligned}
$$

All of these utilities operate secondary networks, as well as extensive underground systems using other operating arrangements, as does the Boston Edison Company. 
INFLATION

Considerable inflation has occurred since 1967. Bureau of Labor Statistics (BLS) data have been used in an effort to recognize this factor. Table C-IV shows published BLS price and wage indices. It is believed that the wage index more closely approximates power company operating and maintenance cost trends; this has been used for the study. However, it can be noted that there is little difference between the price and wage indices, and that any difference in trends would be negligible, regardless of which was used. INVESTMENT

Table $\mathrm{C}-\mathrm{I}$ shows the investment in underground distribution system plant since 1967. This table shows that the Boston Edison Company investment has doubled, while that of most of the other utilities has increased somewhat slower. This might not be pivotal, because many factors such as urban redevelopment can cause such differentials.

Table C-II shows the investment with amounts spent each year since 1967, adjusted to that year by means of the BLS wage index.

EXPENSES

Underground operation and maintenance expenses from 1967 are shown on Table C-III. It can be noted that the allocation of expenses between operation and maintenance differ 
markedly from utility to utility. However, the total of these two accounts should adequately represent total yearly underground investment in the major part of the system (exclusive of services and the portions assigned to supervision and engineering).

The expenses are shown on Table C-IV, adjusted by the BLS Wage Index to 1967 costs. Accumulated expenses are also shown on this table.

Table $\mathrm{C}-\mathrm{V}$ shows a development of operating and maintenance expenses, expressed as a percent of underground investment.

\section{ANALYSIS}

Boston Edison depends heavily on oil for its electric generation. The BECo dependence on oil, compared to other utilities, is shown by the following table for 1978:

\begin{tabular}{lc} 
Utility & \& Generation From Oil \\
\hline Boston Edison Co. & 66.3 \\
Commonwealth Edison Co. & 7.1 \\
Consolidated Edison Co. & 58.7 \\
The Detroit Edison Co. & 7.2 \\
Philadelphia Electric Co. & 23.7
\end{tabular}

The oil embargo had a deep impact on Boston Edison, which was deeply committed to capital outlays, notably for generation and transmission additions that could not be halted. The 
embargo placed a heavy financial strain on the company. The result was the cancellation or deferral of all but the most essential capital outlays and reduction wherever possible in expenses. These reductions affected operating and maintenance expenditures.

Exhibit $\mathrm{C}-1$ shows annual operating and maintenance expenses for underground systems, with 1967 expenses taken as the index (i.e., 100 percent). It can be observed that Boston Edison Company expenditures rose between 1967 and 1972, but have shown a steady decline since that time. This coincides with precipitous oil cost increases in later years. This has been a handicap to all power companies, but particularly to those in the Northeast, where imported oil has been the basic fuel for fossil-fired generating units. Relative to other utilities included in this type of analysis, the Boston Edison operating and maintenance expenditures appear to have been steadily declining since 1972. The erratic behavior of the BECo curve in 1971, 1972 and 1973 can be at least partially attributed to strikes in 1971 and 1973.

The O\&M expenditure per mile of underground distribution conductor for 1978 experienced by the various utilities is developed by the following table: 
O\&M Expenditure UG Dist. Expend. for UG, $\$ 1000$ Cond., Mi.. $\$ / \mathrm{Mi}$.

Boston Edison Co.

Commonwealth Edison Co.

Consolidated Edison Co.

The Detroit Edison Co.

Philadelphia Electric Co:

$$
5,727
$$

15,936

38,586

4,266

$5,474^{\prime \prime}$
7,416

17,134

57,012

5,886

10,797

507

This table includes both conductors in ducts (as in a dowritown system) and direct burial (as in a suburban system).

Underground distribution operating and maintenance (O\&M) expenses on an accumulated basis are shown on Exhibit C-2. It can be observed that the Boston Edison Company expenditures have shown a relative reduction since 1973, with the BECo curve showing a lesser slope than Detroit Edison, Commonwealth Edison or Philadelphia Electric, but about the same as Consolidated Edison.

Exhibit $\mathrm{C}-3$ shows a somewhat different result when compared to the other utilities. This curve is based on O\&M expenses expressed as a percentage of total underground invest: ment. It can be observed that BECo expenses were much greater in early years, but have been steadily declining since 1972, to become comparable to those of other utilities, although remaining higher than any of them in 1977. The reason for this situation is not readily ascertainabie. 
CONCLUSION

It is not feasible to draw specific conclusions for a particular incident from statistical data as grouped for this appendix. However, it is evident that there has been a reduction in underground distribution system maintenance by Boston Edison Company in recent years. This can lead to : failure to detect incipient failures on cables or other equipment. This is particularly true with lead-sheathed, paperinsulated cable, which is extremely vulnerable to failure upon entry of moisture. A good inspection and testing program can locate such problems as cracked or worn sheaths or changes in characteristics which are indications of possible failure in the near term.

The Wellesley, Roslindale, and East Boston/Chelsea outages were all caused by multiple failures of old cable. It is possible that at least some of these could have been forestalled by an aggressive cable inspection and testing program. 


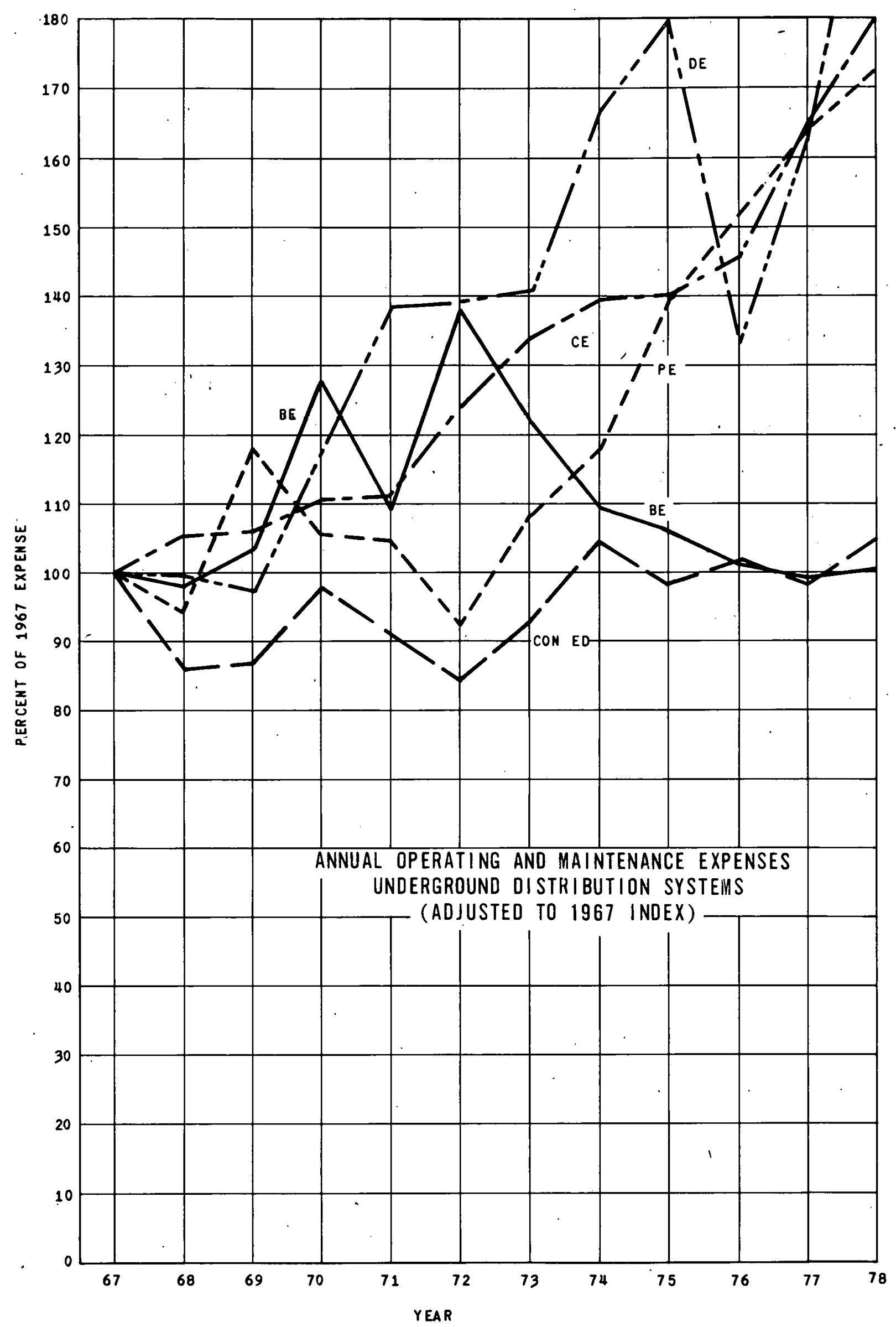


EXHIBIT C-2

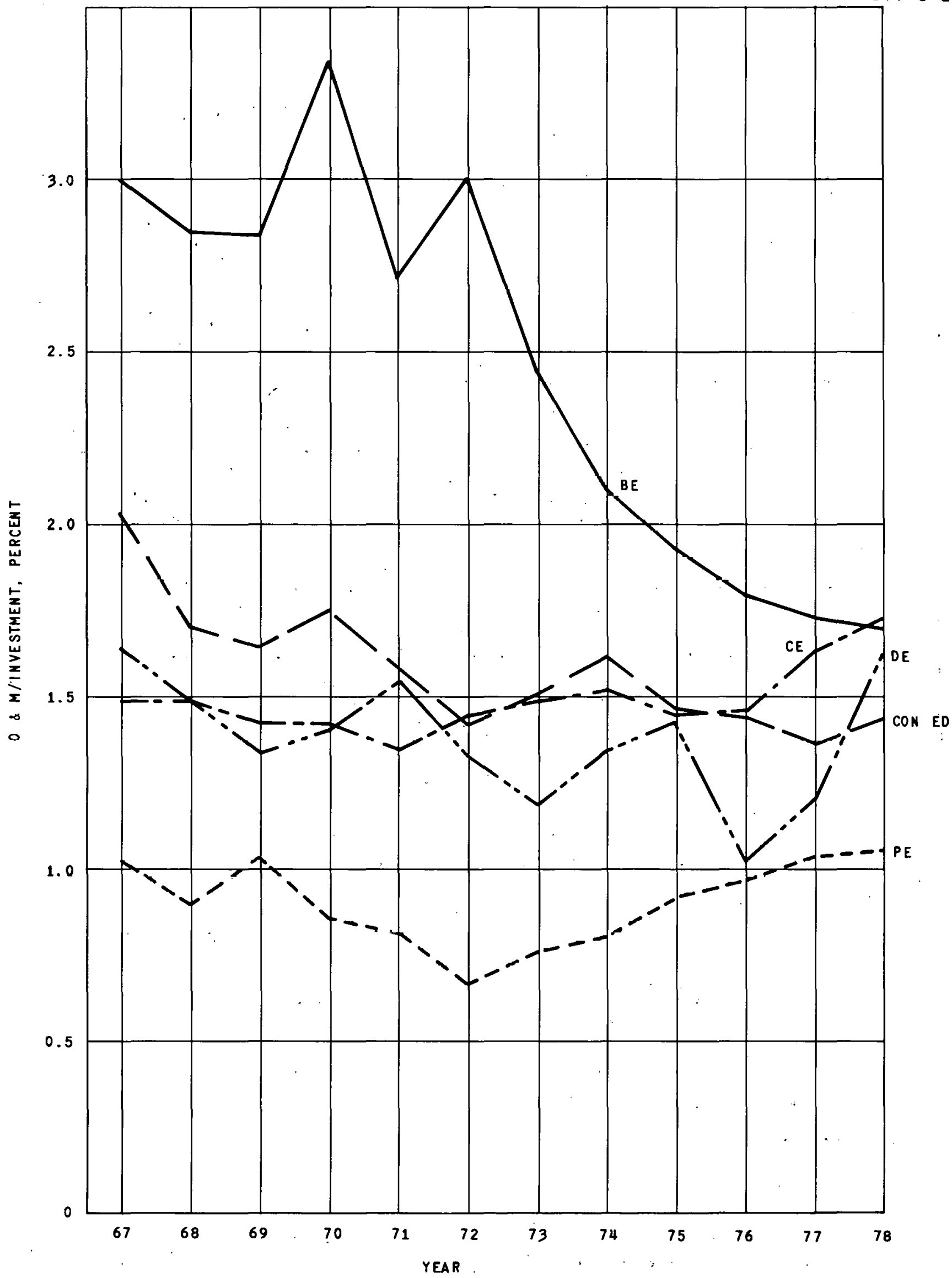




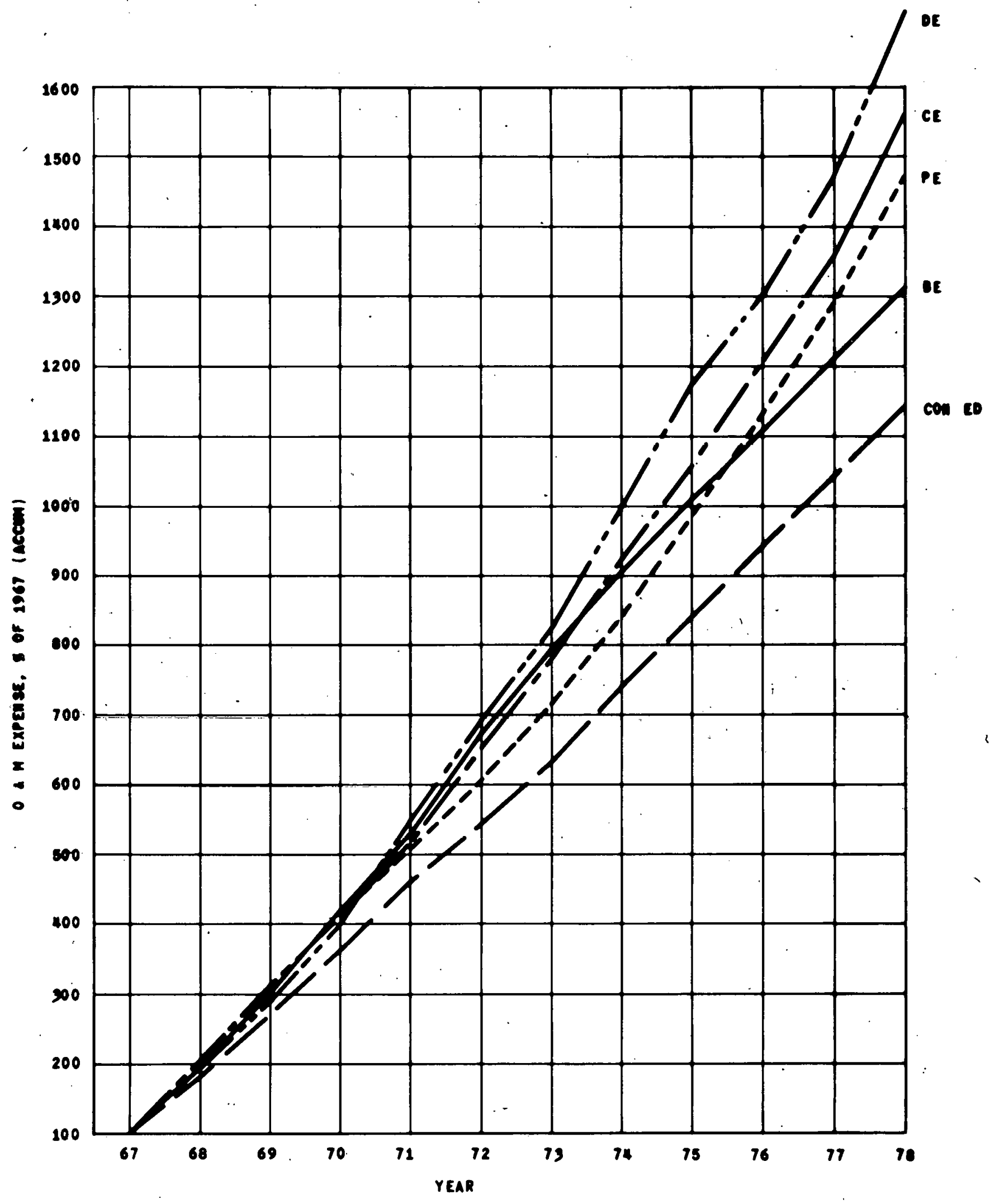

ACCUMULATED OPERATING AND MAINTENANCE EXPENSES

UNDERGROUND DISTRIBUTION SYSTEMS

(ADJUSTED TO 1967 INOEX) 
TABLE C-I

UNDERGROUND DISTRIBUTION SYSTEM INVESTMENT

Acct 366 - Underground Conduit

Acct 367 - Underground Conductors and Devices

\begin{tabular}{|c|c|c|c|c|c|c|c|c|c|c|c|c|c|}
\hline Acct & & 1967 & $\underline{1968}$ & 1969 & 1970 & 1971 & 1972 & 1973 & 1974 & $\underline{1975}$ & 1976 & 1977 & 1978 \\
\hline & Boston Edison Co & & & & & & & & & & & & \\
\hline 366 & Underground Conduit & 30375 & 31163 & 32782 & 34320 & 35849 & 41202 & 45588 & 47754 & 49419 & 51244 & 52407 & 53298 \\
\hline \multirow[t]{4}{*}{367} & Underground Conductor & $\underline{64955}$ & $\underline{66935}$ & 71366 & $\underline{77150}$ & $\underline{81932}$ & $\underline{98289}$ & 111109 & $\underline{118214}$ & $\underline{129610}$ & $\underline{134568}$ & $\underline{138643}$ & 146003 \\
\hline & Total & 95330 & 98098 & 104148 & 111470 & 117781 & 139491 & 156697 & 165968 & 179029 & 185812 & 191050 & 199301 \\
\hline & 8 of 1967 & 100.0 & 102.9 & 109.2 & 116.9 & 123.6 & 146.3 & 164.4 & 174.1 & 187.8 & 194.9 & 200.4 & 209.1 \\
\hline & Commonwealth Edison $\mathrm{Cc}$ & & & & & & & & & & & & \\
\hline 366 & Underground Conduit & 144413 & 149670 & 155523 & $160697^{\circ}$ & 168677 & 174202 & 182420 & 185611 & 193258 & 199937 & 203777 & 204000 \\
\hline \multirow[t]{4}{*}{367} & Underground Conductor & $\underline{149330}$ & 160622 & $\underline{173315}$ & 185110 & 200937 & $\underline{219339}$ & $\underline{235587}$ & $\underline{249797}$ & 270096 & $\underline{285547}$ & 305184 & 324593 \\
\hline & : Total & 293743 & 310292 & 328838 & 345807 & 369614 & 393541 & 418007 & 435408 & 463354 & 485484 & 508961 & 538593 \\
\hline & 8 of 1967 & $100.0^{\prime}$ & 105.6 & 111.9 & 117.7 & 125.8 & 134.0 & 142.3 & 148.2 & 157.7 & 165.3 & 173.3 & 183.4 \\
\hline & Consolidated Edison Co & & & & & & - & & & & & & \\
\hline 366 & Underground Conduit & 500693 & 514078 & 531916 & 562957 & 581668 & 596313 & 620286 & 644805 & 676748 & 701159 & 719497 & 738931 \\
\hline \multirow[t]{4}{*}{367} & Underground Conductor & $\underline{402482}$ & $\underline{421597}$ & $\underline{445029}$ & 473753 & $\underline{500808}$ & $\underline{536722}$ & $\underline{573534}$ & $\underline{625241}$ & $\underline{675764}$ & $\underline{725933}$ & 774433 & 824429 \\
\hline & Total & 903175 & 935675 & 976945 & 1036710 & 1082476 & 1133035 & 1193820 & 1270046 & 1352512 & 1427092 & $\overline{.1493930}$ & 1563360 \\
\hline & 8. of 1967 & 100.0 & 103.6 & 108.2 & 114.8 & 119.9 & 125.4 & 132.1 & 140.6 & 149.7 & 158.0 & 165.4 & 173.1 \\
\hline & Detroit Edison Co & & & & & & & & & & & & \\
\hline 366 & Underground Conduit & 30094 & 31206 & 32670 & 36223 & 34710 & 43448 & 48948 & 57897 & 49516 & 51303 & 52877 & 53421 \\
\hline \multirow[t]{4}{*}{367} & Underground Conductor & 26284 & 30500 & 35381 & 43568 & 51922 & 62787 & 74444 & 74123 & 85729 & 91746 & 98127 & 107001 \\
\hline & Total & 56378 & 61706 & 68051 & 79791 & 86632 & 106235 & 123392 & 132029 & 135245 & 143049 & 151004 & 160422 \\
\hline & 8 of 1967 & 100.0 & 109.4 & 120.6 & 141.5 & 153.7 & 188.4 & 218.9 & 234.1 & 239.9 & 25.3 .7 & 267.8 & 284.5 \\
\hline & Philadelphia Electric & & & & & & & & & & & & \\
\hline 366 & Underground Conduit & 71319 & 75507 & 83539 & 90054 & 98137 & 104276 . & 111242 & 115315 & 119897 & 123615 & 124933 & 126607 \\
\hline \multirow[t]{3}{*}{367} & Underground Conductor & 83655 & 90350 & 98427 & $\underline{105505}$ & $\underline{115750}$ & $\underline{123358}$ & 131319 & 137429 & 145939 & 153983 & 161284 & $\underline{170630}$ \\
\hline & Total & 154974 & 165857 & 181966 & 195559 & 213887 & 227634 & 242561 & 252744 & 265836 & 277598 & 286217 & 297237 \\
\hline & 8 of 1967 & 100.0 & 107.0 & 117.4 & 126.2 & 138.0 & 146.9 & 156.5 & 163.1 & 171.5 & 179.1 & 184.7 & 191. \\
\hline
\end{tabular}
Source: "Statistics of Privately-Owned Electric Utilities in the United States",
FPC and DOE/EIA

JAN $11 / 6 / 79$ 
TABLE C-II

UNDERGROUND DISTRIBUTION SYSTEM INVESTMERI REFERRED TO 1967 INDEX

ACCTS 366 and 367

$$
\$ 1000
$$

Boston Edison Co
Investment, Year Bnd
Investment, Year Start
Added Inv in year
Added Inv, 1967 Equiv
Adjusted Inv, Year End
Adjusted Inv, of 1967
CommonweaIth Edison Co
Investment, Year End
Investment, Year Start
Added Inv in Year
Added Inv, 1967 Equiv
Adjusted Inv, Year. End
Adjusted, Inv, 8 of 1967
Consolidated Edison Co
Investment, Year End
Investment, Year Start
Added Inv, in Year
Added Inv, 1967 Equiv
Adjus ted Inv, Year End
Adjusted Inv, 8 of 1967
Detroit Edison Co
Investment, Year End
Investment, Year Start
Added Inv in Year
Added Inv, 1967 Equiv
Adjusted Inv, Year End
Adjusted Inv, 8 of 1967
Philadelphia Electric Co
Investment, Year End
Investment, Year Start
Added Inv in Year
Added Inv, 1967 Equiv
Adjusted Inv, Year End
Adjusted Inv, 8 of 1967

$\underline{1967} \quad \underline{1968} \quad \underline{1969} \quad \underline{1970}$

95330

104148

$\frac{98098}{6050}$

5378

in...

$\underline{1971}$

$\underline{1972}$

$\underline{1973}$

104148

117781

$\frac{112470}{6311}$

5045

6221

95330
100.0

279

102.7

108.4

$\begin{array}{r}114.9 \\ \hline\end{array}$

120.2

139491

$\frac{117781}{22021}$

16385

130975

137.4

156697

$\frac{13949 \mathrm{l}}{17205}$

12043

14302 :

293743

310292
293743

328838

345807

369614

393541

16549

15642

$293743 \quad 30938$

$\frac{310292}{185+6}$

$\begin{array}{r}345838 \\ 328838 \\ \hline\end{array}$

16969

345807

23807

19030

369614

23927
17803

418007

325870

340287

159317
122.3

377120

$\begin{array}{r}418007 \\ 393541 \\ \hline\end{array}$

2446

1713

134253
131.2

105.3

903175

\begin{tabular}{l}
935675 \\
903175 \\
\hline 32500
\end{tabular}

1036710

1082476

128.

131.2

- $\quad \frac{903175}{32500}$

976945
59765

50777

$1036710 \quad 1133035$

$\frac{036710}{45766}, \frac{1082470}{50565}$

1193820

30718

36634
970577

1021354

$1057938 \quad 37623$

$100.0 \quad 103.4$

107.4 .

117.1

121.3
12561

60785

42567

125.0

$\frac{1193820}{76226}$

50149

188277

$68051 \quad 79791$

$86632 \quad .106235$

61706

$\frac{56378}{5328}$

5297

$56378 \cdot 61675$

$\frac{61706}{6345}$

$\begin{array}{r}79791 \\ 68051 \\ \hline 11740\end{array}$

$\frac{68051}{11740}$

9975

$673155 \quad 77290$

$\frac{79791}{6841}$

5468 -

$\frac{86632}{19603}$

123392

123392
106235

1715.7
12015
109359

82758.

14586
97344

65857

181956

195559

213887

$\frac{154974}{10883}$

10883

10286

1658.57

16139

14319
179579

$\frac{181966}{13593}$

213887

$\begin{array}{r}195559 \\ \hline 18328\end{array}$

172.7

194.0

$\frac{123392}{8637}$

8682

115041

204.0

227634

$\begin{array}{r}227634 \\ 213837 \\ \hline\end{array}$

$4974 \quad 165260$

115.9

11549
191128

1466

13747
10228

$\begin{array}{r}242561 \\ 227634 \\ \hline\end{array}$

$\frac{227634}{14927}$

$\begin{array}{r}252744 \\ 242561 \\ \hline\end{array}$

205779

216007

1045

146.1

6699

6699
33159

$>$

100.0

105.3

112.5

117.7

125.1

134.4

142.8

152.0

160.6

JAN $11 / 7 / 79$ 


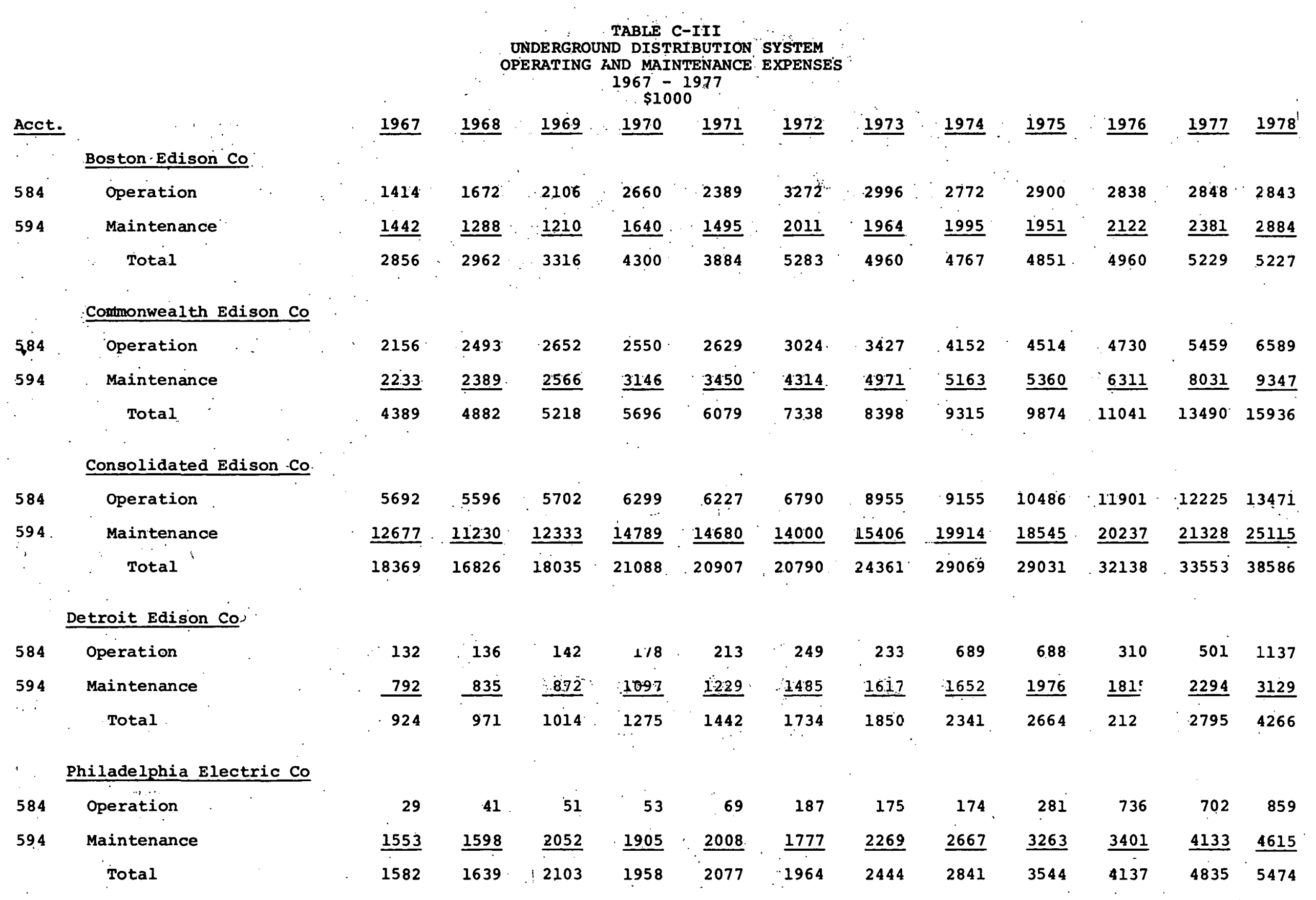

Source: "Statistics of Privately-owned Electric vtilities in the United states," FPC and DOE/EIA

JAN $: I 1 / 5 / 79$ 
TABLE C-IV

UNDERGROUND DISTRIBUTION SYSTE

OPERATING AND MAINTENANCE EXPENSES REFERRED TO 1967 INDEX $1967-1977$

Annual $\$ 1000$

Annual $\$ 1000$ (1967)

Annual of of 196.7.

Accumulated $\$ 1000$ (1967)

Accumulated 8 of 1967

Commonwealth Edison Co

Annual $\$ 1000$

Annual $\$ 1000$ (1967)

Annual of 1967

Accumulated $\$ 1000$ (1967)

Accumulated 8: of 1967

Consolidated Edison Co

\section{Annual $\$ 1000$}

Annual $\$ 1000$ (1967)

Annual of 1967

Accumulated $\$ 1000$ (1967)

Accumulated 8 of 1967

\section{Detroit Edison Co}

\section{Annual $\$ 1000$}

Annual $\$ 1000$ (1967)

Annual of 1967

Accumulated $\$ 1000$ (1967)

Accumulated of 1967

Philadelphia Electric Co

\section{Annual $\$ 1000$}

Annúal $\$ 1000$ (1967)

Annual 8 of 1967

Accumulated $\$ 1000$ (1967)

Accumulated \& of 1967

BLs Earnings Index

\begin{tabular}{|c|c|c|c|c|c|c|c|c|c|c|c|}
\hline 1967 & 1968 & 1959 & 1970 & 1971. & 1972 & 1973 & 1974 & 1975. & 1976 & 1977 & 1978 \\
\hline 2856 & 2962 & 3316 & 4300 & 3884 & 5283 & 4960 . & 4767 & 4851 & 4960 & 5229 & 5727 \\
\hline 2856 & 2800 & 2948 & 3653 & 3105 & 3931 & 3473 & 3136 & 3021 & 2879 & 2817 & $2863^{\circ}$ \\
\hline $100 . .0$ & -98.0 & 103.2 & 127.9 & 108.7 & 137.6 & . 121.6 & 109.8 & 105.8 & 101.4 & 98.6 & 100.2 \\
\hline 2856 & 5656 & 8604 & 12257 & 15362 & 19293 & 22766 & 25902 . & 28923 & 31802 & -34619 & 37482 \\
\hline 100.0 & 198.0 & 301.3 & 429.2 & 537.9 & 675.5 & 797.1 & 906.9 & 1012.7 & 1113.5 & 1212.1 & 1312.4 \\
\hline 4389 & 4882 & 5218 & 5696 & 6079 & 7338 & 8398 & 9315 & 9874 & 11041 & 13490 & 159.36. \\
\hline 4389 & 4614 & 4638 & 4839 & 4859 & 5460 & 5881 & 6128 & 6148 & 6408 & 7268 & 7968 \\
\hline 100.0 & 105.1 & 105.7 & 110.3 & 110.7 & 124.4 & 134.0 & 139.6 & 140.1 & 146.0 & 165.6 & 181.5 \\
\hline 4389 & 9003 & 13641 & 18430 & 23339 & $28779^{\circ}$ & 34680 & 40808 & 46596 & 53364 & 60632 & 68600 \\
\hline 100.0 & 205.1 & $3: 0.8$ & 421.1 & 531.8 & 656.2 & 790.2 & 929.8 & 1069.9 & 1215.9 & 1368.5 & 1563.0 \\
\hline & & & & & & & & & & & \\
\hline 18369 & 16826 & 18035 & 21088 & 20907 & 20790 & 24361 & 29069 & 29031 & 32138 & 33553 & 38586 \\
\hline 18369 & 15904 & 16031 & 17917 & 16712 & 15469 & 17060 & 19124 & 18077 & 18652 & 18078 & 19293 \\
\hline 1.00 .0 & .86 .5 & E: 7.3 & 97.6 & 91.0 & 84.2 & .9. & 104.1 & .98 .4 & 101.5 & 98.4 & 105.0 \\
\hline 18369 & 34273 & $503 C 4$ & 68221 & 84933 & 100402 & 117462 & 136586 & 154663 & 173315 & 191393 & 210686 \\
\hline .100 .0 & 186.6 & 273.8 & $=371.4$ & 462.4 & 546.6 & 639.5 & 743.6 & 842.0 & 943.5 & 1041.9 & 1147.0 \\
\hline 924 & 971 & 1014 & 1275 & 1442 & 1734 & 1850 & .2341 & 2664 & 2125 & 2795 & 4266 \\
\hline 924 & 918 & 901 & 1083 & 1282 & 1290 & 1296 & 1540 & 1659 & 1233 & 1506 & 2133 \\
\hline 100.0 & 99.4 & 97.5 & 317.2 & 138.7 & 139.6 & 140.3 & 166.7 & 179.5 & 133.4 & 163.0 & 230.8 \\
\hline 924 & 1842 & 2743 & 3826 & 5108 & 6398 & 7694 & 9234 & 10893 & 12126 & 13632 & 15765 \\
\hline 100.0 & .199 .3 & 296.9 & 414.1 . & 552.8 & 692.4. & 832.5 & 999.3 & 1178.8 & 1312.3 & 1475.3 & 1706.2 \\
\hline 1582 & 1639 & 2103 & 1958 & 2077 & 1964 & 2444 & 2841 & -3544 & 4137. & 4835 & 5474 \\
\hline 1582 & 1495 & 1869 & 1664 & $1660^{\circ}$ & 1461 & 1711 & 1869 & 2207 & 2401 & 2605 & 2737 \\
\hline 100.0 & 94.5 & $11 B .1$ & 105.2 & 104.9 & 92.4 & 108.2 & 118.1 & 139.5 & 151.8 & 164.7 & 173.0 \\
\hline 1582. & 3077 & 4946 & 6610 & 8270 & 9731 & 11442 & 13311 & 15518 & 17919 & 20524 & 23261 \\
\hline 100.0 & 194.5 & 312.6 & 417.8 & 522.8 & 615.1 & 723.3 & 841.4 & 980.9 & 1132.7 & 1297.3 & 1470.4 \\
\hline 100.0 & 105.8 & $112.5=$ & 117.7 & 125.1 & 134.4 & 142.3 & 152.0 & 160.6 & 172.3 & 185.6 & 200.0 \\
\hline
\end{tabular}


TABLE C-V

UNDERGROUHD DISTRIBUTION SYSTEM INVESTMENT RELATED TO ANNUAL OPERATING AND MAINTENANCE EXPENSES

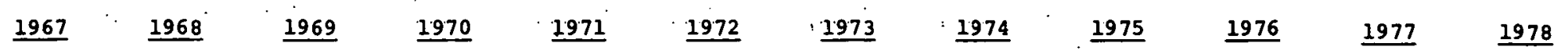

Boston Edison Co

o \& M (adj to 1967)

\begin{abstract}
95330
$-28.5 .6$
\end{abstract}

97946

$103324 \quad 109545$

$114590 \quad 130975 \quad 143024$

Ratio, $O \& M /$ inv, 8

. 3:00

2.86

$2948 \quad 3653$

3105

3931

3473

2.71

\begin{abstract}
3.00
\end{abstract}
2.43

$149124 \quad 157257$

161194

164016

168141

\title{
Commonwealth Edison Co
}

Investment (adj to 1967

O\& M (adj to 1967).

Ratio, o \& M/inv, 8

\begin{tabular}{|c|c|c|c|c|c|c|c|c|c|c|c|}
\hline 293743 & $30938 \overline{5}$ & 325870 & 340287 & 359317 & 377120 & 394253 & 405701 & 423102 & 435946 & 448595 & 463411 \\
\hline 4389 & 4614 & 4638 & 4839 & 4859 & 5460 & 5881 & 6128 & 6148 & 6408 & 7268 & 7968 \\
\hline 1.49 & 1.49 & 1.42 & 1.42 & 1.35 & 1.45 & 1.49 & 1.51 & 1.45 & 1.47 & 1.62 & 1.72 \\
\hline
\end{tabular}

\section{Consolidated Edison Co}

Investment (adj to 1967)

O M (adj to 1967)

$\begin{array}{rrrrrrrrrrrrrr}903175 & 933893 & 970577 & 1021354 & 1057938 & 1095561 & 1138128 & 1188277 & 1239626 & 1282911 & 1318923 & 1353638 & & \\ 18369 & 15904 & 16031 & 17917 & 16712 & 15469 & 17060 & 19124 & 18077 & 18652 & 18078 & 19293 & \\ 2.03 & 1.70 & 1.65 & 1.75 & 1.58 & 1.41 & 1.50 & 1.61 & 1.46 & 1.45 & 1.37 & 1.43\end{array}$

Ratio $0 \& M /$ inv, 8

Detroit Edison Co

Investment (adj to 1967)

O M (adj to i967)

Ratio, $O \& M / i n v, 8$

\begin{tabular}{|c|c|c|c|c|c|c|c|c|c|c|c|}
\hline 56378 & 61675 & 67315 & 77290 & 82758 & 97344 & 109359 & 115041 & 117043 & 121572 & 125858 & 130817 \\
\hline 924 & 918 & 901 & 1083 & 1282 & 1290 & 1296 & 1540 & 1659 & 1233 & 1506 & 21.33 \\
\hline 1.64 & 1.49 & 1.34 & 1.40 & 1.55 & 1.33 & 1.19. & $1: 34$ & 1.42 & 1.01 & 1.20 & 1.63 \\
\hline
\end{tabular}

Philadelphia Edectric Co

Investment (adj to 1967).

O\&M (adj to 1967)

$154974 \quad 165260$

\begin{tabular}{rrrrrrrrrrrrrr}
154974 & 165260 & 179579 & 191128 & 205779 & \multicolumn{1}{c}{016007} & 226460 & 233159 & 241311. & 248137 & 252781 & 258291 \\
1582 & 1495 & 1869 & 1664 & 1660 & 1461 & 1711 & 1869 & 2207 & 2401 & 2605 & 2737 \\
1.02 & $\therefore$ & 0.90 & 1.04 & 0.87 & 0.81 & 0.68 & 0.76 & 0.80 & 0.91 & 0.97 & 1.03 & 1.06
\end{tabular} Ration, $0 \& M /$ invio

0.76

JAN $11 / 7 / 79$ 


\section{APPENDIX D \\ CABLE OPERATION}

An underground electric distribution system in a major urban area such as Boston requires a significant amount of cable. In the Back Bay network there are about 125 miles of $14 \mathrm{kV}$ primary system cable and about 200 miles of $208 / 120 \mathrm{~V}$ secondary cable. The primary cables feed the network transformers, and the secondary cables connect the system to the customers. Superimposed on the ac system is the dc system with about 40 miles of $250 \mathrm{~V}$ cable in operation. In total, there are about 365 miles of insulated cable under the streets in an area of less than one-half square mile.

Cable in such an underground environment is subjected to many hostile influences. Manholes and ducts are frequently filled with brackish ground water. There are strong corrusive influences, both from chemical action and from dc transit systems. Mechanical damage can be caused by load cycling of the cable with attendant contraction and expansion and by vibrations from heavy street traffic. In addition, electrical overloads can sometimes occur. Of necessity, splices are handmade and often are more vulnerable than the cable itself. Cable systems ałso become more subject to failure with age, since the effects of all of the detrimental influences are cumulative. In addition, the cable insulation deteriorates to some extent with time.

Important loads supplied by underground cable systems usually have redundant power supplies. For example, the Back 
Bay network supply is designed so that several primary or secondary cables can be out of service simultaneously without interruption to customer load. There have been 86 primary cable or splice failures during the past six years, but it has not been necessary to remove the network from service prior to the April, 1979, incident.

Table D-I shows the primary system failure record since 1973 for cables supplying the Back Bay Network. An overall rate of 11.4 failures per 100 miles per year has been derived by this täble. Of these, about 22 perrent occurred on tcat. Testing is performed during off-peak periods when the cable under test can be spared without riśk to integrity of the power supply. Moreover, the tests are performed with nondestructive dc testing methods with negligible risk of damage to adjacent cables. Conversely, failures in service interrupt system elements carrying power and do carry an attendant risk of damage to adjacent cables.

Table D-II and Exhibit D-1 show the Boston Edison Company overall cable failure rates from 1958 through 1978 . It can be seen that the average failure rate for the 21 . years covered by the data that the failure rate was uniformly higher than in the Back Bay network area and that there was no trend - either toward an increasing or decreasing rate. Of the 5,615 failures, 672 or about 12 percent occurred when the cable was being tested.

Cable failure data are reported by member companies to the Edison Electric Institute (EEI), and an annual cable operation report is prepared. Based on the latest available EEI information, the overall rate was 3.91 failures per 100 miles per year. This is derived from 1,049 cable failures 
and 205 splice failures for 32,056 conductor miles of cable. The EEI data includes other types of cable and other types of installation than used for the Back Bay Network, and might not be wholly representative. About half of the cable outages were for paper-insulated lead-covered (PILC) cables similar to that used in Boston. Even so, it seems fair to conclude that the Back Bay Network failure rate is above the national average and is higher than it should be.

Boston Edison Co. investigates each cable failure and attempts to assign a cause. It has been determined that the failure causes are assignable approximately as follows:

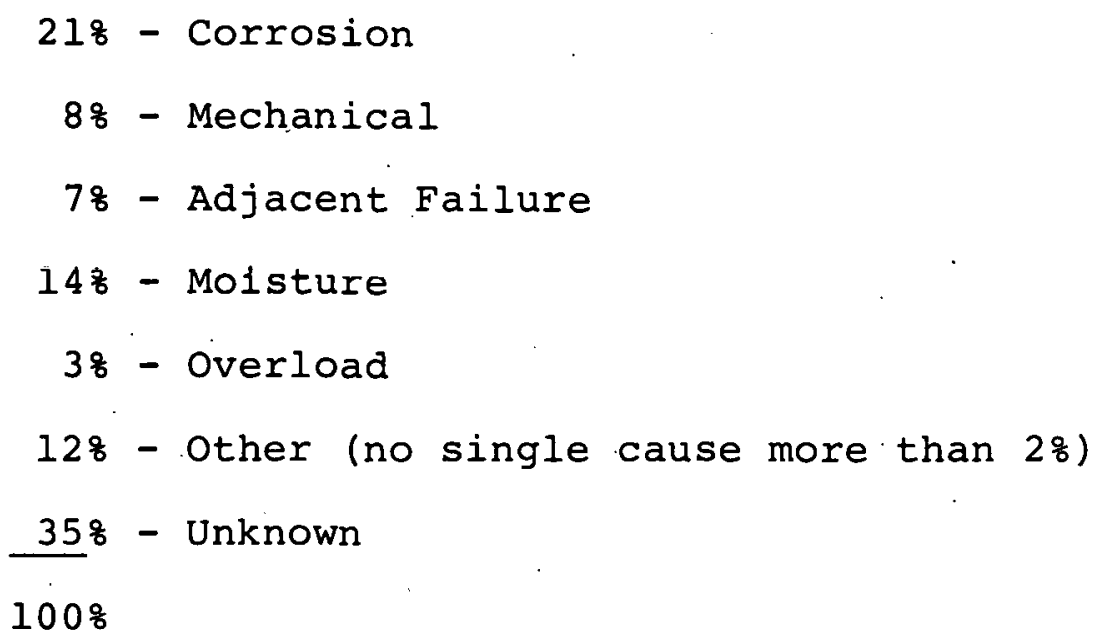

The "unknown" category is better than the national average, where about half the failures have the cause listed as unknown.

About 66 percent of the failures with known causes have been attributed to corrosion, mechanical damage, and moisture. Some of the older cable does not have a protective 
D-4

jacket over the lead sheath. A protective jacket would improve protection against corrosion, mechanical damage, and those moisture-induced failures which can be coupled to sheath wear. A carefully-designed cathodic protection system can also reduce the number of failures caused by corrosion. Such systems are in place, but it is possible that improvements could be made. 
CABLE SYSTEN FAILURE RATES

6.9 KY ANO ABOVE

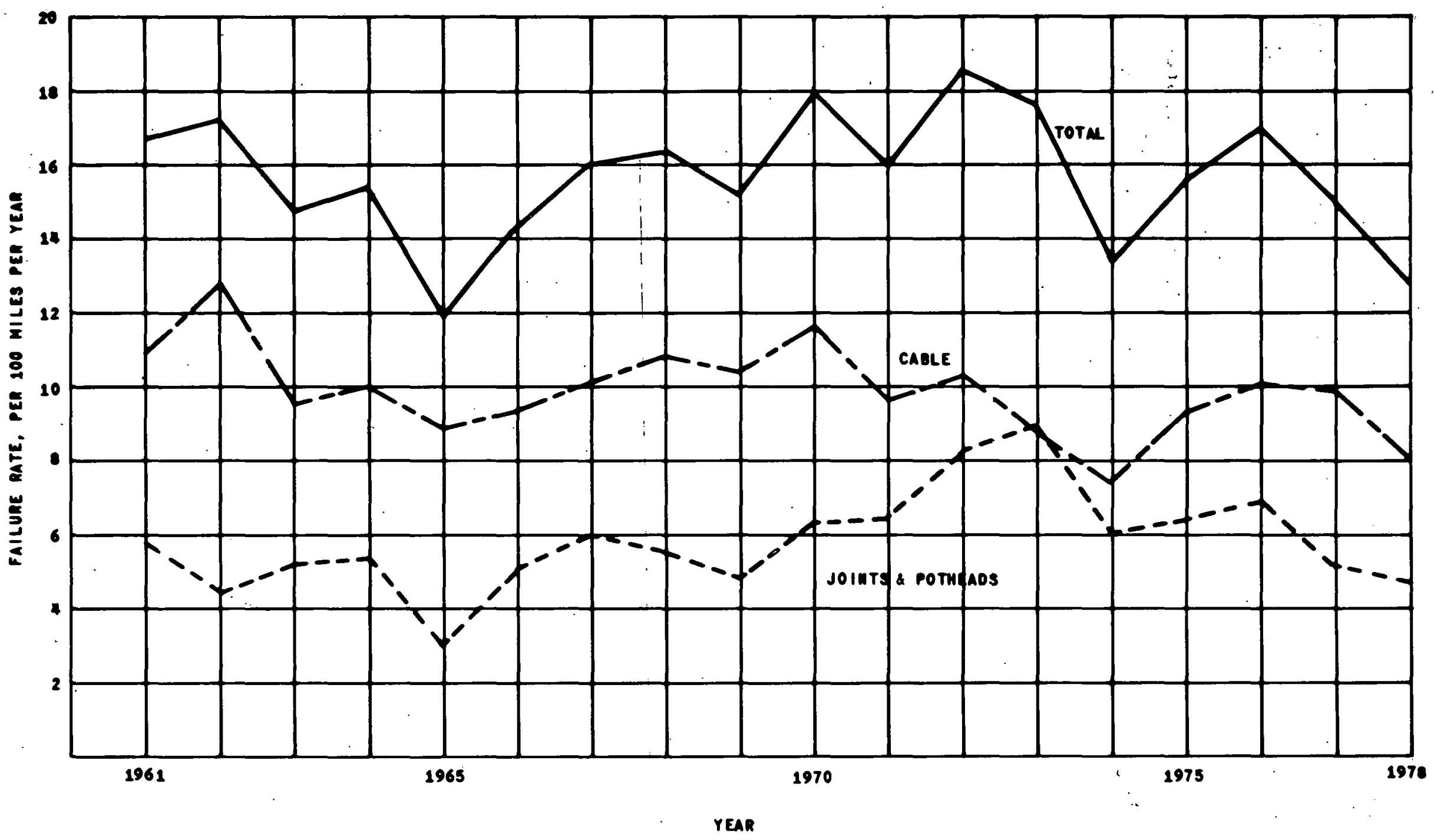


TABLE D-I

BOSTON EDISON COMPANY

CABLE SYSTEM FAILURE RATES

\begin{tabular}{|c|c|c|c|c|c|}
\hline Year & $\begin{array}{l}\text { Joints \& } \\
\text { Potheads } \\
\end{array}$ & Cable & Total & $\begin{array}{c}\text { Cable } \\
\text { Length, Mi. }\end{array}$ & $\begin{array}{l}\text { Failure Rate } \\
\text { Per } 100 \text { Miles } \\
\text { Per Year } \\
\end{array}$ \\
\hline $\begin{array}{l}1958 \\
1959\end{array}$ & $\begin{array}{l}42 \\
49\end{array}$ & $\begin{array}{l}126 \\
158\end{array}$ & $\begin{array}{l}168 \\
207\end{array}$ & $\begin{array}{l}1348 \\
1368\end{array}$ & $\begin{array}{l}12.46 \\
15.13\end{array}$ \\
\hline $\begin{array}{l}1960 \\
1961 \\
1962 \\
1963 \\
1964\end{array}$ & $\begin{array}{l}55 \\
82 \\
65 \\
79 \\
82\end{array}$ & $\begin{array}{l}142 \\
156 \\
189 \\
144 \\
153\end{array}$ & $\begin{array}{l}197 \\
238 \\
254 \\
223 \\
235\end{array}$ & $\begin{array}{l}1397 \\
1430 \\
1475 \\
1517 \\
1527\end{array}$ & $\begin{array}{l}14.10 \\
16.64 \\
17.22 \\
14.70 \\
15.39\end{array}$ \\
\hline $\begin{array}{l}1965 \\
1966 \\
1967 \\
1968 \\
1969\end{array}$ & $\begin{array}{l}47 \\
80 \\
99 \\
96 \\
86\end{array}$ & $\begin{array}{l}140 \\
148 \\
168 \\
188 \\
187\end{array}$ & $\begin{array}{l}187 \\
228 \\
267 \\
284 \\
273\end{array}$ & $\begin{array}{l}1580 \\
1590 \\
1660 \\
1740 \\
1803\end{array}$ & $\begin{array}{l}11.89 \\
14.34 \\
16.08 \\
16.32 \\
15.14\end{array}$ \\
\hline $\begin{array}{r}1970 \\
1971 \\
.1972 \\
1973 \\
1974\end{array}$ & $\begin{array}{l}118 \\
123 \\
161 \\
162 \\
117\end{array}$ & $\begin{array}{l}216 \\
185 \\
202 \\
158 \\
142\end{array}$ & $\begin{array}{l}334 \\
308 \\
363 \\
320 \\
259\end{array}$ & $\begin{array}{l}1870 \\
1930 \\
1958 \\
1818 \\
1941\end{array}$ & $\begin{array}{l}17.86 \\
15.96 \\
18.54 \\
17.60 \\
13.34\end{array}$ \\
\hline $\begin{array}{l}1975 \\
1976 \\
1977 \\
1978\end{array}$ & $\begin{array}{l}126 \\
145 \\
111 \\
104 \\
\end{array}$ & $\begin{array}{r}183 \\
209 \\
215 \\
177 \\
\end{array}$ & $\begin{array}{l}309 \\
354 \\
326 \\
281 \\
\end{array}$ & $\begin{array}{l}1984 \\
2084 \\
2171 \\
2200\end{array}$ & $\begin{array}{l}15.57 \\
16.99 \\
15.02 \\
12.77 \\
\end{array}$ \\
\hline Total & 2029 & 3586 & 5615 & & 15.43 \\
\hline
\end{tabular}


BACK BAY AC NETWORK

$14 \mathrm{kV}$ SYSTEM CABLE FAILURES

$$
\text { 1973-1979 }
$$

Failures

\begin{tabular}{|c|c|}
\hline Cable & Join \\
\hline 5 & 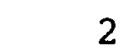 \\
\hline 4 & \\
\hline 3 & 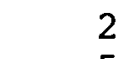 \\
\hline 5 & \\
\hline
\end{tabular}

1N22

$1 \mathrm{~N} 23$

$1 \mathrm{~N} 24$

$1 \mathrm{~N} 25$

$1 \mathrm{~N} 32$

$1 \mathrm{~N} 33$

$1 N 34$

1N35

$1 \mathrm{~N} 42$

$1 \mathrm{~N} 43$

1N44

1N45

Total

3
6
2
1

7

0

u

2

$\begin{array}{r}3 \\ 6 \\ 3 \\ 3 \\ \hline\end{array}$

53
Cable Length, Mi.

6.15

9.27

6.33

9.18

10.35

10.41

7.89

6.33

0.19

5.88

4.02

7.77

8.97

8.13

8.28

8.82

125.97
Failure Rate, Per $100 \mathrm{Mi}$.

Per Year

19.0

12.0

13.2

$18: 2$

4.8

16.0

8.4

5.3

26.5

0

0

8.6

9.3

12.3

8.1

11.3,

11.4 


\section{APPENDIX E \\ COST OF INTERRUPTIONS}

The Boston Edison Company has prepared a statement of the cost of the five outages through November 15, 1979 . Table E-I shows that the total cost is estimated to be $\$ 513,750$. This value represents only the cost of materials used and line and repair crews directly assigned to the work. No allowance is made for engineering costs, overheads, or management expenses. In addition, the cost of lost revenue and customer claims have not been estimated or included by Boston Edison.

The outage duration for the various interruptions, together with recorded substation meter readings at the time of the beginning of the interruptions, can be used to derive a reasonable estinlate of the oulage magnitude in terms of cncrgy not delivered to the customers. Typical load pattern information is also used in the derivation. Using this approach, the energy delivery curtailment was approximately as follows:

\begin{tabular}{ccc}
$\begin{array}{c}\text { Normal Peak } \\
\text { Load, } \mathrm{kW}\end{array}$ & $\begin{array}{c}\text { Time out of } \\
\text { Service } \\
\text { Hrs-Min. }\end{array}$ & $\begin{array}{c}\text { Estimated } \\
\text { Curtailment } \\
\mathrm{kWh}\end{array}$ \\
\hline
\end{tabular}

Back Bay Area:

Beacon St. Sta.

18,090

$0-35$

7,600

South Grid

26,100

4-42

88,000

North Grid

31,320

$38-10$

857,100

Total Back Bay

75,510

952,700 


\begin{tabular}{|c|c|c|c|}
\hline & $\begin{array}{c}\text { Normal Peak } \\
\text { Load, } \mathrm{kW} \\
\end{array}$ & $\begin{array}{c}\text { Time Out of } \\
\text { Service } \\
\text { Hrs-Min. }\end{array}$ & $\begin{array}{l}\text { Estimated } \\
\text { Curtailment } \\
\mathrm{kWh} \\
\end{array}$ \\
\hline Brighton & 125,000 & $4-09$ (avg) & 490,700 \\
\hline Chelsea/East Boston & 32,000 & $1-22$ (avg) & 43,700 \\
\hline Wellesley & 8,530 & $32-12$ & 82,400 \\
\hline Roslindale & 8,100 & $3-48(a v g)$ & 35,700 \\
\hline Total & & & $1,605,200$ \\
\hline
\end{tabular}

About 95,000 customers were involved in the five outages. Almost all of them were either residential or commercial. If this group of customers conforms to Boston Edison system-wide averages, 84,000 of them were residential, while 11,000 were commercial. However, 64 percent of the energy would have been consumed by the commercial customers, with 36 percent consumed by the residential customers.

The revenue lost by Boston Edison can be estimated on the basis of average revenue per.kWh for each class of customer, but excluding demand charge component. On this basis, the average revenue per $\mathrm{kWh}$ in 1978 was $5.85 \mathrm{c}$ and $4.08 \mathrm{f}$ for residential and commercial customers, respectively.

Using these values, the revenue lost to Boston Edison during these outages can be estimated as follows:

$$
\begin{aligned}
& \$ 33,800 \text { - residential } \\
& \frac{41,900-\text { commercial }}{\$ 75,700-\text { total }}
\end{aligned}
$$


of course, energy not sold was also not generated, and there was a resulting fuel saving. Based.on system average, this saving was about $1.68 \%$ per $\mathrm{kWh}$, or a total of $\$ 27,000$ for the energy curtailment. Thus, the loss to Boston Edison was about $\$ 48,700$ as a consequence of lost revenue.

This lost revenue can be considered to be an expense analogous to the service restoration expense shown on Table E-I. If they are added together, the total cost to Boston Edison for the outages was about $\$ 562,000$. 
TABLE E-I

BOSTON EDISON COMPANY

ESTIMATED COST OF OUTAGES

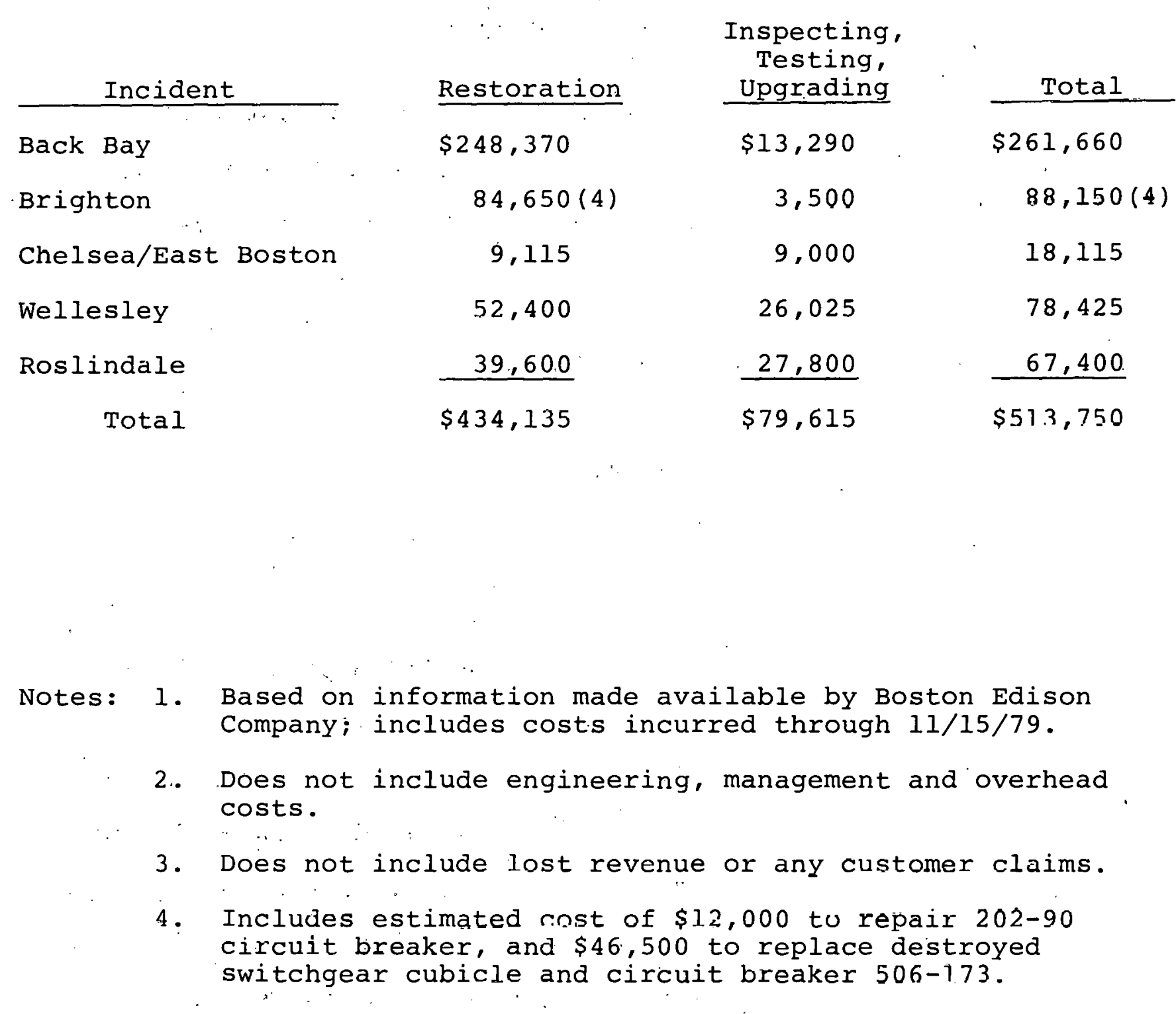




\section{APPENDIX F \\ DISTRIBUTION SYSTEMS}

Electric distribution systems may be classified according to the manner of delivery of power, including provision of alternate supply sources. The most common are:

- Radial

- Radial-Multiple Supply

- Primary Network

- Secondary Network

- Spot Network

RADIAL SYSTEM

The radial system is the simplest type of distribution. A customer is supplied by means of a single primary circuit (14 kV, for:example) one distribution transformer, and one secondary circuit $(240 / 120 \mathrm{~V}$ or $208 \mathrm{Y} / 120 \mathrm{~V}$, for example). Al1 of these elements are in series and a fault in any one of them results in a power interruption to all of the customers located beyond the protective device which clears the fault. There is noialternate supply and service can be restored only after repairs have been made. Continuity of service can be improved by insertion of sectionalizing protective devices, so that the substation circuit breaker does not open for faults located beyond such devices.

Radial systems are commonly used for overhead systems, particularly in low load-density areas. In general, dàmage to lines or equipment can be quickly located; and 
repairs can be made expeditiously. However, such systems are not generally suitable for underground distribution because of the time required for making repairs in case of failure of a system element.

This type system is not used in any of the Boston Edison Company areas involved in this report.

A radial system is illustrated by Exhibit F-1.

\section{RADIAL-MÜLTIPLE SUPPLY}

A variation of the radial system occurs when primary circuits are cunnected together by normally-open switches nr when a normally-open connection is available to another substation. Customers outage due to a fault can be localized by means of proper operation of switches or circuit breakers. In some cases, entire circuits can be switched to an alternate substation so that a substation can be removed from service without an interruption. The switching is usually accomplished manually, but automatic operation or remote control by operators is used to some extent. On underground systems, sw1tches are usually provided at each transformer location, so that the open point may be conveniently relocated, usually for service restoration after a cable fault.

This arrangement is extensively used for both overhead and underground distribution. It is quite common on the Boston Edison system. None of the outages discussed in this report 
occurred on precisely this type system. However, the power supply to Wellesley is a variation of such a system, with four circuits in a single conduit system operating in parallel to feed distribution load. The Roslindale system is somewhat similar, except that two $14 \mathrm{kV}$ circuits are brought to each load center.

Exhibit $\mathrm{F}-2$ shows a radial system with multiple supply.

PRIMARY NETWORK

A primary network system has a group of primary circuits supplied by several substations, all interconnected with all switches and circuit breakers normally closed. The purpose is to localize outages caused by primary faults by means of automatic circuit breaker operation. This involves a complex and expensive control scheme for the protective devices. Power flow across the system, that should be carried by highervoltage transmission, can occur on the primary lines. This can load them so that there is little remaining capacity for distribution load. There are several primary networks in operation in the United States; but their cost, complexity, and limited benefits derived when compared to other systems are factors which have retarded their general application. On the Boston Edison Company system, a primary network would typically operate at $14 \mathrm{kV}$.

Exhibit $\mathrm{F}-3$ shows a primary network. 


\section{SECONDARY NETWORK}

The secondary network system is used to provide the maximum possible reliability to densely populated load areas. It is specially applicable to areas such as Back Bay north of Boylston street, where there are a large number of customers with small or moderate loads spaced close together.

This system. features a grid (or "network") composed of cables operating at secondary voltage. The voltage is commonly $208 \mathrm{Y} / 120 \mathrm{~V}$, so that customers will have $120 \mathrm{~V}$ for lighting and small appliances, and $208 \mathrm{~V}$, three-phase, for larger loads and appliances. A few general networks have been constructed... in recent years using $480 \mathrm{Y} / 277 \mathrm{~V}$, but these are not common, and this voltage is usually applied to spot network systems. Exhibit F-4 shows a secondary network. A fault anywhere on the system can be sustained without loss of power to any customer, except in the case of a secondary fault on a cable section directly connected to customer service. Secondary networks are designed so that all of the transformers supplied by one primary $(14 \mathrm{kV})$ feeder can be taken out of service without any interruption to a customer. On larger networks, several feeders can be removed. For example, the Back Bay. Network can sustain the loss of three primary feeders and the. transformers they supply without customer interruption. 
All elements of a secondary network are permanently joined together. In such a system, a fault on a primary circuit can be fed by another through the secondary grid. To prevent this, network protectors are used on all transformers. This device opens very quickly in case of power flow from secondary to primary through a transformer.

Faults on a $208 \mathrm{Y} / 120 \mathrm{~V}$ cable usually burn clear; thus extingulshing themselvees, with no circuit' element going out of service. However, this cannot be depended upon with certainty. Most utilities insert "limiters," which are high capacity fuses calibrated according to cable size, in the secondary grid. These limiters blow in case of secondary system faults, thus isolating the faulted section.

A secondary grid is actually composed of several cables in parallel. Boston Edison commonly uses seven $4 / 0$ AWG cables. The total capacity of this configuration is about $450 \mathrm{kVA}$. This large capacity is necessary because power must be transmitted at secondary voltage in case of transformer outages.

SPOT NETWORK

Loads in lárge high-rise buildings have increased dramatically in recent years because of air-conditioning and other loads. This causes a higher secondary voltage than $208 \mathrm{Y} / 120 \mathrm{~V}$ to be necessary and/or economical. As a result, such buildings commonly have $480 \mathrm{Y} / 277 \mathrm{~V}$ distribution systems, which cannot be fed from existing secondary networks. In 
addition, new high-rise buildings frequently feature "green areas" or open space at ground level, such as the Prudential Center in Boston. Parking lots also create such areas with little electrical load. Power transmission at secondary voltage through such areas to large loads would be difficilt and prohibitively expensive.

For these reasons, "spot network" is widely used for such buildings. Two (or more) primary circuits feed two (or more) transformers stepping the voltage down to $4804 / 2 \% \mathrm{~V}$ or $208 \mathrm{y} / 120 \mathrm{~V}$ : The low-voltage system is solidly connected at the transformer, so that a network is created. The system requires network protectors, as in the general network.

The secondary distribution system is restricted to one building or a building complex. It is usually owned by the customer, although there are exceptions.

A spot network can susțain, without load interruption, the loss of one or more primary circuits or one or more stepdown transformers, depending on the design criteria

Exhibit F-5 shows a spot-network power supply.

A feature of all network systems is that the power supply must come from one substation. 


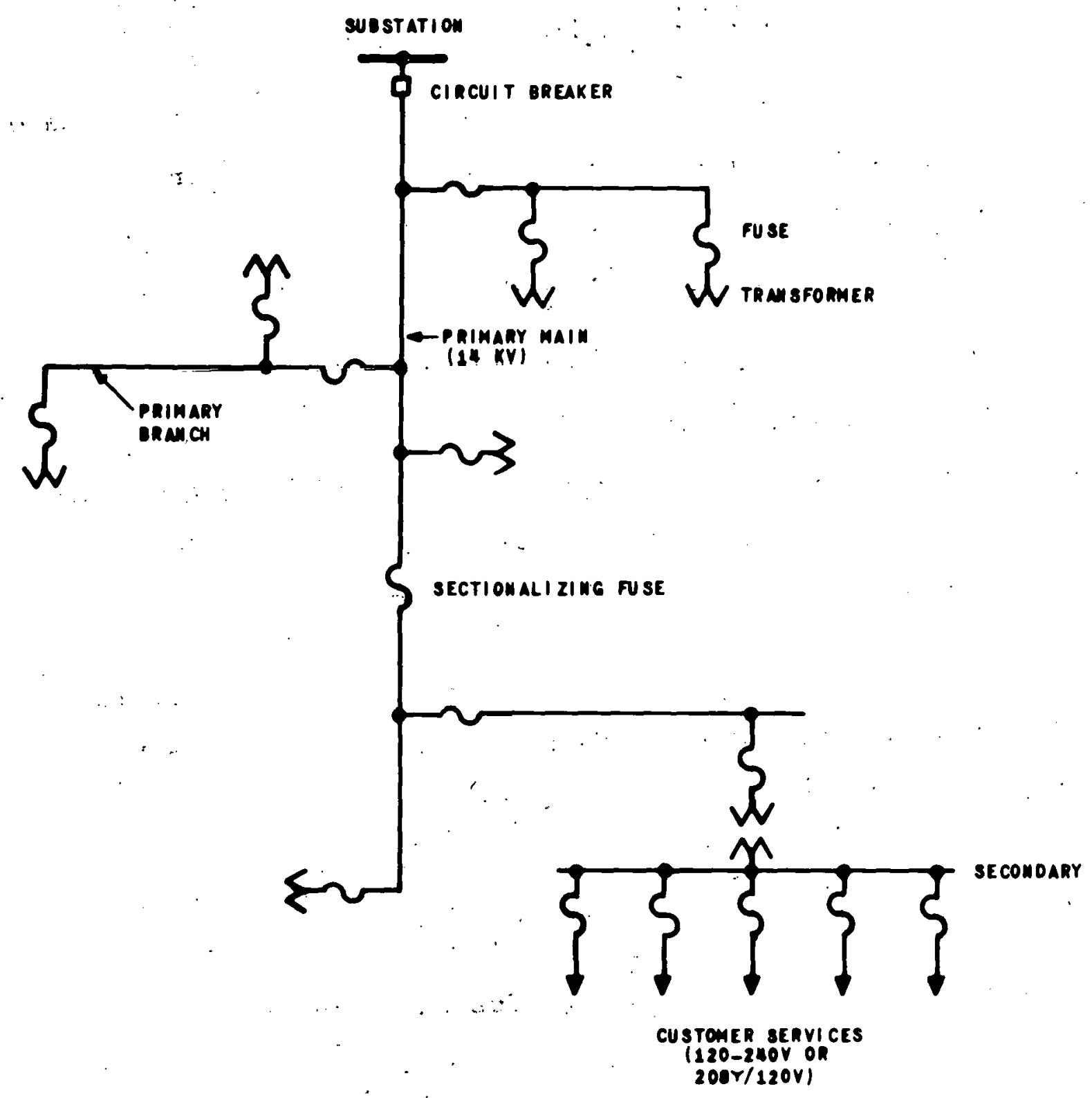

RADIAL DISTRIBUTION SYSTEM 


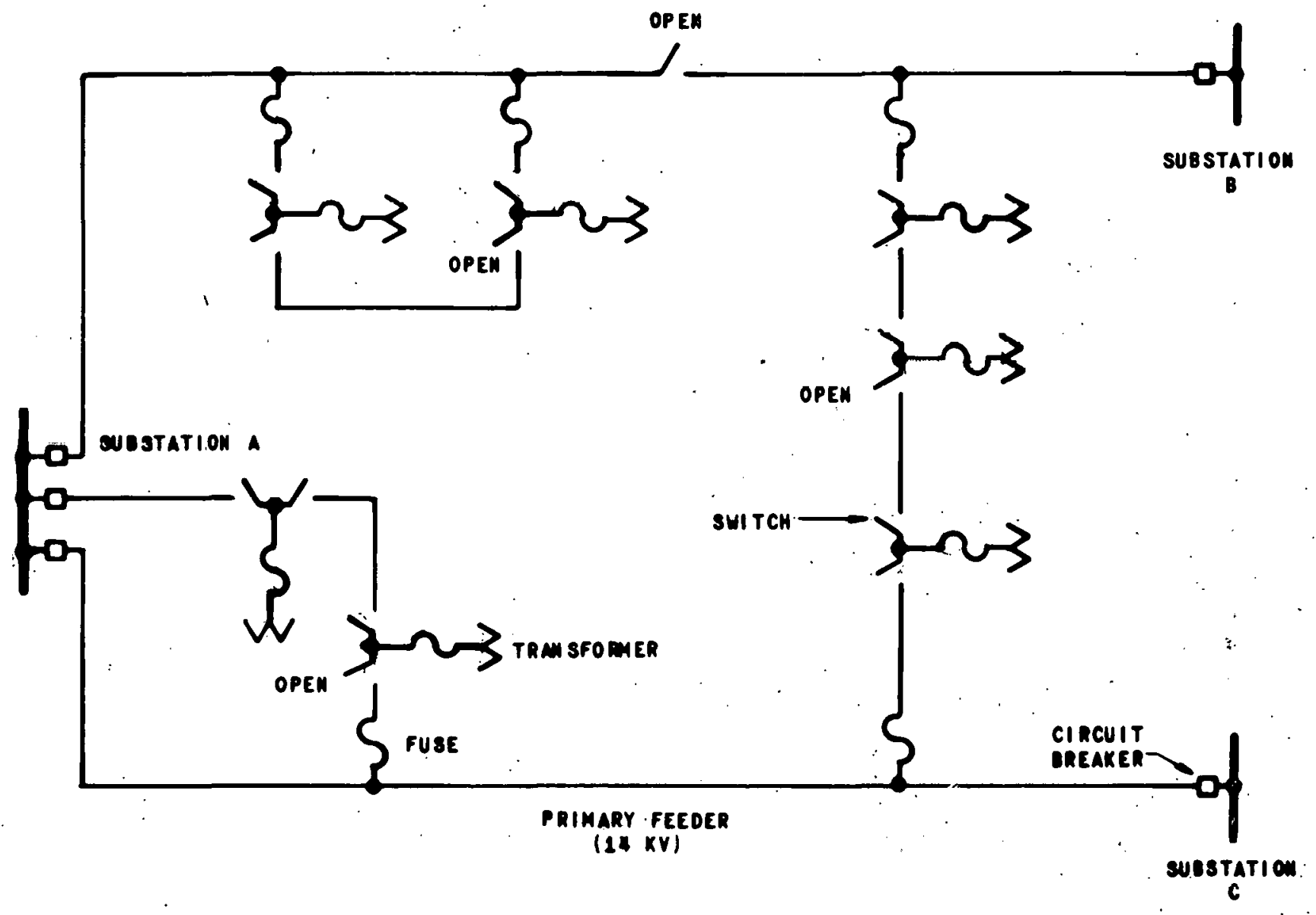

RADIAL SYSTEM

MULTIPLE SUPPLY 


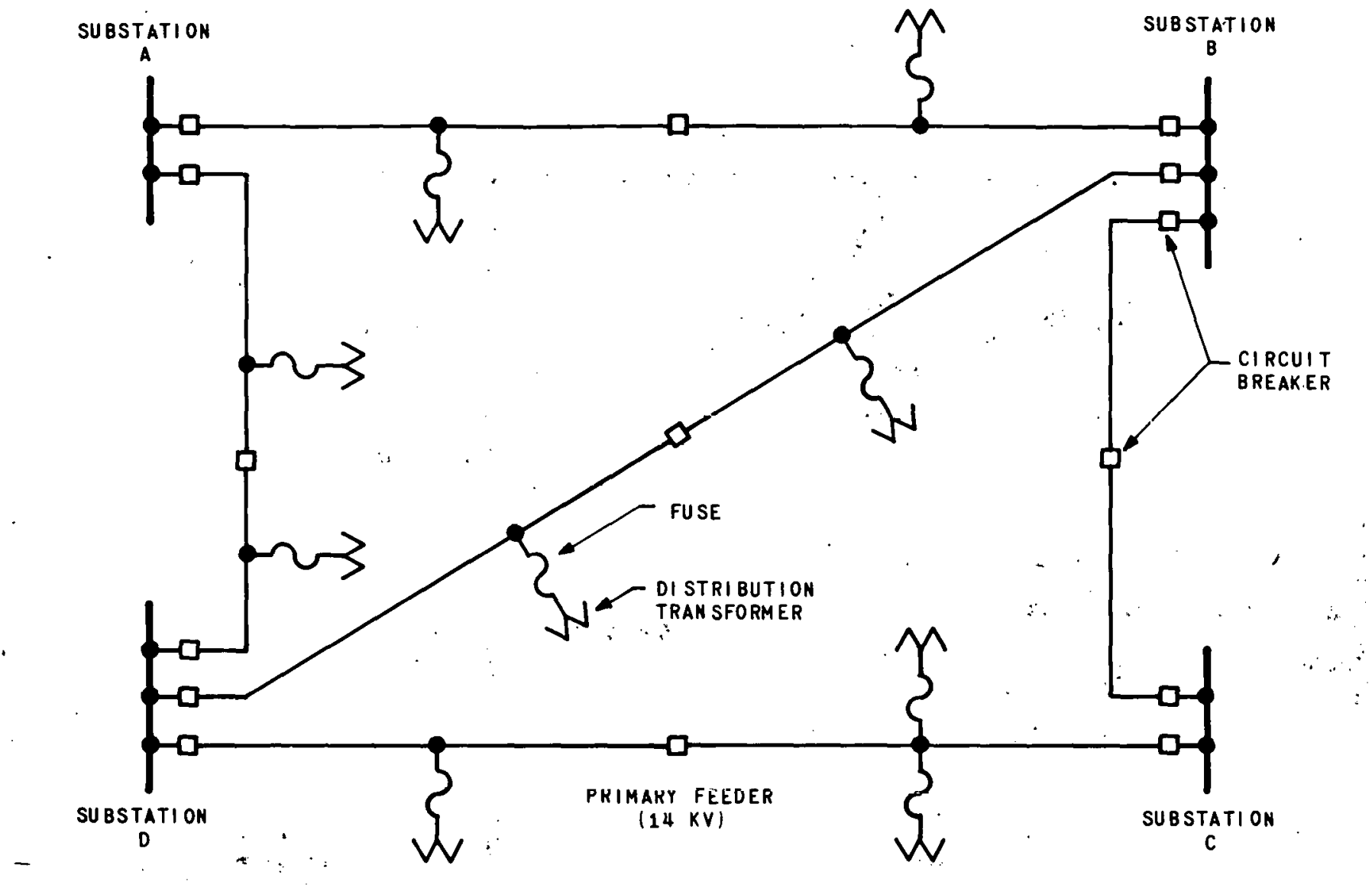

MOTE: ALL CIRCUIT BREAKERS NORMALLY CLOSED. 


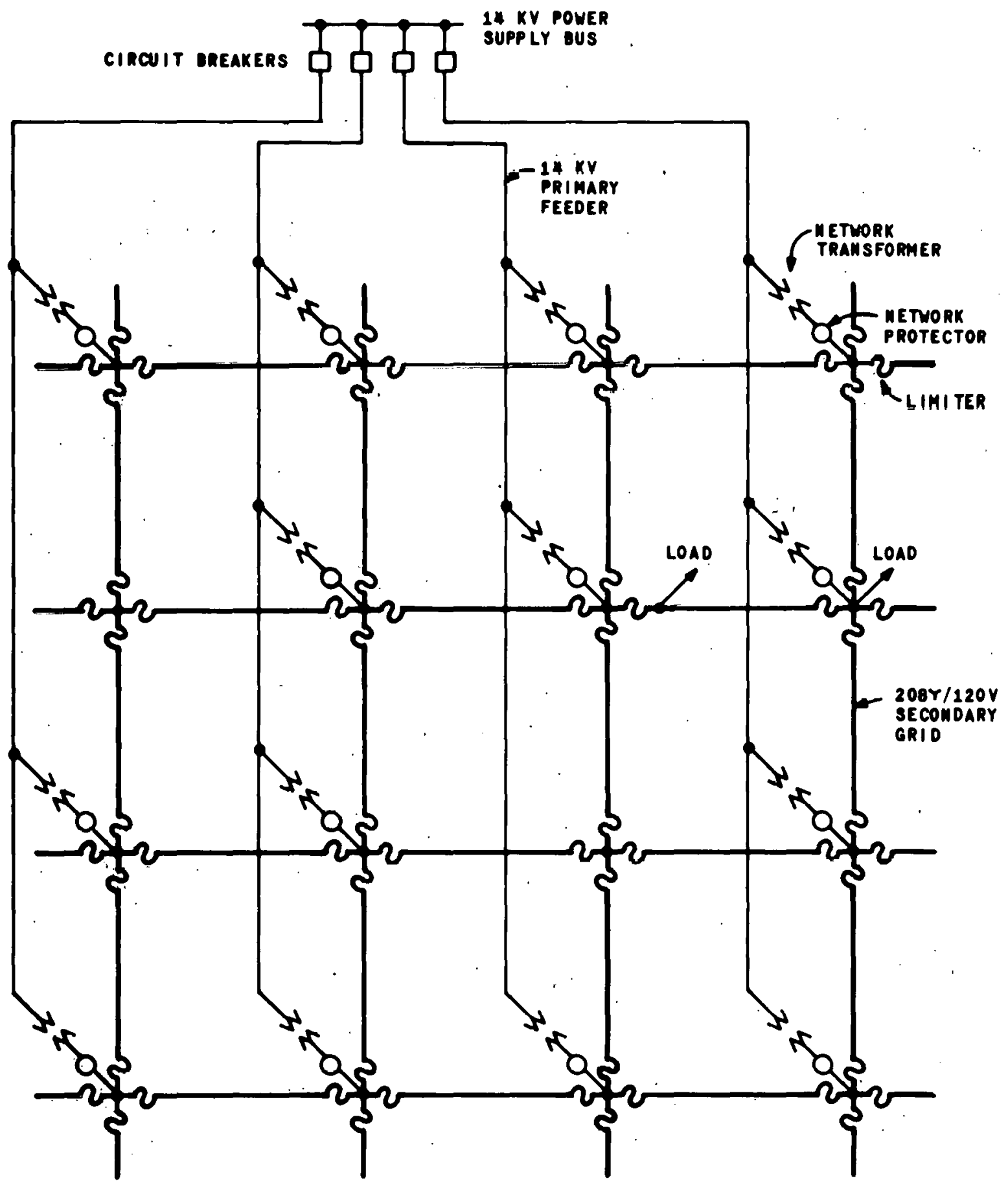

SECONDARY NETWORK DISTRIBUTION SYSTEM 
EXHIBIT F-5

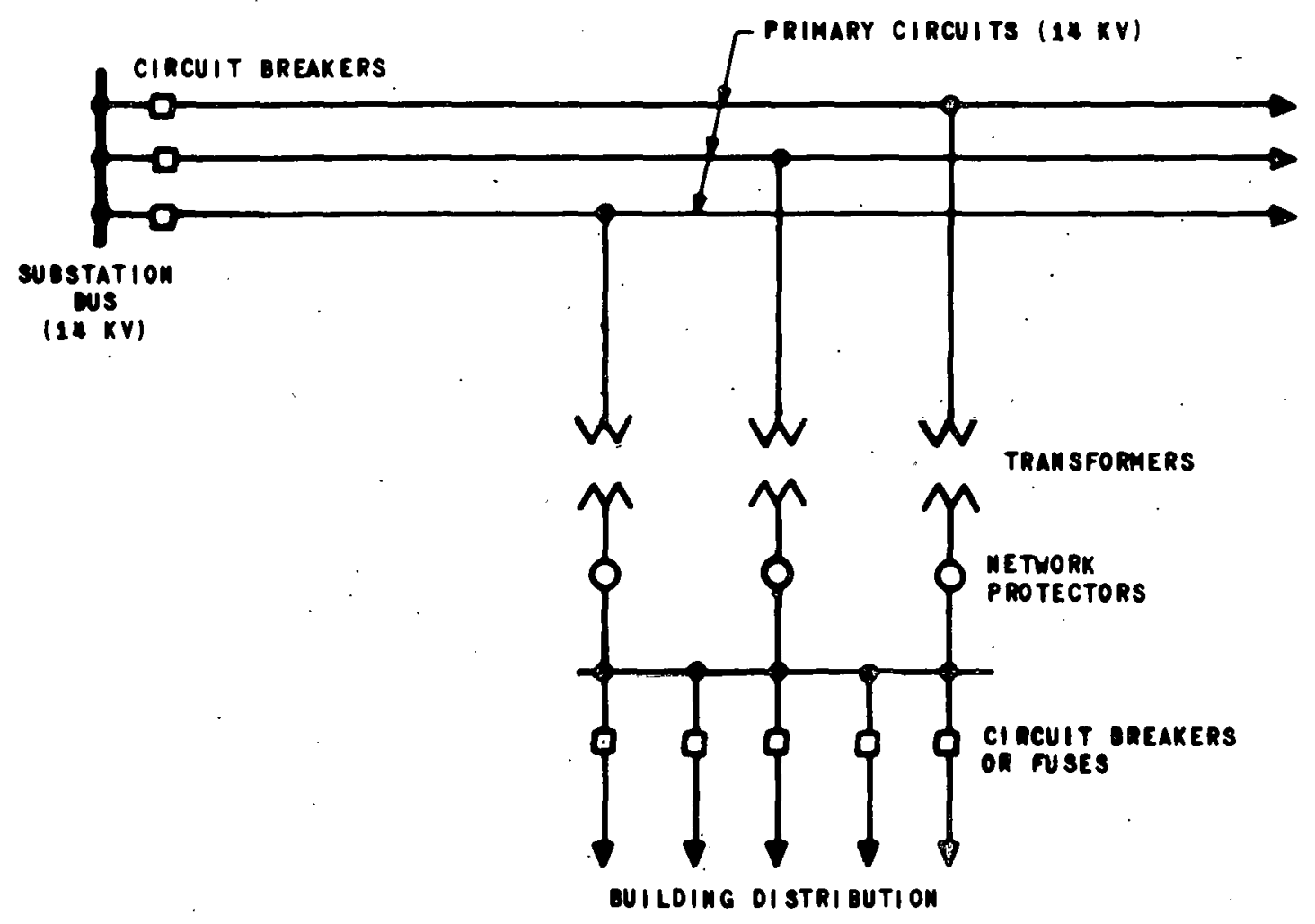

SPOT NETWORK 


\section{APPENDIX G \\ GLOSSARY}

AC - alternating current, a periodic current that reverses at regularly recurring intervals of time. In U.S. power systems, the standard ac frequency is 60 cycles per second.

Allowable operating limit - an operating term describing a limit of safe operation or a limit beyond which equipment damage may occur.

Ammeter - an instrument to measure electric current.

Annual load factor - the ratio of the average load during a year to the peak load occurring during the year.

Arc-proofing - a protective covering, the purpose of which is to protect equipment (as a cable) from damage resulting from fire or electrical arcs from external sources (as other cables).

Asbestos cement - a material containing asbestos and cement, commonly fabricated into sheets and to be used as barriers between electric equipment for protection of one against failure of another.

Assoriated feeners - primary (1.4 kV) distribution circuit.s which supply the same load locations.

AWG - American Wire Gauge, a system of electrical conductor cross-sectional area measurement, describing. wires equal to or smaller than 0.166 square inches ( $4 / 0$ AWG).

Bulk power station - a power plant or a substation which serves as the power supply for a large number of distribution or transmission lines.

Bus - a switchgear assembly which serves as a common connection for several circuits.

Bus, double - an arrangement of duplicate buses, with provision for connection of electrical circuits to either or both; used for reliability and flexibility of electric supply. 
Bus, ring - an arrangement whereby electric circuits are connected to a bus which has its two ends connected together, so that a single open point will not result in any interruption to power supply.

Cable - an electric conductor which is insulated from other electric conductors and from all external objects and the environment.

Cable, overhead spacer - a cable system designed to be supported by poles, with the conductor separated by spacers (usually polyethylene or porcelain) at intervals of about 30 feet.

Cable, PILC - cable with oil-impregnated paper insulation, with a lead sheath overall for protection against moisture.

Cable, primary - cable used to transmit power at primary voltage $(14 \mathrm{kV})$ between sulstatiuns dol distribution transformer locations.

Cable, secondary - cable used to transmit power at secondary voltage (usually $480 \mathrm{~V}$ and below) between distribution transformers and customer service connections or utilization equipment.

Cable, solid dielectric - cable insulated with a solid material, such as rubber, polyethylene, or ethylene propylene.

Cable, transmission - cable used to transmit power at transmission voltage (above $14 \mathrm{kV}$, usually $115 \mathrm{kV}$ on the Boston Edison system) from bulk supply stations to distribution substations.

Cable, shielded - cable which has a grounded conductor (usually a copper tape) in contact with the outside of the insulation.

Cable, nonshielded (or belted) - cable without shielding, but commonly with a "belt," or supplementary layer of material between the conductors. At voltages of $14 \mathrm{kV}$ and above, an obsolescent construction.

Cathodic protection - a method of corrosion protection, in which current entering or leaving the protected material is controiled. 
Circuit breaker - a device that automatically removes power supply from an element of the power system, usually resulting from a failure or an overload.

Circuit breaker, primary - a circuit breaker in the primary $(14 \mathrm{kV})$ system, usually located at a substation.

Circuit breaker, secondary - a circuit breaker in the secondary (480V and below) system, usually at a distribution transformer location.

Cold pickup - restoration of power after load has been removed for some time, so that ail automatic devices start simultaneously. This causes a current surge, which sometimes causes circuit breakers to open. In this event it is necessary to sectionalize circuits before restoring power to reduce this effect.

Contingency plans - plans, usually pre-arranged, for operation of an electric system under abnormal conditions, usually with some elements out of service.

CRT display - a display on a cathode-ray tube, as television or a test instrument.

Cubicle, metering and control - a compartment, usually in a substation, containing transformer and other devices used to derive quantities for metering and control systems.

Cut-and-cap - an emergency operation whereby electric cables are cut at a failure location, and capped, so that service may be restored to loads between the failure location and the power-supply point.

DC - direct current, a unidirectional current. In the context of power supply, a dc distribution system is obsolete.

Demand - a term applied to the electric load that a power system is required to supply.

Dispatcher - an officer of the utility, whose responsibility it is to determine system configuration (i.e. manner of system connections) during both normal and emergency conditions.

Distribution system - the circuits or network used to carry electric energy from the power source to the customers. Several types are described in Appendix F. 
Double contingency - a situation with two normally-available system elements out of service.

Duct bank - a system of pipes placed underground, commonly in city streets, in which cables are placed for electric power distribution.

Failure - an occurrence causing inability of a power system element to perform its intended function.

Failure, simultaneous - a failure that involves two or more system'elements becoming unavailable at the same time, but not necessarily due to the same cause.

Failure, multiple - a failure that involves two or more system elements becoming unavailable, not necessarily at the same time, nor due to the same cause.

Failure, cascading - a failure that involves two or more system elements, usually leading to a suspension of service, whereby subsequent failures are caused by earlier failures (i.e. a "domino" effect).

Fault - a failure in the electric system, resulting from either an open circuit or an insulation failure (short circuit).

Fault, arcing - a short circuit in which the conductor does not actually contact ground or another conductor, but is close enough so that high currents flow through the air, resulting in a sustained electric arc.

Fault, bus - a fault occurring on a bus in a substation.

Fault, cable - a fault occurring in an electric cable.

Fault, clearing - the process of reiliovilig a fault (uoually a short-circuit) from the electric system, usually by means of operation of a circuit breaker, switch or fuse.

Feeder - a distribution system circuit, either primary (14 kV) or secondary $(480 \mathrm{~V}$ and below).

Fuse - a protective device consisting of an element that opens as a result of heat generated by passage of excessive current through it.

Jumper, temporary overground - a temporary cable used to bypass a cable in an underground system. Such a jumper is usually placed on the ground surface or supported by low structures. 
k - kilo, a prefix meaning one thousand, as in kW (kilowatt), $\mathrm{kWh}$ (kilowatt-hour), kVA (kilovolt-ampere), kV (kilovolt).

kcmil - thousand circular mil; a. size measuring system, usually used for conductors larger than 4/0 AWG. 1 circular mil is equal to $7.854 \times 10^{-7}$ square inches.

Limiter - a fuse which is placed in an electric cable to open in case of a short circuit, for the purpose of isolating the faulted cable, with all others continuing in service.

Load center - a location with a large electric load, relative to the surrounding area.

M - mega, a prefix meaning one million, as in MW (megawatt), MVA (megavolt-ampere).

Maintenance, cable - preventive procedures consisting of inspection, testing and repair of electric cable.

Mimic board - a system display, usually wall-sized, which shows electric system generators, transmission lines, transformers, and distribution lines. Provision is usually made so that availability of system elements and the position of all switches and circuit breakers is indicated by appropriate lights and/or symbols.

Network - an electric transmission or distribution system. Strictly defined, a network refers only to a multiple supply part of the system with all switches and circuit breakers closed.

Overreach - a situation where a circuit breaker is incorrectly caused to open by a relay, when a circuit breaker closer to the fault should have opened instead.

Pad-mounted - installed on the surface, as a pad-mounted transformer. Usually refers to an enclosed device which is on public or private property.

Protector, network - An assembly comprising a circuit breaker and control devices for automatically disconnecting a network transformer from the network in the event of power flow from the secondary (low-voltage side) to the primary (high voltage side). The network protector is electrically located between the transformer secondary and the network. 
Rectifier, solid state - a devicé for supplying a dc distribution system from an ac source. Solid state devices such as diodes are used instead of vacuum or gas-filled tubes in the internal circuits.

Relay - a device which interprets system conditions (current flow quantity, for example) and responds to cause operation of circuit breakers or other devices when pre-determined conditions (such as excessive current) are satisfied.

Relay, overcurrent - a relay that is controlled by current flow.

Relay, differential - a relay that functions by reason of llie diffeieliee between two quantiticc, for example, when the current or power entering a substation bus is not equal to the current or power leaving it.

Relay, directional - a relay that operates on current or power flow in one direction only.

Relayed out of service - a term used to indicate that a system element, such as a distribution circuit, has been removed from service by a protective device opening as a result of protective relay operation.

Switching and tagging - a system of control whereby switches on an electric system are opened to isolate a part of it, with tags being placed to prevent inadvertent erroneous operation during maintenance period's; usually a safety procedure.

System Control Center - the operating control center of a power system, where decisions pertaining to generation schedules, purchase or sale of power, and operation of major transmission system elements are made. Much of the control and many of the decisions may be madc by digital or analog computers with operator cognizance.

Telemetering - a system whereby metering and control information is transmitted between a substation or load center and a control center for remote control and supervision.

Test, high-voltage - a test whereby a voltage higher than normal operating voltage is impressed on equipment in order to ascertain its suitability for routine service. 
Testing program, cable - a planned program of routine highvoltage and insulation resistance testing of electrical cable after installation and operation to determine whether the cable under test is suitable for further operation.

Transformer - a device to transform electric energy from one voltage to another.

Transformer, distribution - a transformer located on a distribution system that transforms electric energy from primary voltage $(14 \mathrm{kV})$ to secondary voltage ( $480 \mathrm{~V}$ or below) so that it can be used by customers' lighting or power equipment.

Transformer, network - a distribution transformer specially designed and constructed for service to a secondary network, commonly for submersible service and usually for use in conjunction with a network protector.

Voltage Nomenclatures - the system voltage designations as used in this report are:

$115 \mathrm{kV}$ - a systemwide transmission system with $115 \mathrm{kV}$ between phase conductors, used by Boston Edison

$25 \mathrm{kV}$ - a local transmission system with $25 \mathrm{kV}$ between phase conductors, used to supply a few (2 to 4) substations (sometimes called sub-transmission)

$13.8 \mathrm{Y} / 8.0 \mathrm{kV}$ - a 4-wire primary distribution system, with $13.8 \mathrm{kV}$ between phase conductors and $8.0 \mathrm{kV}$ between each phase conductor and the grounded neutral conductor. Used to supply either three-phase or single-phase distribution transformers.

$14 \mathrm{kV}$ - a short-form designation for a $13.8 \mathrm{Y} / 8.0 \mathrm{kV}$ primary distribution voltage.

$480 Y / 277 \mathrm{~V}$-a 4-wire secondary distribution system, with $480 \mathrm{~V}$ between phase conductors and $277 \mathrm{~V}$ between each phase conductor and the grounded neutral conductor. Used to supply $480 \mathrm{~V}$ for customer three-phase load (usually motors), or $27.7 \mathrm{~V}$ for single-phase load (such as lighting and single-phase motors). Commonly used for spot networks and large customers. 
$480 \mathrm{~V}$ - a short-form designation for a $480 \mathrm{Y} / 277 \mathrm{~V}$ secondary distribution voltage.

$208 Y / 120 \mathrm{~V}$ - a 4-wire secondary distribution system, with $208 \mathrm{~V}$ between phase conductors and $120 \mathrm{~V}$ between each phase conductor and the grounded neutral conductor. Used to supply $208 \mathrm{~V}$ for customer three-phase load (usually motors) or $120 \mathrm{~V}$ for single-phase load (such as lighting and single-phase motors). Common $\perp$ y used for general networks, such as the Back Bay Network.

$208 \mathrm{~V}$ - a short-form designation for a $208 \mathrm{Y} / 120 \mathrm{~V}$ secondary distribution voltage.

120/240 v - a 3-wire single-phase secondary distribution system (either ac or dc) with $240 \mathrm{~V}$ between two of the conductors and $120 \mathrm{~V}$ belweil each of them and the grounded neutral. commonly used to supply residential or small commercial customers.

Voltage transient - a temporary higher-than-normal voltage condition that can exist on an electrical system as a result of lightning or switching surges.

Wipe - the process used for joining of lead cable sheaths by means of application of semi-molten lead to form a mechanically strong, moisture-proof connection. 
Mr. James M. Brown, Jr.

Chief, System Reliability and

Emergency Response Branch

Economic Regulatory Administration

Department of Energy

Washington, D. C. 20461

Dear Mr. Brown:

Discussions between representatives of DOE and Boston Edison Company have indicated that our comments on the report "Outages of Electric Power Supp1y Resulting from Cable Failures, Boston Edison Company" prepared by Commonwealth Associates Inc. for you, will be incorporated into the final DOE/ERA issue. We appreciate the opportunity and accordingly, our comments are attached.

I must say that I am very upset with the report. Many of the comments in the Summary, Mitigative Measures and Restoration Measures Sections are pure conjecture and not supported by fact. Perhaps even more disturbing is the style in which these sections are prepared. Boston Edison Company, in the vast majority of cases where factual support exists has been taking action exactly along the lines of the Commonwealth Associates recommendations, as would be the case with any responsible electric utility. In addition, in most cases these actions were in process prior to the outages that triggered the investigation. This fact is silent throughout the report; therefore, an uninformed reader could only draw the conclusion that we are negligent in our service reliability responsibility. I cannot object strongly enough to this implication.

We are surprised by the lack of comment as regards Boston Edison's positive actions in what I call the "hilite" sections of the Report for two reasons (1) we believe we cooperated fully with. Commonwealth Associates during the entire investigation by making them well aware of all of the ramifications surrounding the several incidents and our many related practices and efforts; and (2) several of our efforts are acknowledged in the details of the Commonwealth Report, but not in the most commonly reviewed summary and action "hilite" sections. 
Mr. James M. Brown, Jr.

We trust that our comments are taken constructively in an effort to produce an overall report that is truthful, objective, informative and useful which I know from our discussion is your intent.

Attachments

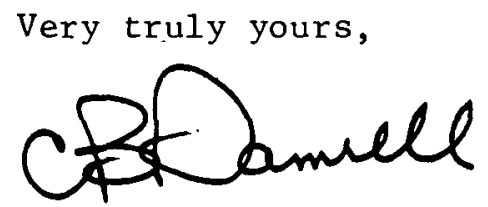

cc: Mr. W. J. White

Chief Engineer

Massachusetts DPU 


\section{COMMENTS BY BOSTON EDISON COMPANY ON REPORT ENTITLED \\ "OUTAGES OF ELECTRIC POWER SUPPLY \\ RESULTING FROM CABLE FAILURES \\ BOSTON EDISON COMPANY" \\ PREPARED BY AND FOR \\ U. S. DEPARTMENT OF ENERGY \\ ECONOMIC REGULATORY ADMINISTRATION \\ DIVISION OF POWER SUPPLY AND RELIABILITY}

BECo. does acknowledge the opportunity of commenting on this report and appreciates the DOE/ERA offer of having these comments incorporated into the final report in the interest of providing a balanced, objective document which might be helpful not only to DOE/ERA and Boston Edison Company, but also to the electric utility industry as a whole.

We note at the outset that the Company has had the benefit of reviewing the second draft of the above titled report, prepared by the Commonwealth Associates, Inc., subcontractor to the Department of Energy, Economic Regulatory Administration, Division of Power Supply and Reliability. It is our understanding that the abstract of the report which we reviewed will be replaced by a Forward, and a new section entitled "Conclusion" added along with Recommendations. These report additions will be prepared by members of the DOE/ERA staff.

Before proceeding with our commentary, it would be valuable to provide some additional background to the report. Our background comments, which follow, precede specific comments which are divided into two categories -- General and Specific.

- BACKGROUND -

On June 26, 1979, Boston Edison was requested to attend an afternoon meeting at the Engineering staff offices of the Massachusetts Department of Public Utilities (DPU). At thịs meeting with representatives of the 
DPU, Department of Energy (DOE) and Commonwealth Associates, a subcontractor of DOE, the Company was informed that DOE in cooperation with the Massachusetts DPU was actively preparing to undertake a study of five distribution incidents which occurred during the second quarter of 1979 on Boston Edison's service territory.

The reason for this meeting was to inform the Company of their intended study and to seek our cooperation in that effort. Our willingness to cooperate was openly expressed.

The five incidents which are focussed upon in this study and its subsequent report are identified as follows:

1. Back Bay Area Interruption

2. Brighton Area Interruption

3. Chelsea/East Boston Area Interruption

4. Town of Wellesley

5. Roslindale Area Outage
April 1-4, 1979

May 21, 1979

June 2, 1979

June 18,1979

June 23, 1979

It should be noted that these are not the same five incidents listed in the Thursday, August 2, 1979 Federal Register under the title, "Investigation Into Electric Power Outages in Boston, Massachusetts", by the DOE and also reported in the Augusl 13, 1979 issuc of Electrical World magarine.

Tn the course of this study, the subcontractor, Commonwealth Associates, Inc., came to Boston twice to gather information and to visit Company facilities similar to those involved in these five incidents. Formal responses were made by BECo. personnel to all written requests of the subcontractor, and on several occasions verbal responses were provided to specific questions raised during the preparation of their report. It is our belief that each response was complete and submitted in a timely fashion. 
The Company has always, as a matter of responsible management and good operating practice, prepared reports of any significant incidents on its system, notably those affecting a large number of customers. These reports address the cause, the result, actions to be taken to eliminate or reduce similar occurrences and recommendations that may be incorporated into future designs or revised operating procedures. In regard to the five incidents investigated by Commonwealth Associates, Inc., reports had already been prepared by the Company on three of the five incidents and reports were in process on the other two prior to the start of the DOE-funded investigation.

For unique occurrences such as the Back Bay area interruption of April 1-4, 1979, more detailed reports are compiled than for other large outages. A copy of each of the three reports, already prepared, was forwarded to DOE prior to their formal investigation. Two of the three were also sent to the DPU on a similar basis. The third report, Back Bay incident, included answers to specific questions posed by the DPU and provided a complete explanation of the Company's detailed investigation of the incident. The reports prepared for the Chelsea/East Boston incident of June 2 and for the Roslindale area outage of June 23 were provided to the DOE subcontractor after the first meeting with the Company.

In addition to preparing reports on significant occurrences, the Company usually forms a Task Force to review all aspects of the occurrence, the Company's response, and to recommend to top management policy or other. changes that should be considered. These Task Forces are usually formed by and report directly to a corporate officer. After the Back Bay area interruption, a Task Force was established by Mr. C. B. Damrell, Vice 
President of Engineering and Distribution, to review the Boston Edison secondary network system and to prepare a formal plan for restoration after a major secondary network disturbance.

\section{- GENERAL COMMENTS -}

Before proceeding with specific comments on the report, the Company is particularly concerned about the report itself and certain findings which we object to. The report unfairly characterizes the Company and its operating personnel as being unaware of the seriousness of these outages. It further fails to compare Edison's maintenance and operating practices to other utilities which are introduced in the report and, by inference, are far superior to Edison's. A third shortcoming is the notion that one specific situation involving switching during one of the outages is symbolic of Edison's practices and experiences in other similar situations. These failings would lead the reader to believe that the Company was unresponsive and ill-prepared to deal with the problems it faced during these outages when in fact the opposite was true. In spite of a myriad of unconnected and in some cases unpredictable circumstances, the Company was able to promptly respond to the general public, with due concern to safety, and restored electric service to the greatest number of customers at the earliest opportunity.

As a matter of policy, Boston Edison has always strịed to plan, design and operate its system consistent with good utility practices. One self-reported incident was noted in the report where an operating guideline was not correctly followed during one of the five incidents. The report through implication suggests that this is often not the case and we take exception to this incorrect conclusion. 
Furthermore, the subcontractor has visited other similar utilities to examine some of their operating and maintenance practices. From these visits, mitigative and restoration measures are suggested which may reduce the potential of future system incidents. The report fails to indicate many of the things that Bosțon Edison has been doing in each of these areas. This report is based upon incidents on the Boston Edison system. This approach leaves the reader uninformed of what we have been doing; and, even worse, the reader must therefore conclude that we do nothing in these areas. There are points brought in the report which we do not refute. We comment where appropriate in the "specific" section which follows and in some cases indicate actions being taken by the Company in response to Commonwealth Associates.

Boston Edison stands on its record to mobilize the various organizations (Operations, Engineering, and support groups) which were quickly assembled and provided valuable assistance in the restoration of service during the incidents. This response by Company personnel can be attributed in part to the Company's Major Emergency Plan of Operation which is designed to coordinate internal functions, as well as outside resources, in response to major disturbances affecting numerous customers under unusual circumstances.

Acknowledgement must be given to the excellent graphical representations put together in this report. The ability to reduce a very complex situation to a single or a series of single, simple one-line diagrams, is noteworthy. There is no doubt that some of the techniques used will be employed in future in-house reports, and we give due credit to Commonwealth Associates. 
For ease of reading, our specific comments will follow the format of the report. We will include all topical headings and will also provide either the statement itself or an abridgement so that our comment can be quickly referenced.

\section{Introduction}

"The Boston Edison Company operates 7,416 miles of distribution system conductor, contained in 1,119 miles of conduit bank. Oil-impregnated paper-insulated, lead sheathed cable is used almost exclusively."

Oil impregnated paper-insulated, lead sheathed cable is used almost exclusively on our 14 and $24 \mathrm{kV}$ distribution supply systems. The miles of distribution system conductor (7,416 miles) published in the Uniform Statistical Report (USR) and used in this report includes significant amounts of $4 \mathrm{kV}$ distribution cable which is primarily rubber and lead (R\&L).

\section{Summa ry}

Routine underground system operating and maintenance effort has declined by about $30 \%$ since 1974 , as measured by expenses corrected for inflation (Exhibit C-1).

Exhibit $C-1$ indicates that our U.G. O\&M expenses have decreased $30 \%$. However, this is not to say our attention to preventive maintenance has diminished. Faced with declining earnings we had to review completely our O\&M requirements and focus upon those areas which would provide the best cost/benefit ratio. An example of this can best be shown by the results of our O\&M efforts in one of our other secondary network grids, Atlantic Avenue. A high network feeder failure rate trend was observed particularly in 1975 /and 1976. Maintenance efforts were focussed on this area resulting in a 67 percent drop in network feeder cable test and service failures for the years 1978 and 1979. 
Appendix " $C$ " also points out that although our O\&M expenses have decreased, they still remain second highest of the five companies when based upon dollars expended on $O \& M$ versus miles of underground distribution conductor. This would indicate that our O\&M costs for U.G. are now more in line with other companies then was previously the case.

Operating procedures were not followed in the period preceeding the Chelsea/East Boston interruption.

This statement is correct. However, this fact was told to Gilbert/ Commonwealth right from the beginning. No attempt was ever made to describe the incident differently. As stated elsewhere in the report our "Guidelines for Scheduling Equipment Outages" has been revised to emphasize the importance for consideration of second-contingency outages.

Emergency situations were not recognized and acted upon quickly enough, particularly in the case of the Back Bay secondary network interruption.

This is a harsh commentary and in our opinion a completely unfounded, "Monday Morning Quarterback" statement. It means that in all four cases the seriousness of the situation was not recognized and response was not prompt. This is simply not true.

In the case of the Back Bay secondary network interruption, the seriousness of the problem was recognized immediately. The aid of the Engineering Department personnel in assessing the state of the network was quickly obtained on that Sunday afternoon and they, along with supplementary operating personnel, were on the job continuously. Load readings were taken and, as pointed out on page 28 of the DOE report, were within acceptable operating limits.

Plans were developed in early. afternoon to cut and cap feeders and personnel were assembled to assure restoration of feeders prior to Monday morning load pick-up with sufficient transformer capacity to meet this 
load. It is important to note that we attained this goal. In addition, we dealt with the interruption of the network, restoration of Station 非9, the separating of the network into two (2) grids, and restoration of the undamaged (South) grid.

Sales personnel were scheduled to be in early Monday morning to contact customers and effect load relief, if required.

In the light of these efforts, it is completely misleading to say that the seriousness of the situation was not recognized until the sixth (6) feeder tripped late Sunday evening.

When the manhole fire was reported prior to the trip of the sixth line on Sunday evening there was no reason to conclude that the tire was caused by overload since readings taken earlier indicated that elements were within limits. In the past, instances of secondary mains burning have occurred and, in each case, the mains were isolated without interrupting the entire network. The ability of the network to safely carry the load with five network feeders out of service was later confirmed by load flow study.

When the sixth feeder tripped there was concern for continuing to operate the network. However it was late Sunday evening and minimum load values were expected. As pointed out in the report, load readings available from a network are minimal and not readily available to support a decision to interrupt the network or to continue to operate the network. At that time we had no immediate way of confirming that 'overloads existed.

A decision to interrupt service to a large and critical area of your distribution system including many hi-rise buildings, hotels, etc., is not one to be made lightly.

Potential problems of the dc secondary grid were not recognized in the case of the Back Bay area network interruption. 
The dc system has long been recognized as a operating problem to Boston Edison. There has been an on-going program for several years to eliminate any equipment on our dc system which was not essential for service. Furthermore, prior to this incident the Company was well into an in-depth study of the dc system. The results of this study will establish a new Company policy towards future dc operation including a plan on how to exit this portion of our business.

The age of cables probably contributed to the Back Bay network, Wellesley and Roslindale.

The Back Bay problem was initiated by a 57 year old dc cable. The age of the Wellesley cables cannot be documented; however, the initiating fault was on a $500 \mathrm{kcmil}$ paper-insulated, lead sheathed cable with special rubber jacketing. This indicates that the cable was less than twenty years old. The initiating Roslindale cable fault was on non-shielded belted cable. The age of this cable is not easily determined.

Age by itself is not suitable criteria for replacing cable. Based upon our investigations, there does not appear to be any utility which replaces cable based solely on age.

Inability to gain timely access to Boston Edison Company facilities located in customer buildings caused delays during the Back Bay network interruption.

Delay in gaining access to Boston Edison facilities was experienced in only one instance. This was the Hancock Tower complex.

The Electrical Operations Department has maintained for many years a list of all their facilities with customer contacts to keep delays such as this to an absolute minimum. 


\section{CONTRIBUTING FACTORS TO SERVICE INTERRUPTIONS}

Operating \& Maintenance

The report concludes that a reduction in $0 \& M$ expenses reflects an equal reduction in routine inspection and testing of equipment. In fact a greater effort has been placed in this area. A larger share of the O\&M dollar is now being channeled into preventive maintenance programs:

Furthermore, reductions in the $0 \& M$ cost areas can be attributed to several factors. For example, in $1972 / 73$ period T\&D modified some of its operating practices to improve underground distribution reliability. One of these changes was a conscious and substantial reduction of making cable plece-ours (án expense item) and instead replacing the entire cable sectinn(s) (a plant item).

Maintenance, testing and inspection procedures could very well result in the discovery of potential problems. It is conjecture that such increased efforts may have resulted in discovery of potential problems and avoidance of the Back Bay, Wellesley and Roslindale interruptions. As brought out in the report the fault manhole in the Back Bay area had been inspected and was the scene of a TV documentary just days before. The manholes associated with the lines in the Roslindale outage were the object of an extensive upgrading program approximately two years ago. In 1975, the manholes for the Wellesley lines were also thoroughly inspected and upgraded in a joint BECo./Wellesley effort.

\section{Operators and Operating Procedures}

The report again indicates that with five network feeders out of service a serious problem existed and an emergency situation should have been recognized. It further contends that it could have been predicted that the 
three remaining cables could not be expected to supply the heavy weekday load of the North network.

As stated in our earlier comments an emergency situation was recognized immediately. It was predicted that the three remaining cables would not meet the load demands of a weekday. As previously stated:

1. Operating personnel had been assembled.

2. Engineering personnel were assembled and assessing the state of the network.

3. Efforts to return the feeder out for routine work had been initiated.

4. Commercial Organization was notified and had scheduled people for early Monday morning in case customer load curtailment was necessary.

5. Load readings were being taken periodically.

6. Plans to cut a cap each of the faulted feeders to return as many transformers as possible had been prepared and was being implemented.

Given what was being done in the field and observed load readings, the shutting down of the Back Bay network at this time would be entirely intuitive, arbitrary, without documentation and have caused outage to many hirise buildings, hotels and apartments.

\section{Corrective Actions}

Institute, and vigorously enforce a testing program whereby all primary distribution and transmission system cables would receive a high voltage test once each year. Defective cable should be replaced.

We assume that the report is aiming at our 14 and $24 \mathrm{kV}$ distribution supply system and network feeders. At present, BECo. has a testing program. Supply cables are discriminately selected for test. The primary criteria is to test all cables that have experienced three or more failures within a twelve. month period. Furthermore, if a cable supply system is showing an 
abnormal failure rate trend, it will also be scheduled for testing. This was the situation mentioned earlier in the Atlantic Avenue secondary network grid.

Testing of distribution supply cables is severely limited during our winter and summer peak periods. The ability to take lines out for test is many times hampered by our customers. Many customer facilities have single line supplies. To arrange customer outage for routine work can be very difficult due to the resulting customer inconvenience. Nonetheless, we schedule these lines for test.

The Company has through the years conducted studies to determine high voltage testing policy. Results of recent year studies appear to be leading towards more frequent testing. We are not yet convinced especially considering customer inconvenience that annual testing is optimum.

There is another testing procedure that is being closely followed by our Engineering Department. This is very high DC voltage têsting for a long duration (30 minutes). This would locate more incipient faults. This also has the advantage of requiring less frequent tests. Some European results have shown a 30 percent reduction in "in-service" cable failures by vigorous testing of their lines in this manner.

- Reduce vulnerability to multiple outages from a single cause by regrouping cable circuits and by reducing the number exposed in single manholes.

This statement is irrefutable. The report does correctly highlight the problems of gaining street access for additional conduit facilities in the Boston area. Implementing this would incur an enormous capital expenditure which would be impossible to economically justify. Will succeeding regulatory action allow proper recovery of these costs in light of the few 
occurrences? The company in its current plant development plans does place greater emphasis on evaluating the cost/benefits of regrouping or reducing the number of cables in single duct banks.

The relaying schemes at our network bulk supply stations are designed and set to clear network faults very quickly. Each network feeder is equipped with ground relays and instantaneous phase-to-phase relays. Fast acting back-up protection is also provided in case a breaker fails to operate correctly. This rapid clearing of a fault reduces the potential of a manhole problem.

Consider the use of solid dielectric cable systems to reduce vulnerability to immediate failure upon loss of integrity of lead sheaths:

There appears to be universal agreement that P\&L cable when properly installed provides a very reliable, long lasting cable system. It is also a more costly system. The Company does use solid dielectric (extruded insulated) cables. These exist primarily on our direct-buried (URD) systems. It might be added that many of the pressures placed on companies with rapidly expanding U.G. systems (especially URD) to go to extruded-insulated direct buried cables (polyethylene) were not felt by our Company. Subsequently, when an URD policy was finally adopted it was with the benefit of other companies' experience.

The Company recognizes that other companies are using these cables in much larger quantities in their underground duct systems. There appears at this time mixed reports on its success.

Extruded insulated cable by nature of its manufacture contains contaminants and voids. When water is added a phenomena called electro-chemical treeing occurs. Failure becomes inevitable. However, the time to failure is just now becoming apparent in the industry and it appears to be less (possibly substantially less) than that of $P \& L$ cable. 
The addition of a lead sheath on extruded insulated cables reduces significantly the possibility of electro-chemical treeing. The cost now becomes significantly higher than P\&L cables. An alternate method and one for which manufacturers are striving is the minimization of these contaminants and voids. Complete elimination is of course not feasible.

Another problem which exists with extruded insulated cables is that electro-chemical treeing occurs on the entire length of the cable exposed to water. This results in very large sections of cable having to be possibly replaced. Because P\&L does tend to fail more rapidly when water is introduced, only smail sections of cable are affected. 'lypically, no more than two sections, one section on each side of the fault, need to be replaced.

Our Engineering Department over the years has been a leader in cable development and continually reviews advances being made in cable develop: ment. As an active participant in the Cable Engineering Section of the Association of Edison Illuminating Companies (AEIC) and the Insulated Conductor Committee of the Institute of Electrical and Electronic Engineers (IEEE), the experiences of other large users of underground cable is closely followed. We are also extremely active in engineering efforts of future cable systems through the Electric Power Research Institute (EPRI).

Although potentially significant savings may exist if the Company was to adopt the wholesale usage of extruded insulated cables (without lead sheathing), it does not feel enough operating experience has been gained to justify moving away from a paper and lead system which has proven itself to be the most reliable over many years of experience.

Boston Edison should continue the detailed development of emergency service restoration plans. 
Boston Edison has completed in past years three detailed plans for emergency service restoration. Each of these plans deals with a different form of emergency. A fourth plan "Major Secondary Network Disturbance, Plan of Operation" has been formulated. The groundwork for a fifth plan has been started. This plan will deal with a major underground distribution disturbance.

\section{Analysis of Electric Supply Outages}

Exhibits 非 1 and 非 incorrectly show the towns of Littleton and Boxboro as towns served at retail by Boston Edison. These towns have no service affiliation with Boston Edison.

On page 47 the report states that Boston Edison acknowledged that testing .... The verb acknowledge implies a different set of circumstances. Boston Edison told Gilbert/Commonwealth right from the onset that correct operating procedure was not followed.

On page 48 the report makes note of the fact that Boston Edison has authorized a second $115 / 14 \mathrm{kV}$ source for the Chelsea/East Boston area. This second source was authorized well before this incident. There is no doubt that a benefit of this source addition will be increased reliability.

On page 52 the report indicates that lead-covered cables in this system have been in place for many years and are of an obsolescent, nonshielded design, that sheath failures were caused by fatigure rather than wear and that use of arsenical or tellurium type lead alloy sheathing would be more resistant to fatigure cracking.

With rare exception, all of the cable in this system is neither obsolescent nor of a non-shielded design. Furthermore, our specifications 
for paper-insulated cables have required arsenical type lead alloy sheathing for over twenty years. Therefore, any cable replacements in this system for twenty years has employed arsenical type lead alloy sheathing. The initiating fault on Line 378-89 and subsequent fault on Line 41-210 were both on cables of shielded construction. The 378-89 cable also was neoprene jacketed and had an arsenical lead alloy sheathing.

The report on thio page goco on to conclude that since there were subsequent cable failures and because the loading on the other cables remained within their ratings that all of the cables are in poor condition. This is a very broad and unsubstantiated statement.

On page 53, the report suggests that the use of high viscosity rompound would reduce the problem of compound migration. In 1964, the Company stocked cable to be used in areas where a ten-foot or greater change in elevation existed over a given section. This is the case for the Wellesley lines. Since 1972, all three conductor cables have been purchased with high viscosity compounds. A further suggestion offered in the report was the use of neoprene jacketing to reduce cable movement. For over twenty years, all $15 \mathrm{kV} 3$-conductor cable purchased has included neoprene jacketing.

On page 57 , the wording in the second paragraph may be misleading. The only customers interrupted on that Saturday were the Conmonwealth of Massachusetts Health Laboratory and the Southwest High School.

Page 60 correctly reports that the cable sheaths were not protected against corrosion (electrolysis) by a cathodic protection system. The cable system because of its location with respect to a dc transit system has been checked frequently for visual signs of electrolysis. These visual inspections did not detect any electrolysis problem. It was not until more sophisticated laboratory tests were made after this incident that a 
potential electrolysis problem was detected. The report correctly notes

that a protection system is being designed by our Laboratory and will be installed.

\section{MITIGATIVE MEASURES}

Inspection of every manhole on a three-to-five year cycle is practiced by some útilities. Critical manholes may need inspection more often. Crews in the field should routinely inspect manholes. Inspection reports can be computerized to summarize the findings of the inspections and to keep a record of the frequency that each manhole is inspected. The computer reports can list priority work and keep track of manholes that require routine work to be completed the next time the crew is in the area.

Boston Edison does not have a cyclical inspection program for its 25,233 manholes. However, it does discriminately select individual manholes and manhole groupings which are associated with particular cable distribution supply systems for inspection.

The Company since 1976 has had in-place a computer oriented inspection report system. Each time a cable crew enters a manhole, it must first make out an inspection report form. This form is set-up in such a manner that all pertinent conditions that may exist in a manhole are quickly and efficiently noted. This form is submitted at the end of the day and its findings submitted to the computer the following day. To date, there

have been 6,477 manholes inspected in this manner. Any work of critical nature would, of course, be done immediately.

Before each manhole job assignment, the computer is accessed to determine whether any other outstanding work reported in the last inspection can be included on this job.

The system also has the capability to provide various manhole output listings. For example, it can list all inspected manholes with signs of sheath break, deficient bonding or needed hangars. 
The system has become a valuable tool in the 0 \& $M$ efforts of the T\&D Cable and Conduit Divisions.

High voltage testing of primary feeder cables each year can minimize the number of "in service" cable failures.

Boston Edison, as the result of on-going studies, is heading towards a policy of more frequent testing. It is not convinced that annual testing can minimize "in service" cable failures; however, based upon some preliminary results, it appears that it will reduce "in service" failures.

Attention to routine equipment maintenance is a must. Good results have been obtained in using computers to maintain maintenance schedules and track actual maintenance performed.

Exlensive use of computer based programs for scheduling maintenance has been going on for several years at Boston Edison. For example, the Electrical Operations Department has a program which tracks maintenance on all its major station equipment. This includes transformers, tap changers and breakers. The System Electrical Division responsible for our relay systems maintains a program which contains every relay on our system. This program lists monthly those relays which now require testing.

Older cables - particularly those with non-shielding belled construction - should rcceive epecial attention, with more frequent inspection than newer cables. Replacement should be made when such cables fail a voltage test and/or when general condition indicates a possibility of failure.

We cannot agree that because a cable of older design fails a voltage test it should be replaced. There are other considerations which must also be included in this type of decision. Has this cable shown a history. of failure significantly higher than system average; is it in an environment which dictates the use of a new design cable; etc.? 
It goes without saying that any cable condition which indicates a possibility of failure is rectified.

\section{Quality of Material and Workmanship}

Stringent specification and quality control measures can be implemented to insure the use of only the highest quality cable.

We agree with this comment, but feel it is misleading as applied to our Company. Boston Edison has always purchased high quality cable. Our specifications for cable have always met and in some instances surpassed AEIC cable standards. These standards provide User Specifications for cable. They have been assembled by the Cable Engineering Section of the AEIC. This section consists of 20 - 25 engineers representing power utility companies across the country with major underground plant. Boston Edison has been very active in this section of AEIC since its inception.

An illustration of our specifications at one time surpassing those sf the AEIC deals with solid dielectric (extruded insulated) cables. Our cable specifications for extruded insulated cables required voids/contaminates not to exceed $10 \mathrm{mils}$. Cable was rejected because of some manufacturers' inability to meet this stringent requirement. Since this time AEIC has also adopted similar void/contaminant standards.

Manufacturers of cable must meet stringent requirements to be placed on our approved vendors list. They must allow full examination of cables; and they must provide full reports on Quality Control for the manufacturing process, testing, and material handling portions of their operations. Company engineers make frequent visits to cable manufacturers' plant facilities. As of this writing there are only three manufacturers of 
paper-insulated lead sheathed cable and six manufacturers of solid dielectric cables on the Company's Vendors Approved List.

Boston Edison has its own laboratory facilities to conduct high quality visual inspection of cable. It has cooperated with other utilities with more extensive testing facilities to determine quality of cable material.

To reinforce the fact that we purchase high quality cable, it has already been stated that:

1. For over twenty years all paper-insulated lead sheathed cables have been jacketed with neoprene.

2. Since 1964 , the Company has stocked cable with high viscosity compound for areas of its system where a 10 foot or greater slope is experienced in a section of cable. Since 1972, all three-conductor paper-insulal: ed cables have been purchased with high viscosity compound.

3. For over twenty years, the lead sheathing on our cables has been of a arsenical type lead alloy.

- The quality of the workmanship to install cables and make splices and terminations is a function of training and constant attention to the work performed. Inspections, dissection and analysis of failed splices, records of each craftman's failures and the use of $X$-rays arc tcchniques of measuring the quality of work performed.

Again, we agree with this comment also, and have had systems in place for many years to do just what is says.

Quality Control Inspection is an ongoing function in our Underground Section and is covered in two areas, inspection during construction and fault analysis. 
During cable installation and joint construction a field supervișor periodically visits a job location to spot check for conformance with construction standards and procedures. On job completion, a management person, other than a field supervisor, selects a random group of work orders for final field inspection.

Cable and joint failures when analyzed in the field by supervision and in the Fault Analysis Room by engineering personnel are carefully checked for any defects in workmanship. All joints are stencilled with a splicer's assigned number. Field records and jointing cards also help to identify personnel involved in poor workmanship.

An unusual failure rate on a particular type of joint in conjunction with Fault analysis sheets that point to a deviation in standard work will lead to a review of procedures with all splicing personnel. In addition general splicing techniques are reviewed when inclement weather prohibits routine work.

Whenever a defective joint that is submitted for analysis is suspected of "poor Workmanship", the splicer and his steward are directed to ovserve the disection. If poor workmanship is detected, the splicer will be retrained and evaluated in the splicing school and counselled as to proper work procedures. All meetings with employees including retraining and disciplinary actions are documented.

$X$-ray techniques are used primarily to test welds on our pipe type cable system and occassionally pothead or cable termination points. $\mathrm{X}$-rays have bery limited value on lead sheathed cables. Our problems with P\&L are occurring primarily in the manholes. The largest percentage of failures are due to moisture. X-ray techniques will not assist in detecting these potential weak spots. Creasing of paper tapes or soft spots in the insulation also will not show up in an X-ray test. 
Even a system adequately maintained and well-designed with quality material can fail if it is operated improperly or beyond its capability. Under emergency conditions, the system operators have a very limited amount of information on the status of the distribution system. Sophisticated systems to monitor the state of these systems are, at the present time, technically feasible but prohibitively expensive. To make up for lack of actual data, the system operators need to have a good understanding of how the system will behave under abnormal conditions. One method of achleving this understanding is the greater use of simulation techniques to study the distribution system for probable emergency situations. Operating procedures and guidelines can be developed from these studies. Training programs on a regular basis would encourage system operators to keeo up-to-date on new procedures and guidelines.

The first part of the statement can not be refuted. In each of the five indicents investigated in this report, the system was never knowingly operated beyond its capability nor operated improperly.

During the Back Bay event, the limitations of network metering was fully comprehended and for this reason load readings were obtained at critical locations to assure ourselves we were operating within the capability of the system. The fact that the network operated throughout the entire load period Monday with no unacceptable overloads being reported is a clear indication that a serious network problem had been successfully handled.

In January, 1979 Boscon Edison signed a contract with Moore Systems for a Supervisory Control and Data Acquisition (SCADA) system. This system will improve significantly the amount of data immediately available to the system dispatcher; it will permit quicker acknowledgement and response to a system problem. This should aid in reducing customer outage time. 
In recent years the Distribution Division of the Engineering, Planning and Research Department has modelled each of the five secondary network grids in a digital load flow program. All single and double network feeder as well as loss of bus section contingencies are simulated. The results are tabulated and a copy is given to the System Operations Department for their use. These simulations are used as guidelines in decisions regarding equipment outage for routine work or identifying the next worse contingency.

High priority should be assigned to activities to keep the system in its normal state. When a feeder is out of service, immediate action should be taken to return that feeder to service even if all customers are being supplied. Also while the feeder is out of service, the system operators should be anticipating actions to be taken, should a second contingency occur.

The suggestion implied is that all secondary network $14 \mathrm{kV}$ feeder repairs be on an overtime basis is inconsistent with good utility practice. There are times when a network can sustain multiple contingencies without any significant risk of shutdown. Likewise, in some of our multiple line distribution supply systems the loss of one supply line does not necessitate overtime repairs. At various times of the year they also can experience more than a single contingency without exceeding equipment ratings.

Furthermore, second contingency or the next worse contingency is always a consideration. For example, our guidelines for scheduling outages prohibits taking out any bulk power source to the network except on Saturdays or Sundays. The System Dispatchers' Morning Status Report lists potential operating problems. This identifies second contingency possibilities and operators are aware of what must be done to deal with these possibilities. Furthermore, during major system cutovers, elaborate plans are prepared to deal with a contingency during this period. 
Identifying areas served by a given distribution system and the number of people in these areas, and

. The potential duration of a major outage.

The Company has had in place for many years a Major Notification

Plan. As part of this plan it certain criteria are met the DPU and DOE are notified. The area affected, an estimate of the number of customers without service and the potential duration of a major outage is provided. The criteria for notification of a public agency is set by that public ageñcy.

"The utility should be aware of all critical loads served by each distribution system so that proprity attention can be given. These loads......."

All designated critical customers are identified on our system diagram board and distribution points. Critical customers are so-designated by our Commercial Organization. Critical customers are hospitals, households with life-support systems, high-rise housing for the elderly, etc.

The statement that we contact police for possible evacuation of elderly invalids is a responsibility that should be borne by the operators of these facilities. They are in a far better position to identify their needs.

\section{RESTORATION MEASURES}

Switching to alternate feeders.

Using portable generators.

Installing temporary lines and cables to by pass damaged sections, and

Cutting out damaged sections of cable and reenergizing undamaged sections.

Boston Edison agrees that these measures can be employed and, in fact, has used each of these restoration techniques. 

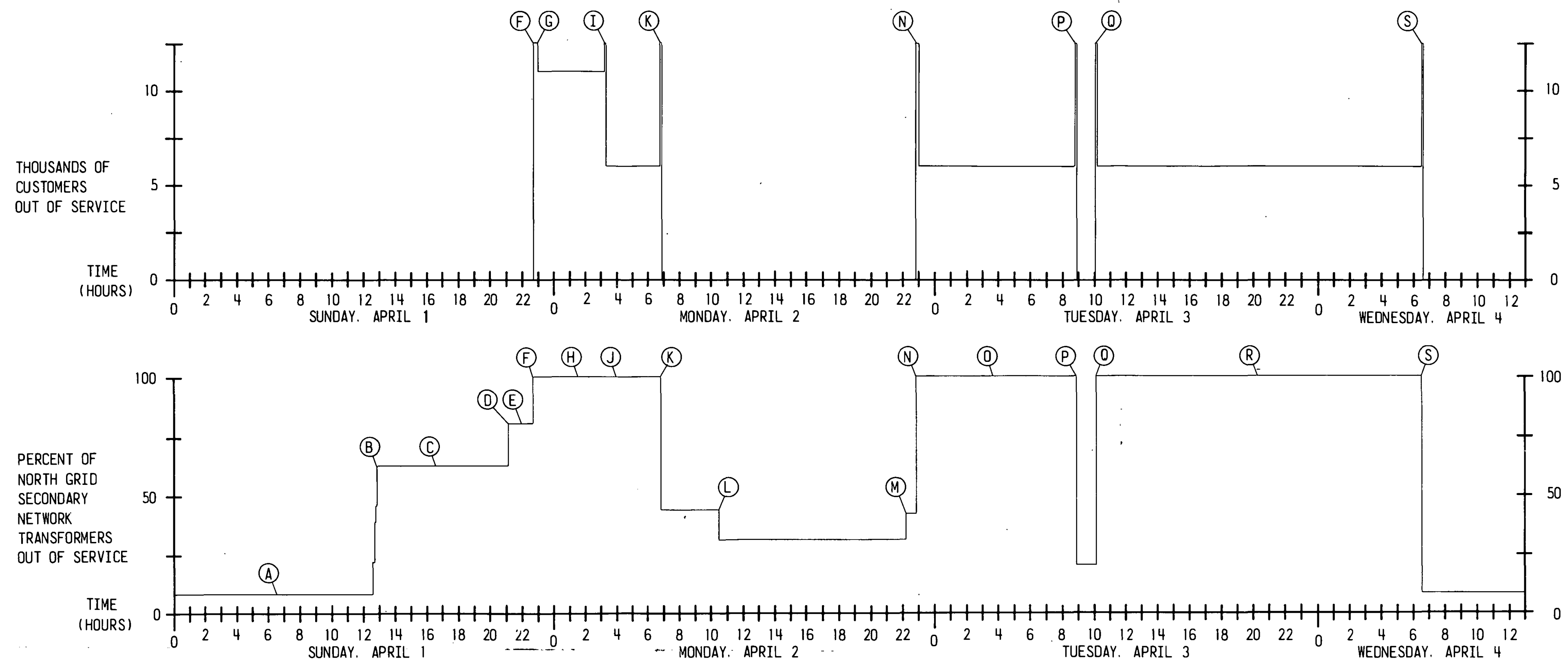

A. FEEDER 25 OUT ON SCHEDULED MAINTENANCE

REPORTED MANHOLE FIRE. FEEDERS 45, 12,11, 22 RELAY CUT RESPECTIVELY TROUBLE SHOOTERS AND MAINTENANCE PERSONNEL DISPATCHED TO I SOLATE FAUL TED CABLES REPORTED MANHOLE FIRE , FEEDER 31 RELAYS OUT

SECONDARY CABLES FAULT AT 5 LOCATIONS

STATION \#492 CIRCUIT BREAKERS MANUALLY TRIPPED DE-ENERGIZING BACK BAY NETWORK AND BACON ST. STATION $\$ 49$

BEACON ST. STATION \#49 RE-ENERGIZED

SECONDARY CABLES CUT SEPARATING NORTH AND SOUTH GRIDS

STATIONS 492 \& 49 DE-ENERGIZED THEN RESTARTED PICKING UP SOUTH GRID

FEEDERS 11.12 \& 22 CUT \& CAPPED ISOLATING DAMAGED SECTIONS

K. STATIONS $492 \& 49$ DE-ENERGIZED THEN RESTARTED PICKING UP NORTH \& SOUTH GRIDS
L. FEEDER 31 CUT \& CAPPED RETURNING UNDAMAGED SECTIONS TO SERVICE M. FEEDER 22 RELAYS OUT

N. STATION 492 \& 49 DE-ENERGIZED THEN RE-STARTED PICKING UP SOUTH GRID

0 . FEEDER 22 CUT AND CAPPED. FEEDER 45 REPAIRED AND RETURNED TO SERVICE

P. STATION 492 \& 49 DE-ENERGIZED THEN RESTARTED PICKING UP NORTH \& SOUTH GRID

O. STATION $492 \& 49$ DE-ENERGIZED THEN RESTARTED PICKING UP SOUTH GRID

R. FEEDERS 22 REPAIRED. 31 PARTIALlY REPAIRED. AND 45 CUT \& CAPPED ISOLATING

S. STATIONS 492 \& 49 DE-ENERGIZED THEN RESTARTED PICKING UP NORTH \& SOUTH GRIDS

\section{CHRONOLOGY}

BACK BAY AREA INTERRUPTION, APRIL 1-4, 1979 


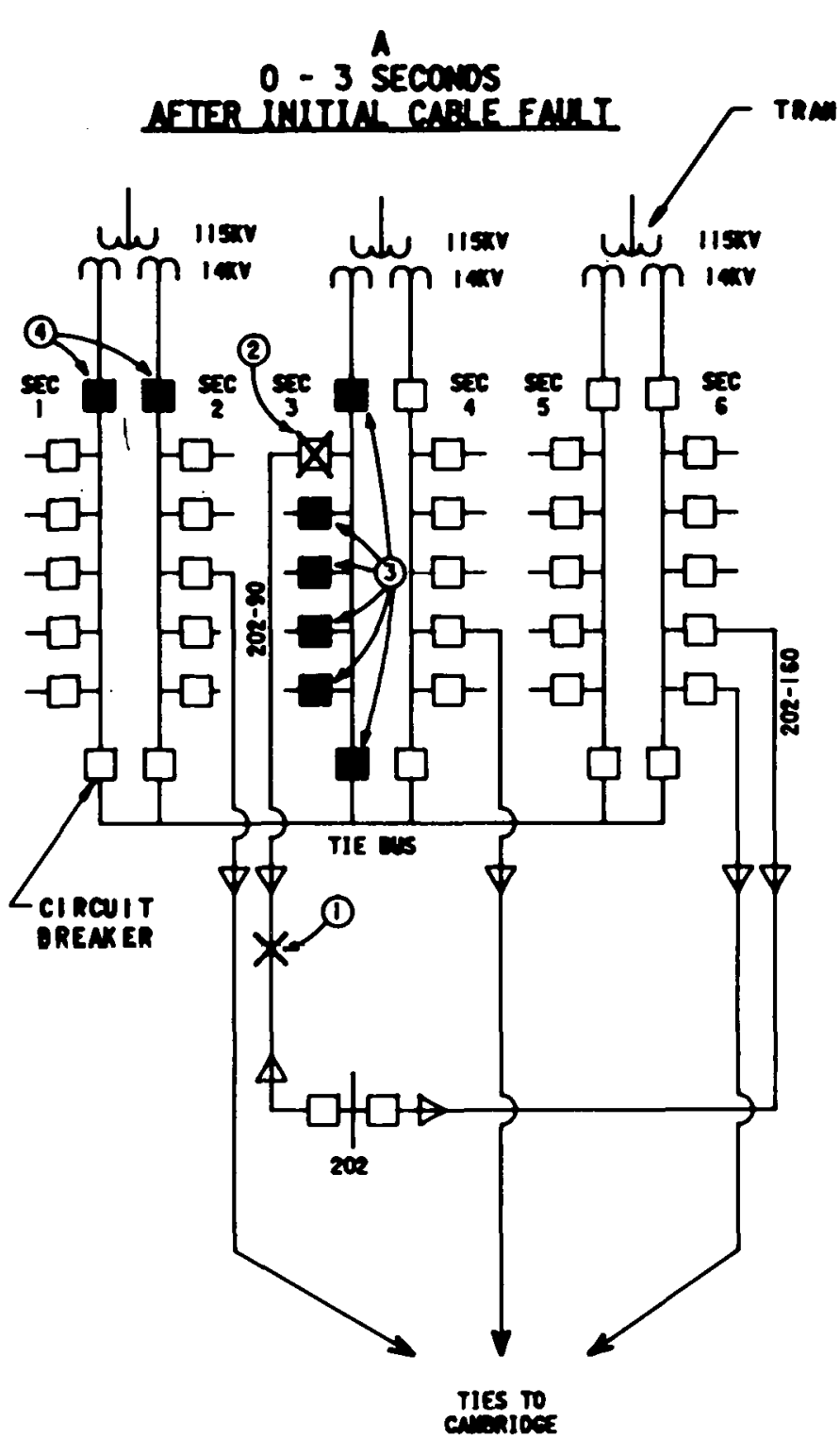

(1) 14KV CABLE FAULTS (TIME O $S$ )

(2) CIRCUIT BREAKER FAILS RESULTING IN BUS FAULT (TIME $2.03 \mathrm{~S}$ )

(3) BUS DIFFERENTIAL REL AYS TRIP ALL BUS SECTION \#3 CIRCUIT (TIME 2.19 S)

(4) UNDESIRED OPERATIONS OF OVERCURRENT PHASE RELAYS OPEN II5KV AND 14KV TRANSFORMER CIRCUIT BREAKERS (TIME $2.19 \mathrm{~S}$ )
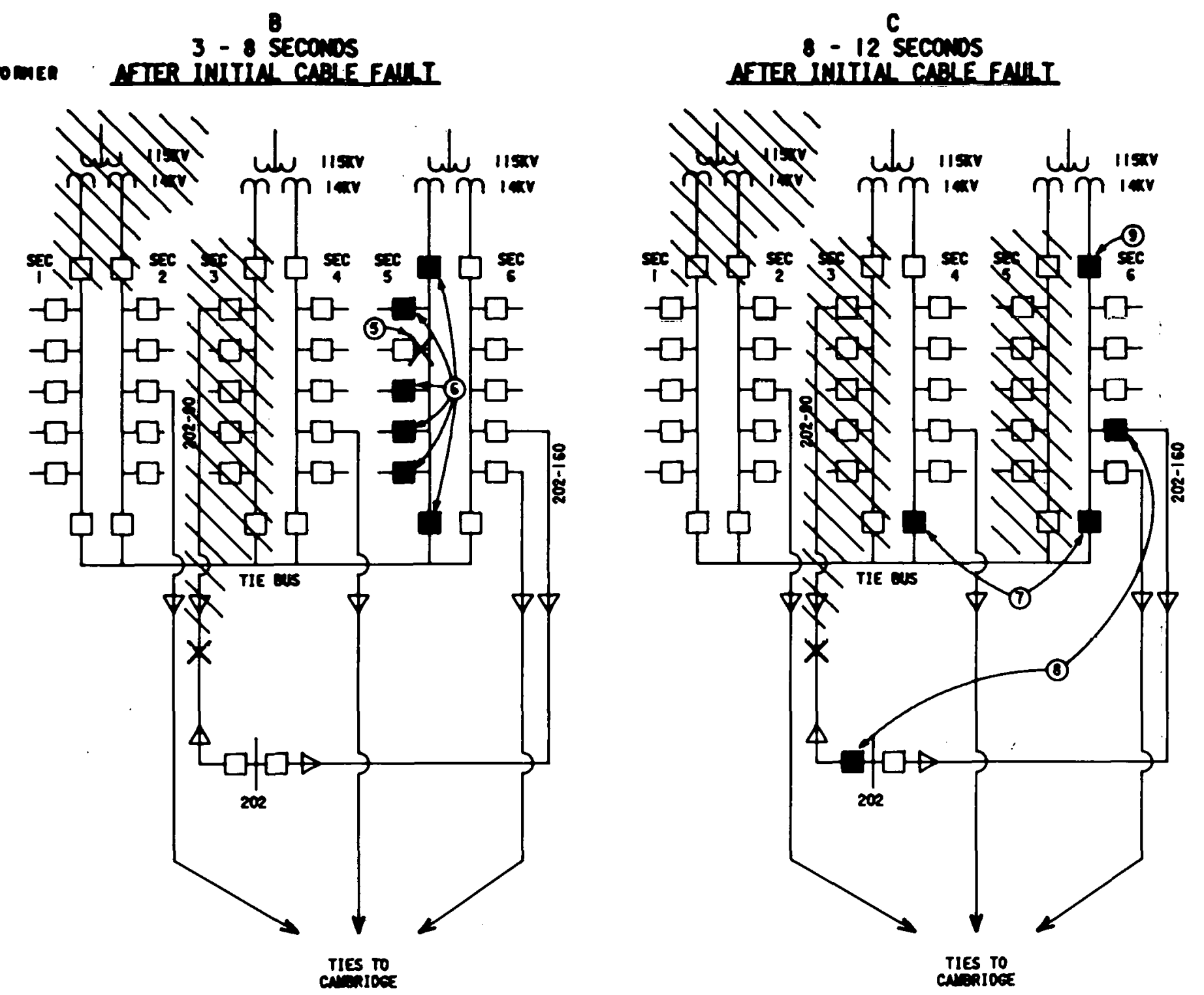

(5) BUS tAP INSULATOR FAILS RESULTING IN BUS FAULT (TIME $7.35 \mathrm{~S}$ )

(6) BUS DIFFERENTIAL RELAYS TRIP ALL BUS SECTION \#5 CIRCUIT BREAKERS CLEARING BUS FAULT (TIME 7.35 S)

(7) OVERCURRENT RELAYS TRIP BUS SECTIONS \#5 AND \#6 BUS TIE CIRCUIT. BREAKERS

(TIME $10.17 \mathrm{~S}$ )

(3) CIRCUIT BREAKERS AT. STATIONS 202 AND BRIGHTON OPERATE TO CLEAR INITIAL CABLE FAULT (TIME 10:27 S)

(9) OVERCURRENT RELAYS TRIP TRANSFORMER CIRCUIT BREAKER (TIME $11.00 \mathrm{~S}$ )
AETER $12-17^{0}$ SEconos

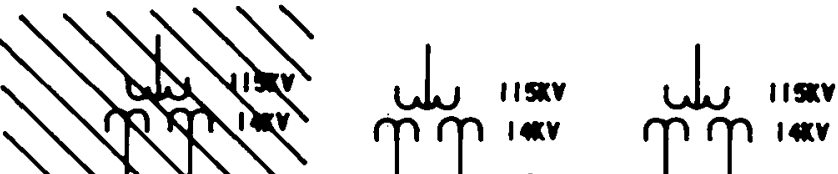

12 ace

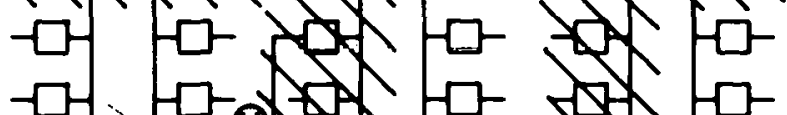

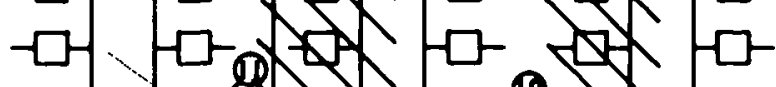

머

무

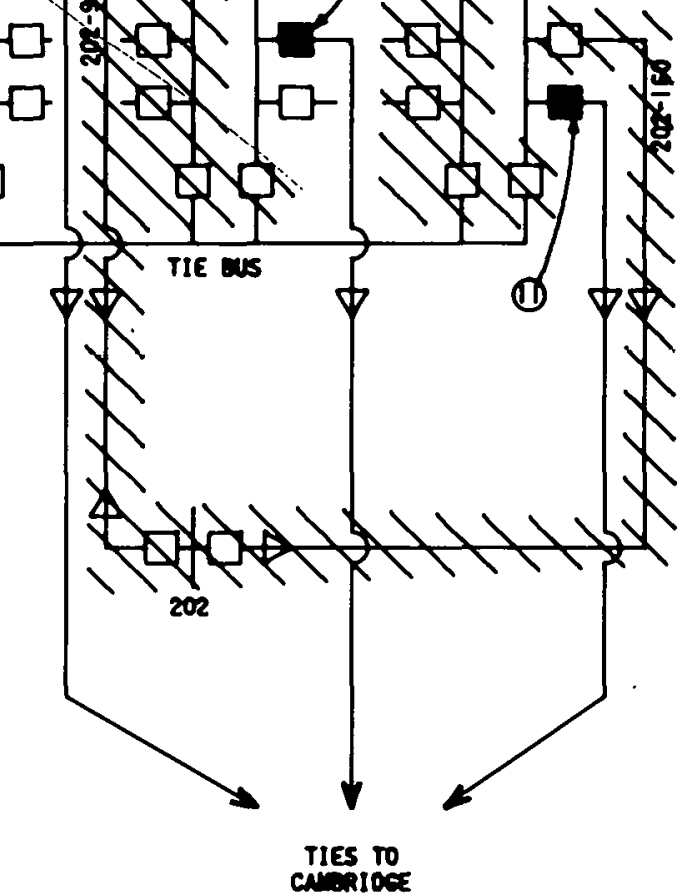

(10) OVERCURRENT REL AYS TRIP CAMBRIDGE TIE (TIME 16.00 S)

(19) OVERCURRENT RELAYS TRIP THREE

REMAINING SOURCES TO 14 KY

BUSES DE-ENERGIZING 14KY

PORTION OF STATION (TIME $17.00 \mathrm{~S}$ ) 

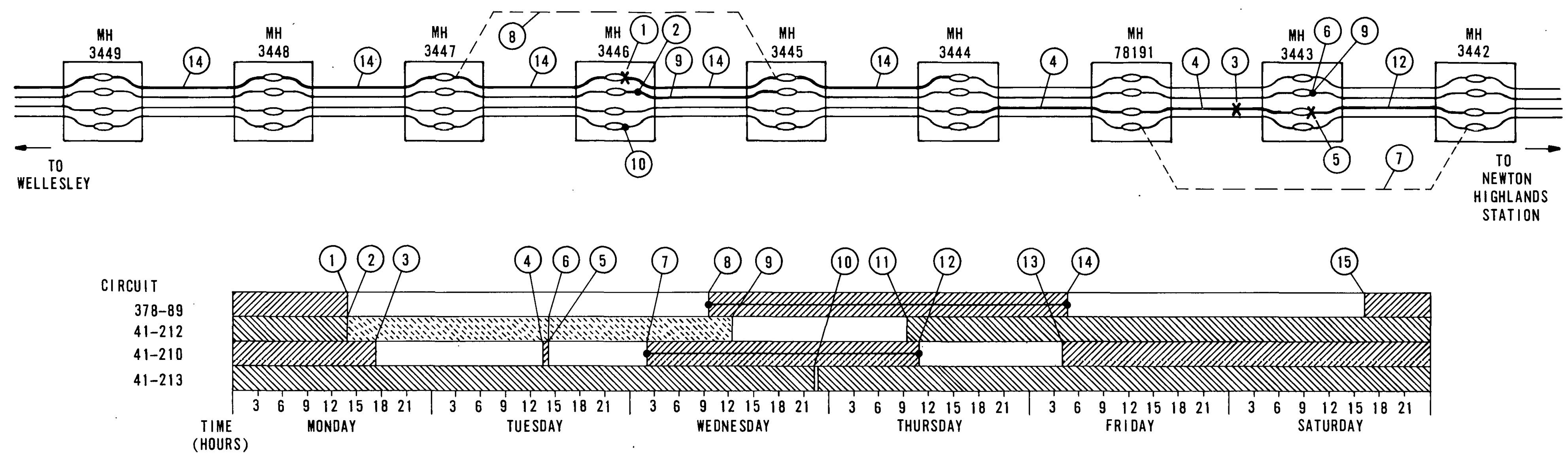

1. JOINT FAILS DUE TO PRESENCE OF MOISTURE (MH 3446)

2. ADJACENT CABLE DAMAGED BUT REMAINS IN SERVICE (MH 3446)

3. CABLE FAULT IN DUCT (MH 3443-18191)

4. TWO SECTIONS OF CABLE REPLACED AND CIRCUIT RE-ENERGIZED (MH 3443-18191-3444)

5. CABLE FAILS AT OLD CABLE END OF NEW JOINT (MH 3443)

6. ADJACENT JOINT SLEEVE DAMAGED BUT REMAINS IN SERVICE (MH 3443)

7. OVERGROUND JUMPER INSTALLEO BY-PASSING MH 3443 (MH 3442-3443-18191)

8. OVERGROUND JUMPER INSTALLED BY-PASSING MH 3446 (MH 3445-3446-3447)

9. CIRCUIT REMOVED FROM SERVICE TO REPLACE CABLE SECTION (MH 3445-3446) AND TO REMAKE JOINT (MH 3443)

10. CIRCUIT OUT OF SERVICE 28 MINUTES TO MAKE PERMANENT PATCH ON SHEATH (MH 3446)

11. REPAIRED CIRCUIT RE-ENERGIZED.

12. CIRCUIT REMOVED FROM SERVICE TO REPLACE CABLE SECTION (MH 3442-3443)

13. TEMPORARY JUMPER REMOVED AND REPAIRED CIRCUIT RE-ENERGIZED.

14. CIRCUIT REMOVED FROM SERVICE TO REPLACE 5 CABLE SECTIONS (MH 3444-3445-3446-3447-3448-3449)

15. REPAIRED CIRCUIT RE-ENERGIZED. 
